Review

\title{
Catalytic Reactions over Halide Cluster Complexes of Group 5-7 Metals
}

\section{Sayoko Nagashima ${ }^{1}$, Satoshi Kamiguchi ${ }^{2,3, *}$ and Teiji Chihara ${ }^{1}$}

1 Graduate School of Science and Engineering, Saitama University, Shimo-Okubo, Sakura-Ku, Saitama City, Saitama 338-8570, Japan; E-Mails: nagasima@apc.saitama-u.ac.jp (S.N.); chihara@apc.saitama-u.ac.jp (T.C.)

2 Organometallic Chemistry Laboratory, RIKEN, 2-1 Hirosawa, Wako City, Saitama 351-0198, Japan

3 Advanced Catalysis Research Group, RIKEN Center for Sustainable Resource Science, 2-1 Hirosawa, Wako City, Saitama 351-0198, Japan

* Author to whom correspondence should be addressed; E-Mail: kamigu@ riken.jp; Tel.: +81-48-467-1349; Fax: +81-48-467-9391.

Received: 9 January 2014; in revised form: 1 June 2014 / Accepted: 4 June 2014 / Published: 23 June 2014

\begin{abstract}
Halide clusters of Group 5-7 metals develop catalytic activity above $150-250{ }^{\circ} \mathrm{C}$, and the activity is retained up to $350-450{ }^{\circ} \mathrm{C}$ by taking advantage of their thermal stability, low vapor pressure, and high melting point. Two types of active site function: the solid Brønsted acid site and a coordinatively unsaturated site that catalyzes like the platinum metals do. Various types of catalytic reactions including new reactions and concerted catalyses have been observed over the clusters: hydrogenation, dehydrogenation, hydrogenolysis, isomerization of alkene and alkyne, and alkylation of toluene, amine, phenol, and thiol. Ring-closure reactions to afford quinoline, benzofuran, indene, and heterocyclic common rings are also catalyzed. Beckmann rearrangement, $S$-acylation of thiol, and dehydrohalogenation are also catalyzed. Although the majority of the reactions proceed over conventional catalysts, closer inspection shows some conspicuous features, particularly in terms of selectivity. Halide cluster catalysts are characterized by some aspects: cluster counter anion is too large to abstract counter cation from the protonated reactants, cluster catalyst is not poisoned by halogen and sulfur atoms. Among others, cluster catalysts are stable at high temperatures up to $350-450{ }^{\circ} \mathrm{C}$. At high temperatures, apparent activation energy decreases, and hence weak acid can be a catalyst without decomposing reactants.
\end{abstract}


Keywords: weak Brønsted acid; oxo acid; large cation; coodinatively unsaturated site; platinum-like catalysis; alkylation; ring closure reaction; activation of hydrogen; high temperature catalysis

\section{Introduction}

One of the most challenging subjects in catalysis is to develop new reactions over new catalysts. We have chosen halide clusters as new catalysts; however, the catalytic nature of the halide clusters was unknown at the beginning of the investigation. One possibility for understanding this catalytic nature is provided by a physicochemical investigation of activated halide clusters. Another possibility is to apply the catalyst to many compounds and to search for reactions catalyzed by halide clusters; a comprehensive view of the catalyst can be obtained by comparison with other catalysts. In other words, the nature of the active site was determined by the inductive method. The reactions proceeded over halide cluster catalysts are listed in Table 1 . The retention of the cluster framework and the active sites developed on the clusters by heat treatment are described in a previous paper [1], which can be summarized as follows. When molecular halide clusters of niobium, tantalum, molybdenum, and tungsten possessing a hexanuclear octahedral metal framework were treated with progressively increasing temperatures in a hydrogen or helium stream, they lost crystallization water at $100-200{ }^{\circ} \mathrm{C}$. Above $150-200{ }^{\circ} \mathrm{C}$, apical halogen ligands were lost as hydrogen halide by reaction with the coordinated water to yield hydroxo ligands, which exhibited as Brønsted acid site. In the case of the molybdenum and tungsten clusters, aqua ligands were removed to yield coordinatively unsaturated sites (Lewis acid sites). The cluster framework as well as the active sites were retained up to $350-450{ }^{\circ} \mathrm{C}$. In the case of the rhenium chloride cluster, the cluster framework is stable up to $300{ }^{\circ} \mathrm{C}$ under inert atmosphere; however, it was reduced to metallic rhenium above $250{ }^{\circ} \mathrm{C}$ under hydrogen. The retention of the cluster frameworks were confirmed by X-ray diffraction analyses (XRD), Raman spectrometry, and extended X-ray absorption fine structure analysis (EXAFS). The appearance of the active sites was confirmed by thermogravimetry-differential thermal analysis (TG-DTA), infrared spectrometry (IR), infrared spectrum of adsorbed pyridine, adsorption of carbon monoxide, acid titration with Hammett indicators, and elemental analyses.

Table 1. Reactions catalyzed by halide cluster.

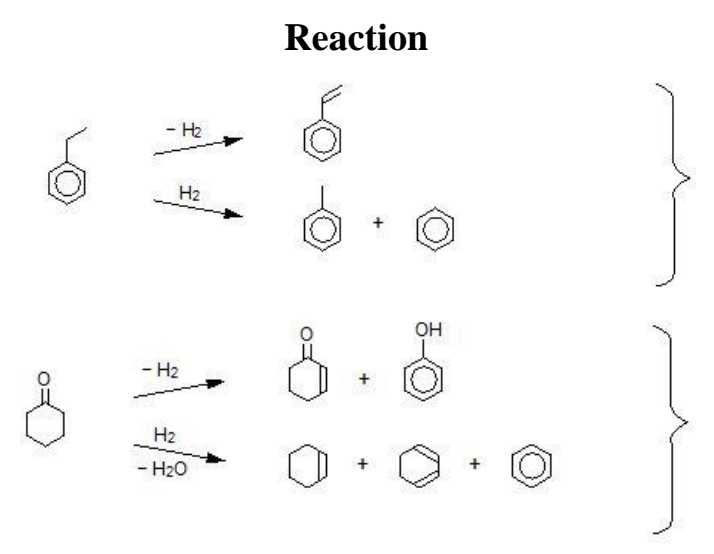

Equation 
Table 1. Cont.

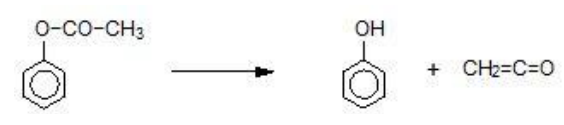

$$
\begin{aligned}
& \sim \cdots+\cdots \\
& \mathrm{OH} \stackrel{-\mathrm{H}_{2} \mathrm{O}}{\longrightarrow}=+\mathrm{ON}^{-}+\mathrm{CO}_{\mathrm{C}} \\
& \hat{\mathrm{O}}+\mathrm{CH}_{3} \mathrm{OH} \stackrel{-\mathrm{H}_{2} \mathrm{O}}{\longrightarrow} \hat{\mathrm{O}}+\hat{\mathrm{O}}+\hat{\mathrm{O}} \\
& \mathcal{\mathrm { N }}+\mathrm{CH}_{3} \mathrm{OH} \stackrel{-\mathrm{H}_{2} \mathrm{O}}{\longrightarrow} \stackrel{\mathrm{N}}{\mathrm{U}} \\
& \text { (O) }+\mathrm{CH}_{3} \mathrm{OH} \stackrel{-\mathrm{H}_{2} \mathrm{O}}{\longrightarrow} \text { (O) } \\
& \stackrel{\mathrm{OH}}{\mathrm{H}}+\mathrm{CH}_{3} \mathrm{OH} \stackrel{\mathrm{H}_{2} \mathrm{O}}{\longrightarrow} \stackrel{\mathrm{OH}}{\longrightarrow} \\
& \stackrel{\mathrm{S}}{\mathrm{S}}+\mathrm{CH}_{3} \mathrm{OH} \stackrel{-\mathrm{H}_{2} \mathrm{O}}{\longrightarrow} \stackrel{\mathrm{S}^{\prime}}{\longrightarrow} \\
& \mathbb{2}^{\mathrm{NH}_{2}}+2 \mathrm{CH}_{3}-\stackrel{\mathrm{C}}{\mathrm{C}-\mathrm{CH}} \stackrel{-\mathrm{H}_{2} \mathrm{O}}{\longrightarrow}
\end{aligned}
$$

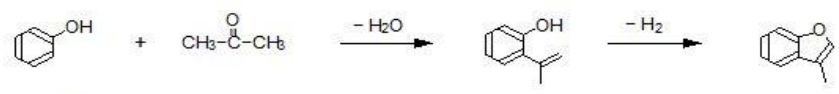

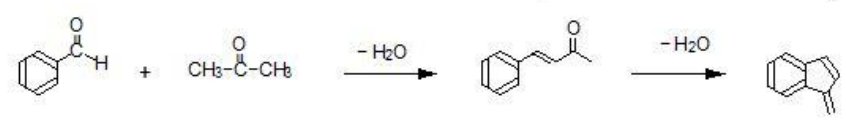

$$
\begin{aligned}
& \text { (O) } \\
& \text { (O) } \rightarrow \text { Q }
\end{aligned}
$$

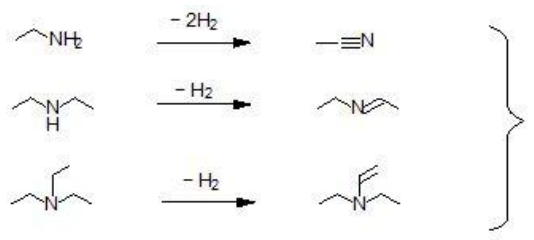

$$
\begin{aligned}
& \mathrm{C}^{\mathrm{N}} \longrightarrow \\
& \text { (0) }{ }^{\mathrm{SH}}+\mathrm{CH}_{3}-\mathrm{C}-\mathrm{OH} \stackrel{-\mathrm{H}_{2} \mathrm{O}}{\longrightarrow} \text { (O) }
\end{aligned}
$$

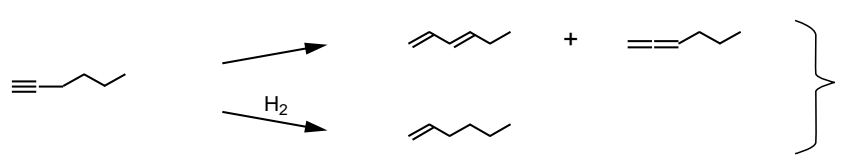

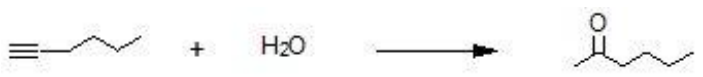

$$
\begin{aligned}
& \curvearrowright \sim \mathrm{HX} \quad(\mathrm{X}=\mathrm{F}, \mathrm{Cl}, \mathrm{Br}, \mathrm{I})
\end{aligned}
$$




\section{Catalysis Involving Hydrogen}

\subsection{Reaction of Ethylbenzene (Equation (1)) [2]}

\subsubsection{Reaction under Helium}

The reactivity of ethylbenzene has been extensively studied, since the manufacture of styrene by dehydrogenation is an industrially important process. Commercially, iron oxide with potassium hydroxide in a steam is used to catalyze this reaction [3]. Metals acting as catalysts are also known: unsupported nickel [4,5] and supported platinum metals [6,7] in both oxygen and nitrogen streams. Thus, metal oxide catalysts have been used in a steam or oxygen stream, whereas nickel and platinum metals have been used in an oxygen or nitrogen stream. On the other hand, when nickel and platinum metals are applied in a hydrogen stream, they act as reductive dealkylation catalysts to yield toluene and benzene [8,9]. Hence, the selectivity of nickel and platinum metals depends on the atmosphere.

To assign the catalytic activity of the halide cluster complexes, they were not supported on inorganic materials but employed in the form of crushed crystals, which compromised their catalytic efficiency. The specific surface area of the crushed and screened (166-200 mesh) crystals of the molecular halide clusters was $4-7 \mathrm{~m}^{2} / \mathrm{g}$.

The general procedure for the catalytic reaction is described. A conventional vertical glass fixed-bed microreactor with a continuous gas-flow system was operated at atmospheric pressure [2]. In each experiment, a weighed supported or non-supported sample of cluster complex (10-200 mg) was packed in a borosilicate glass tube (3-9 mm i.d.) with the aid of quartz glass and placed in the center of an electric furnace. The cluster sample was initially heated from room temperature to a fixed temperature between 50 and $600{ }^{\circ} \mathrm{C}$ in $15 \mathrm{~min}$ in a helium or hydrogen gas stream $(0.3-2.4 \mathrm{~L} / \mathrm{h})$, and then it was held at that temperature for 45 min for activation of the cluster. Then, the reaction was initiated by feeding a reactant into the gas stream by micro feeder with or without changing the temperature. The reaction was monitored every $15-30 \mathrm{~min}$ by sampling the reaction gas (1 mL) with a six-way valve kept at $150{ }^{\circ} \mathrm{C}$ followed by analysis using an online gas-liquid chromatograph (GLC). The reactor effluent was collected in a trap for subsequent analyses by GLC and gas chromatography-mass spectrometry (GC-MS). Products were identified by comparison with commercial products, chromatographic isolation, or independent syntheses.

In this experiment, molybdenum cluster $\left(\mathrm{H}_{3} \mathrm{O}\right)_{2}\left[\left(\mathrm{Mo}_{6} \mathrm{Cl}_{8}\right) \mathrm{Cl}_{6}\right] \cdot 6 \mathrm{H}_{2} \mathrm{O}$ was packed into a glass reaction tube and activated at $450{ }^{\circ} \mathrm{C}$ for $1 \mathrm{~h}$ in a stream of helium. Reaction was initiated by introducing ethylbenzene into the stream of helium at the same temperature. A typical reaction profile is plotted in Figure 1. Although catalytic activity decreased with time, the selectivities leveled off after $2 \mathrm{~h}$. The molybdenum cluster catalyzed dehydrogenation of ethylbenzene to afford styrene in around 90\% selectivity (Equation (22)), and slightly catalyzed dealkylation in the side chain to provide toluene (Equation (23)) and dealkylation of the side chain to yield benzene (Equation (24)). However, neither alkyl chain isomerization to form xylene (Equation (25)) nor intermolecular transalkylation to produce benzene and diethylbenzene (Equation (26)) was observed at all. Dealkylation of the side chain and intermolecular transalkylation are mainly catalyzed by solid acids such as mordenite and ZSM-5 both in helium [10-12] and hydrogen streams [13,14]. It is well known that high-temperature 
processes for the catalytic conversion of hydrocarbons are often accompanied by deposition of hydrogen-deficient coke, and that the deposition of these products causes a decrease in catalytic activity $[15,16]$. For example, a decrease in catalytic activity is reported for ethylbenzene dehydrogenation, in which carbonaceous products are formed from the ethylene by-product as shown in Equation (24) [11].

Dehydrogenation:

$\mathrm{C}_{6} \mathrm{H}_{5}-\mathrm{CH}_{2} \mathrm{CH}_{3} \rightarrow \mathrm{C}_{6} \mathrm{H}_{5}-\mathrm{CH}=\mathrm{CH}_{2}+\mathrm{H}_{2}$

Dealkylation in the side chain $(\mathrm{C}-\mathrm{C}$ cleavage in the side chain):

$\mathrm{C}_{6} \mathrm{H}_{5}-\mathrm{CH}_{2} \mathrm{CH}_{3} \rightarrow \mathrm{C}_{6} \mathrm{H}_{5}-\mathrm{CH}_{3}+\left(\mathrm{CH}_{2}\right)$

Dealkylation of the side chain (elimination of the ring attached alkyl):

$\mathrm{C}_{6} \mathrm{H}_{5}-\mathrm{CH}_{2} \mathrm{CH}_{3} \rightarrow \mathrm{C}_{6} \mathrm{H}_{6}+\mathrm{CH}_{2}=\mathrm{CH}_{2}$

Alkyl chain isomerization (isomerization of the side chain):

$\mathrm{C}_{6} \mathrm{H}_{5}-\mathrm{CH}_{2} \mathrm{CH}_{3} \rightarrow \mathrm{C}_{6} \mathrm{H}_{4}\left(\mathrm{CH}_{3}\right)_{2}$

Intermolecular transalkylation (disproportionation):

$2 \mathrm{C}_{6} \mathrm{H}_{5}-\mathrm{CH}_{2} \mathrm{CH}_{3} \rightarrow \mathrm{C}_{6} \mathrm{H}_{6}+\mathrm{C}_{6} \mathrm{H}_{4}\left(\mathrm{CH}_{2} \mathrm{CH}_{3}\right)_{2}$

Figure 1. Typical reaction profile of ethylbenzene dehydrogenation catalyzed by $\left(\mathrm{H}_{3} \mathrm{O}\right)_{2}\left[\left(\mathrm{Mo}_{6} \mathrm{Cl}_{8}\right) \mathrm{Cl}_{6}\right] \cdot 6 \mathrm{H}_{2} \mathrm{O}$. Following activation of the cluster $(200 \mathrm{mg}, 0.163 \mathrm{mmol})$ in a helium stream $(600 \mathrm{~mL} / \mathrm{h})$ at $450{ }^{\circ} \mathrm{C}$ for $1 \mathrm{~h}$, reaction was initiated by introduction of ethylbenzene $(50 \mu \mathrm{L} / \mathrm{h}, 0.4 \mathrm{mmol} / \mathrm{h})$ to the helium stream without changing the temperature . Conversion $=$ products $/$ products + recovered material $) \times 100(\%)$ based on aromatic compounds.

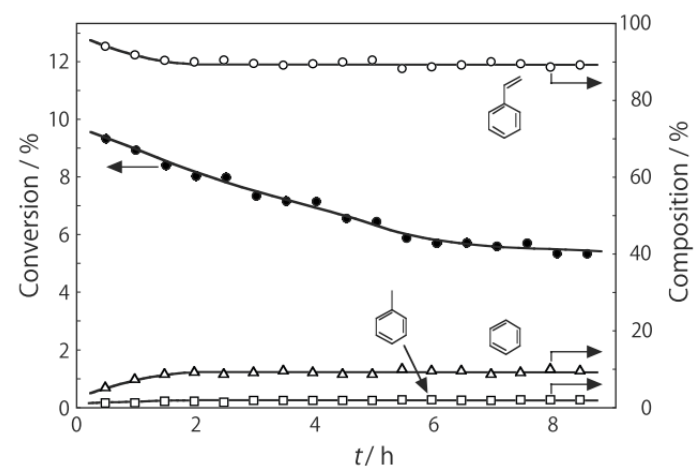

The effect of reaction temperature is presented in Figure 2. No catalytic activity was observed below $250{ }^{\circ} \mathrm{C}$. The activity developed slightly at $300{ }^{\circ} \mathrm{C}$, and increased with increasing temperature. The selectivities for both dehydrogenation and dealkylations remained constant up to $450{ }^{\circ} \mathrm{C}$. Above this temperature, the selectivity for dealkylation to yield benzene increased with increasing temperature.

Table 2 lists the catalytic activity of various clusters and related compounds treated at $450{ }^{\circ} \mathrm{C}$. This table shows that molybdenum metal had no catalytic activity under the same reaction conditions (entry 7). Molybdenum pentachloride cannot be used as a catalyst under the same reaction conditions, as it boils at $268{ }^{\circ} \mathrm{C}$. From these results we can conclude that the halide cluster developed catalytic activity by taking advantage of its low vapor pressure and high melting point, enabling application at high temperatures in an open reaction system. The chloride clusters of niobium and tungsten, with 
an octahedrally arranged $\mathrm{M}_{6}$ metal core, and of rhenium, with a triangular metal core, also catalyzed the dehydrogenation under helium (entries 1, 5, and 6).

Figure 2. Effect of temperature on reactivity and selectivity in dehydrogenation of ethylbenzene over $\left(\mathrm{H}_{3} \mathrm{O}\right)_{2}\left[\left(\mathrm{Mo}_{6} \mathrm{Cl}_{8}\right) \mathrm{Cl}_{6}\right] \cdot 6 \mathrm{H}_{2} \mathrm{O}$ in a helium stream $(600 \mathrm{~mL} / \mathrm{h})$ at $3 \mathrm{~h}$ after the start of the reaction. Other conditions are the same as in Figure 1.

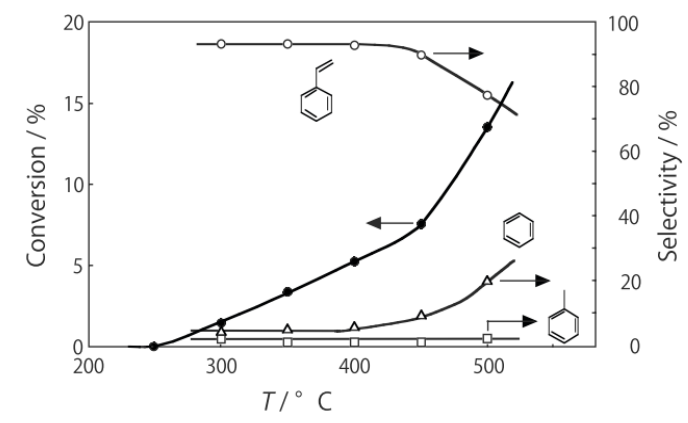

Table 2. Dehydrogenation and reductive dealkylation of ethylbenzene over halide clusters ${ }^{\text {a }}$.

\begin{tabular}{|c|c|c|c|c|c|c|}
\hline \multirow{2}{*}{ Entry } & \multirow{2}{*}{ Catalyst } & \multirow{2}{*}{ Carrier gas } & \multirow{2}{*}{ Conversion $(\%)^{b}$} & \multicolumn{3}{|c|}{ Selectivity (\%) ${ }^{\mathrm{c}}$} \\
\hline & & & & Styrene & Toluene & Benzene \\
\hline 1 & {$\left[\left(\mathrm{Nb}_{6} \mathrm{Cl}_{12}\right) \mathrm{Cl}_{2}\left(\mathrm{H}_{2} \mathrm{O}\right)_{4}\right] \cdot 4 \mathrm{H}_{2} \mathrm{O}$} & $\mathrm{He}$ & 7.8 & 85.5 & 2.9 & 11.6 \\
\hline 2 & $\left(\mathrm{H}_{3} \mathrm{O}\right)_{2}\left[\left(\mathrm{Mo}_{6} \mathrm{Cl}_{8}\right) \mathrm{Cl}_{6}\right] \cdot 6 \mathrm{H}_{2} \mathrm{O}$ & $\mathrm{He}$ & 7.5 & 89.4 & 1.3 & 9.3 \\
\hline 3 & {$\left[\left(\mathrm{Mo}_{6} \mathrm{Br}_{8}\right)(\mathrm{OH})_{4}\left(\mathrm{H}_{2} \mathrm{O}\right)_{2}\right]$} & $\mathrm{He}$ & 1.0 & 86.5 & 5.0 & 8.5 \\
\hline 4 & {$\left[\left(\mathrm{Ta}_{6} \mathrm{Cl}_{12}\right) \mathrm{Cl}_{2}\left(\mathrm{H}_{2} \mathrm{O}\right)_{4}\right] \cdot 4 \mathrm{H}_{2} \mathrm{O}$} & $\mathrm{He}$ & 1.2 & 0.0 & 16.2 & 83.3 \\
\hline 5 & $\left(\mathrm{H}_{3} \mathrm{O}\right)_{2}\left[\left(\mathrm{~W}_{6} \mathrm{Cl}_{8}\right) \mathrm{Cl}_{6}\right] \cdot 6 \mathrm{H}_{2} \mathrm{O}$ & $\mathrm{He}$ & 28.7 & 73.3 & 5.4 & 21.3 \\
\hline 6 & $\mathrm{Re}_{3} \mathrm{Cl}_{9}$ & $\mathrm{He}$ & 2.5 & 76.3 & 4.0 & 19.7 \\
\hline 7 & Mo metal ${ }^{\mathrm{d}}$ & $\mathrm{He}$ & 0.0 & - & - & - \\
\hline 8 & Raney $\mathrm{Ni}^{\mathrm{e}}$ & $\mathrm{He}$ & 9.5 & 98.0 & 0.3 & 1.7 \\
\hline 9 & $\mathrm{Pt} / \mathrm{C}^{\mathrm{f}}$ & $\mathrm{He}$ & 16.1 & 96.9 & 1.8 & 1.3 \\
\hline 10 & no catalyst & $\mathrm{He}$ & 0.0 & - & - & - \\
\hline 11 & $\left(\mathrm{H}_{3} \mathrm{O}\right)_{2}\left[\left(\mathrm{Mo}_{6} \mathrm{Cl}_{8}\right) \mathrm{Cl}_{6}\right] \cdot 6 \mathrm{H}_{2} \mathrm{O}$ & $\mathrm{N}_{2}$ & 1.4 & 85.0 & 2.8 & 12.2 \\
\hline 12 & $\left(\mathrm{H}_{3} \mathrm{O}\right)_{2}\left[\left(\mathrm{Mo}_{6} \mathrm{Cl}_{8}\right) \mathrm{Cl}_{6}\right] \cdot 6 \mathrm{H}_{2} \mathrm{O}$ & $\mathrm{Ar}$ & 1.2 & 86.3 & 3.3 & 10.4 \\
\hline 13 & {$\left[\left(\mathrm{Nb}_{6} \mathrm{Cl}_{12}\right) \mathrm{Cl}_{2}\left(\mathrm{H}_{2} \mathrm{O}\right)_{4}\right] \cdot 4 \mathrm{H}_{2} \mathrm{O}$} & $\mathrm{H}_{2}$ & 0.0 & - & - & - \\
\hline 14 & $\left(\mathrm{H}_{3} \mathrm{O}\right)_{2}\left[\left(\mathrm{Mo}_{6} \mathrm{Cl}_{8}\right) \mathrm{Cl}_{6}\right] \cdot 6 \mathrm{H}_{2} \mathrm{O}$ & $\mathrm{H}_{2}$ & 10.0 & 7.0 & 62.7 & 30.3 \\
\hline 15 & {$\left[\left(\mathrm{Ta}_{6} \mathrm{Cl}_{12}\right) \mathrm{Cl}_{2}\left(\mathrm{H}_{2} \mathrm{O}\right)_{4}\right] \cdot 4 \mathrm{H}_{2} \mathrm{O}$} & $\mathrm{H}_{2}$ & 0.0 & - & - & - \\
\hline 16 & $\left(\mathrm{H}_{3} \mathrm{O}\right)_{2}\left[\left(\mathrm{~W}_{6} \mathrm{Cl}_{8}\right) \mathrm{Cl}_{6}\right] \cdot 6 \mathrm{H}_{2} \mathrm{O}$ & $\mathrm{H}_{2}$ & 47.8 & 1.1 & 4.8 & 94.1 \\
\hline 17 & $\mathrm{Re}_{3} \mathrm{Cl}_{9}$ & $\mathrm{H}_{2}$ & $5.7^{\mathrm{g}}$ & 0.0 & 0.0 & 0.0 \\
\hline 18 & Mo metal ${ }^{\mathrm{d}}$ & $\mathrm{H}_{2}$ & 0.0 & - & - & - \\
\hline 19 & Raney $\mathrm{Ni}^{\mathrm{h}}$ & $\mathrm{H}_{2}$ & 20.9 & 1.9 & 61.1 & 37.0 \\
\hline 20 & $\mathrm{Pt} / \mathrm{C}^{\mathrm{i}}$ & $\mathrm{H}_{2}$ & 2.8 & 18.8 & 65.1 & 16.1 \\
\hline 21 & no catalyst & $\mathrm{H}_{2}$ & 0.0 & - & - & - \\
\hline
\end{tabular}

${ }^{\text {a }}$ After activation of catalyst $(200 \mathrm{mg})$ in a stream of carrier gas $(600 \mathrm{~mL} / \mathrm{h})$ at $450{ }^{\circ} \mathrm{C}$ for $1 \mathrm{~h}$, reaction was started by introduction of ethylbenzene $(50 \mu \mathrm{L} / \mathrm{h}, 0.4 \mathrm{mmol} / \mathrm{h})$ to the stream without changing the temperature;

${ }^{\mathrm{b}}$ Conversion $=$ products $/($ products + recovered ethylbenzene $) \times 100(\%)$ at $3 \mathrm{~h}$ after reaction started;

${ }^{\mathrm{c}}$ Selectivity $=$ product/(total amount of products $) \times 100(\%)$ at $3 \mathrm{~h}$ after reaction started; ${ }^{\mathrm{d}}$ Mo metal (150-200 mesh) $200 \mathrm{mg} ;{ }^{\mathrm{e}}$ Raney Ni $20 \mathrm{mg} ;{ }^{\mathrm{f}} \mathrm{Pt}$ on charcoal (50 wt\%, $\left.30 \mathrm{mesh}\right) 500 \mathrm{mg} ;{ }^{\mathrm{g}}$ Ring opening degradation to yield gaseous products; ${ }^{\mathrm{h}}$ Raney Ni (2 mg) diluted with quartz sand (198 mg); ${ }^{\mathrm{i}} \mathrm{Pt}$ on charcoal (50 wt\%, $30 \mathrm{mesh}) 50 \mathrm{mg}$. 


\subsubsection{Reaction under Hydrogen}

Figure 3 presents the catalytic activity of the molybdenum cluster in a stream of hydrogen at various temperatures. The product selectivity changed. Reductive dealkylations to yield toluene and benzene (Equations (27) and (28) proceeded exclusively above $450{ }^{\circ} \mathrm{C}$, which shows that hydrogen was used in the reaction. For the reaction in a hydrogen stream, no decrease of the catalytic activity was observed even at high temperatures. This accorded with the fact that no unsaturated hydrocarbons were produced, as indicated in Equations (27) and (28).

Reductive dealkylation in the side chain (hydrogenolysis in the side chain):

$\mathrm{C}_{6} \mathrm{H}_{5}-\mathrm{CH}_{2} \mathrm{CH}_{3}+\mathrm{H}_{2} \rightarrow \mathrm{C}_{6} \mathrm{H}_{5}-\mathrm{CH}_{3}+\mathrm{CH}_{4}$

Reductive dealkylation of the side chain (hydrogenolysis of the ring-attached alkyl):

$\mathrm{C}_{6} \mathrm{H}_{5}-\mathrm{CH}_{2} \mathrm{CH}_{3}+\mathrm{H}_{2} \rightarrow \mathrm{C}_{6} \mathrm{H}_{6}+\mathrm{CH}_{3} \mathrm{CH}_{3}$

Figure 3. Effect of temperature on reactivity and selectivity in reductive dealkylation of ethylbenzene over $\left(\mathrm{H}_{3} \mathrm{O}\right)_{2}\left[\left(\mathrm{Mo}_{6} \mathrm{Cl}_{8}\right) \mathrm{Cl}_{6}\right] \cdot 6 \mathrm{H}_{2} \mathrm{O}$ in a hydrogen stream $(600 \mathrm{~mL} / \mathrm{h})$ at $3 \mathrm{~h}$ after the start of the reaction. Other conditions are the same as in Figure 1.

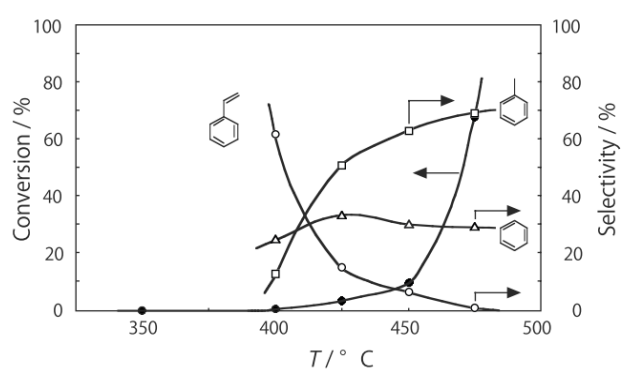

Table 2 summarizes the catalytic activities of the clusters treated in a hydrogen stream. Clusters of Group 5 metals showed no catalytic activity under hydrogen (entries 13 and 15). On the other hand, reductive dealkylations selectively proceeded on Group 6 metal clusters yielding toluene and benzene (entries 14 and 16). Table 2 also lists the selectivity values on nickel and platinum catalysts under identical conditions. Under a helium stream, dehydrogenation proceeded selectively (entries 8 and 9) and under a hydrogen stream, reductive dealkylations progressed selectively (entries 19 and 20), which is the same as on the halide clusters of Group 6 metals.

When $\mathrm{Re}_{3} \mathrm{Cl}_{9}$ was applied to the reaction in a hydrogen stream at $450{ }^{\circ} \mathrm{C}$, it catalyzed ring-opening degradation to yield only gaseous hydrocarbons in $5.7 \%$ conversion (entry 17). Under these conditions, $\mathrm{Re}_{3} \mathrm{Cl}_{9}$ is reduced to metallic $\mathrm{Re}$ by hydrogen [1]. The same degradation has been reported over Pt, $\mathrm{Ni}$, and $\mathrm{Rh}$ metal on $\mathrm{SiO}_{2}$ and $\mathrm{Al}_{2} \mathrm{O}_{3}$ under hydrogen streams. Rhenium is located in the neighboring position to the platinum metals in the periodic table, and shares some properties with these metals.

When ethylbenzene was allowed to react in the presence of typical solid acid catalysts, such as mordenite and ZSM-5, in both helium [10-12] and hydrogen streams [13,14], intermolecular transalkylation and dealkylation of the side chain proceeded. Another typical class of acid catalyst, heteropoly oxometalates, catalyzed dealkylation under a helium stream [17]. However, halide clusters of Group 5-7 metals under a helium stream catalyzed dehydrogenation, which is conventionally catalyzed by nickel [4,5] and platinum metals [6,7] in a nitrogen stream. When ethylbenzene was 
treated in the same way in a hydrogen stream, Group 5 metal clusters exhibited no catalytic activity but Group 6 metal clusters catalyzed reductive dealkylation. Nickel and platinum metals under a hydrogen stream also catalyzed this reaction [8,9]. Consequently, the halide clusters of Group 6 metals, Mo and $\mathrm{W}$, exhibited similar catalysis to the platinum metals showing variable selectivity in helium and hydrogen streams. This catalytic behavior of Group 6 metal clusters is interpreted in terms of the isoelectronic state with the platinum group metals [1].

\subsection{Reaction of Cyclohexanone (Equation (2)) [18]}

\subsubsection{Reaction under Helium}

Cyclohexanone is sometimes used for test reaction in catalysis, because it is susceptible to various reactions. Then it was subjected to catalytic reaction. To increase the catalytic efficiency of heterogeneous molecular cluster catalysts, molybdenum cluster was supported on silica gel (Nippon Aerosil, Tokyo, Japan; Aerosil $380 \mathrm{~m}^{2} / \mathrm{g}$ ) in $5.0 \%$ by weight followed by screening to $150-200$ mesh. The supported molybdenum clusters, $\left(\mathrm{H}_{3} \mathrm{O}\right)_{2}\left[\left(\mathrm{Mo}_{6} \mathrm{Cl}_{8}\right) \mathrm{Cl}_{6}\right] \cdot 6 \mathrm{H}_{2} \mathrm{O} / \mathrm{SiO}_{2}$, were packed in a glass reaction tube and activated in a helium stream for $1 \mathrm{~h}$. The reaction was commenced immediately by introduction of cyclohexanone into the helium stream without changing the temperature. The effect of the reaction temperature is presented in Figure 4. The catalytic activity developed above $300{ }^{\circ} \mathrm{C}$, and increased with increasing temperature. The selectivity for hydrodehydration to yield cyclohexene increased with increasing temperature. The product selectivity for cyclohexanone and related compounds over the supported cluster $\left(\mathrm{H}_{3} \mathrm{O}\right)_{2}\left[\left(\mathrm{Mo}_{6} \mathrm{Cl}_{8}\right) \mathrm{Cl}_{6}\right] \cdot 6 \mathrm{H}_{2} \mathrm{O} / \mathrm{SiO}_{2}$ at $400{ }^{\circ} \mathrm{C}$ under helium is illustrated in Figure 5. The cluster catalyzed the hydrodehydration of cyclohexanone to produce cyclohexene and its dehydrogenation products, 1,3-cyclohexadiene and benzene, with a total selectivity of $57 \%$. Dehydrogenation (to yield 2-cyclohexen-1-one and phenol) and condensation (to yield cyclohexylbenzene and cyclohex-1-enylbenzene) proceeded concomitantly with around $20 \%$ selectivity. A characteristic feature of the reaction of cyclohexanone is a harmonious hydrogen balance: the total amount of hydrogen liberated by dehydrogenation to yield 2-cyclohexen-1-one, phenol, benzene, and cyclohex-1-enylbenzene is equal to that used for the hydrodehydration that generates cyclohexene, provided that the oxygen is removed as $\mathrm{H}_{2} \mathrm{O}$. Therefore, the overall reaction of cyclohexanone under helium can be viewed as disproportionation. Catalytic disproportionation of cyclohexanone has been reported over solid acids such as alumina [19-23]; however, successive dehydration to 1,3-cyclohexadiene and benzene did not proceed. On the other hand, the aromatization of cyclohexanone to phenol has been reported over Group 8-10 metals: $\mathrm{Ni}, \mathrm{Pd}, \mathrm{Pt}$, and $\mathrm{Cu}$ [24-26]. Accordingly, the molybdenum cluster exhibited both acid-base and platinum-like metallic characters in catalysis.

As shown in Figure 5b, 2-cyclohexen-1-one disproportionated similarly to yield cyclohexanone and phenol as the main products. Disproportionation of olefin occurs readily in incipient aromatic systems with or without hydrogen in the presence of the platinum metals [27]. As Figure 5c shows, cyclohexene was dehydrogenated almost exclusively to yield benzene. Thus, the molybdenum cluster exhibited platinum-like metallic characters in these reactions. 
Figure 4. Effect of temperature on reactivity and selectivity in catalysis of cyclohexanone over $\left(\mathrm{H}_{3} \mathrm{O}\right)_{2}\left[\left(\mathrm{Mo}_{6} \mathrm{Cl}_{8}\right) \mathrm{Cl}_{6}\right] \cdot 6 \mathrm{H}_{2} \mathrm{O} / \mathrm{SiO}_{2}$. Following the activation of the supported cluster (30 mg, $1.23 \mu \mathrm{mol})$ in a helium stream $(600 \mathrm{~mL} / \mathrm{h})$ for $1 \mathrm{~h}$, reaction was initiated by introduction of cyclohexanone $(50 \mu \mathrm{L} / \mathrm{h}, 0.48 \mathrm{mmol} / \mathrm{h})$ to the helium stream without changing the temperature. Conversion of cyclohexanone $(\bullet)$; selectivity for hydrodehydration $(\square)$; selectivity for condensation $(\Delta)$; and selectivity for dehydrogenation (०); at 4-5 h after the start of the reaction.

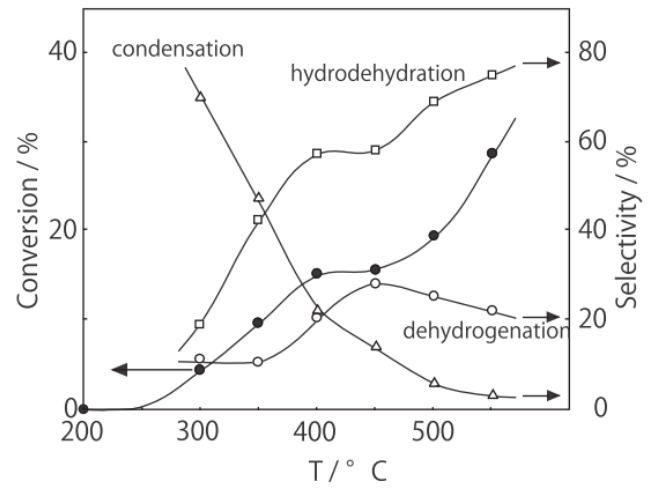

Figure 5. Reaction scheme of (a) cyclohexanone; (b) 2-cyclohexen-1-one, and (c) cyclohexene over $\left(\mathrm{H}_{3} \mathrm{O}\right)_{2}\left[\left(\mathrm{Mo}_{6} \mathrm{Cl}_{8}\right) \mathrm{Cl}_{6}\right] \cdot 6 \mathrm{H}_{2} \mathrm{O} / \mathrm{SiO}_{2}$ in a helium stream at $400{ }^{\circ} \mathrm{C}$ at 4-5 $\mathrm{h}$ after the start of the reaction. Other conditions are the same as in Figure 4. Conversion of each starting material is shown in brackets. The selectivity for each product is shown as a numerical value (\%), and the thickness of the arrow from the starting material is proportional to the corresponding selectivity value for the reaction. A leftward shift corresponds to hydrogen consumption, and a rightward shift corresponds to hydrogen release.

(a)

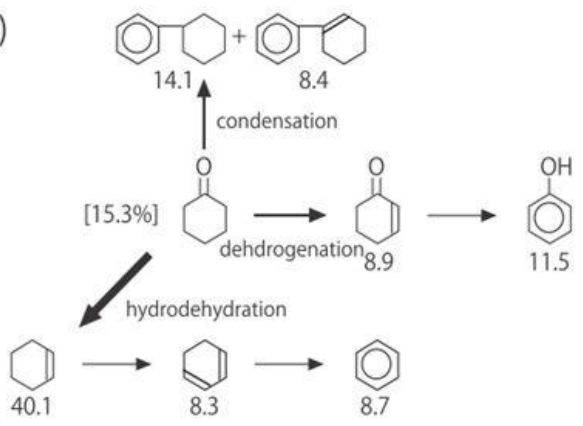

(b)
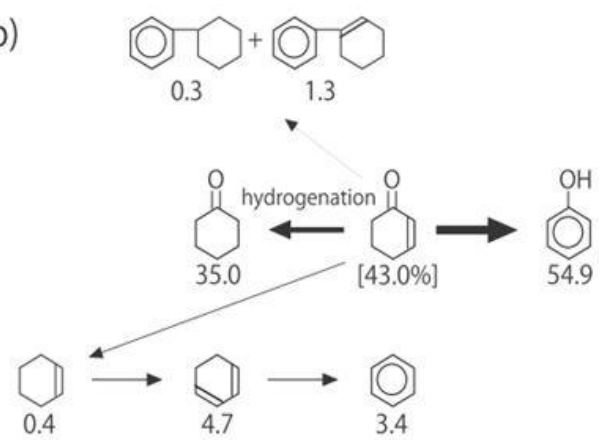
Figure 5. Cont.

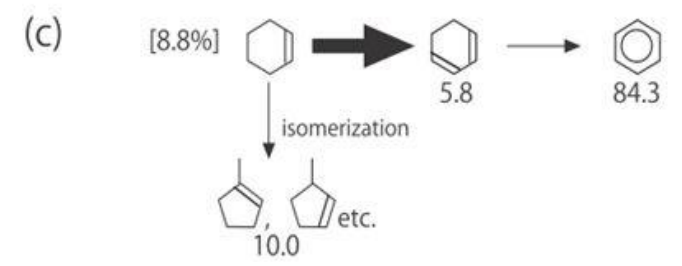

Table 3 lists the catalytic activity of some Group 5 and 6 metal clusters and related compounds. Although the catalytic activity of crushed crystals of the molybdenum cluster was low because of the low surface area $\left(3.95 \mathrm{~m}^{2} / \mathrm{g}\right)$, the selectivity over $\left(\mathrm{H}_{3} \mathrm{O}\right)_{2}\left[\left(\mathrm{Mo}_{6} \mathrm{Cl}_{8}\right) \mathrm{Cl}_{6}\right] \cdot 6 \mathrm{H}_{2} \mathrm{O}$ was virtually the same as that over $\left(\mathrm{H}_{3} \mathrm{O}\right)_{2}\left[\left(\mathrm{Mo}_{6} \mathrm{Cl}_{8}\right) \mathrm{Cl}_{6}\right] \cdot 6 \mathrm{H}_{2} \mathrm{O} / \mathrm{SiO}_{2}$. The chloride clusters of niobium, tantalum, and tungsten of the same metal framework also developed catalytic activity, and the condensation proceeded almost exclusively. The acidic character of these cluster catalysts predominated in the reaction, since the condensation is reported to proceed on solid acid catalysts such as $\mathrm{Fe}_{2} \mathrm{O}_{3}$ and $\mathrm{Al}_{2} \mathrm{O}_{3}$ [28].

\subsubsection{Reaction under Hydrogen}

Figure 6 presents the effect of reaction temperature in a stream of hydrogen over $\left(\mathrm{H}_{3} \mathrm{O}\right)_{2}\left[\left(\mathrm{Mo}_{6} \mathrm{Cl}_{8}\right) \mathrm{Cl}_{6}\right] \cdot 6 \mathrm{H}_{2} \mathrm{O} / \mathrm{SiO}_{2}$. The activity developed above $300{ }^{\circ} \mathrm{C}$ and increased with increasing temperature. The reaction progressed almost quantitatively over $450{ }^{\circ} \mathrm{C}$. Figure 7 illustrates the product selectivities under hydrogen at $400{ }^{\circ} \mathrm{C}$, starting from cyclohexanone and related compounds. The main reaction of cyclohexanone is hydrodehydration leading to the formation of cyclohexene, which requires one equivalent of hydrogen molecules. Although one and two equivalents of hydrogen molecules can be liberated when benzene and phenol are produced, respectively, the total amount of released hydrogen is insufficient to generate cyclohexene with $66 \%$ selectivity. Atmospheric hydrogen was utilized for hydrodehydration. The molybdenum cluster apparently catalyzed the hydrogenolysis of the $\mathrm{C}-\mathrm{O}$ bond, utilizing atmospheric hydrogen like the platinum metals do.

Figure 6. Effect of temperature on reactivity and selectivity in the catalysis of cyclohexanone over $\left(\mathrm{H}_{3} \mathrm{O}\right)_{2}\left[\left(\mathrm{Mo}_{6} \mathrm{Cl}_{8}\right) \mathrm{Cl}_{6}\right] \cdot 6 \mathrm{H}_{2} \mathrm{O} / \mathrm{SiO}_{2}$ in a hydrogen stream $(600 \mathrm{~mL} / \mathrm{h})$. Other conditions are the same as in Figure 4. Conversion of cyclohexanone $(\bullet)$; selectivity for hydrodehydration $(\square)$; selectivity for condensation $(\Delta)$; and selectivity for dehydrogenation $(\mathrm{O})$.

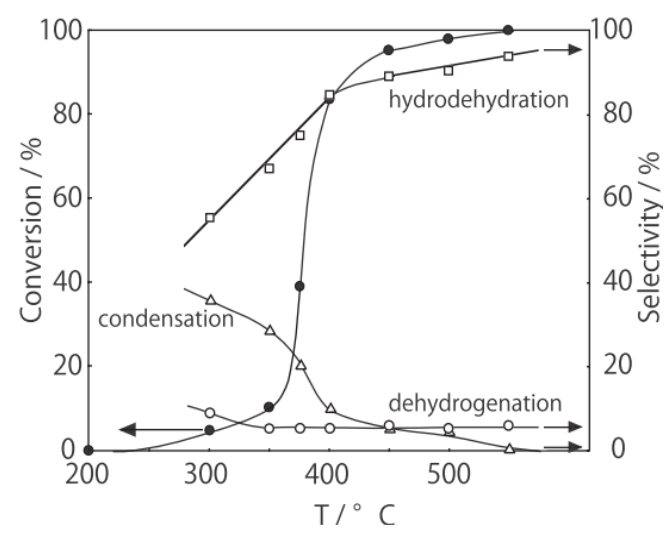


Table 3. Hydrodehydration, dehydrogenation, and condensation of cyclohexanone over halide clusters a

\begin{tabular}{|c|c|c|c|c|c|c|c|}
\hline \multirow[b]{3}{*}{ Catalyst } & \multirow[b]{3}{*}{ Conversion $(\%)^{b}$} & \multicolumn{6}{|c|}{ Selectivity $(\%)^{c}$} \\
\hline & & \multicolumn{3}{|c|}{ Hydrodehydration } & \multicolumn{2}{|c|}{ Dehydrogenation } & \multirow{2}{*}{$\begin{array}{c}\text { Condensation } \\
\text { Product }^{\mathrm{d}} \\
\end{array}$} \\
\hline & & Cyclohexene & 1,3-Cyclohexadiene & Benzene & 2-Cyclohexen-1-one & Phenol & \\
\hline$\left[\left(\mathrm{Nb}_{6} \mathrm{Cl}_{12}\right) \mathrm{Cl}_{2}\left(\mathrm{H}_{2} \mathrm{O}\right)_{4}\right] \cdot 4 \mathrm{H}_{2} \mathrm{O} / \mathrm{SiO}_{2}$ & 87.0 & 5.1 & 3.6 & 1.1 & 0.0 & 1.2 & 88.9 \\
\hline$\left(\mathrm{H}_{3} \mathrm{O}\right)_{2}\left[\left(\mathrm{Mo}_{6} \mathrm{Cl}_{8}\right) \mathrm{Cl}_{6}\right] \cdot 6 \mathrm{H}_{2} \mathrm{O} / \mathrm{SiO}_{2}$ & 15.3 & 40.1 & 8.3 & 8.7 & 8.9 & 11.5 & 22.5 \\
\hline$\left[\left(\mathrm{Ta}_{6} \mathrm{Cl}_{12}\right) \mathrm{Cl}_{2}\left(\mathrm{H}_{2} \mathrm{O}\right)_{4}\right] \cdot 4 \mathrm{H}_{2} \mathrm{O} / \mathrm{SiO}_{2}$ & 94.3 & 6.1 & 4.2 & 1.3 & 0.0 & 1.1 & 87.4 \\
\hline$\left(\mathrm{H}_{3} \mathrm{O}\right)_{2}\left[\left(\mathrm{~W}_{6} \mathrm{Cl}_{8}\right) \mathrm{Cl}_{6}\right] \cdot 6 \mathrm{H}_{2} \mathrm{O} / \mathrm{SiO}_{2}$ & 70.0 & 4.6 & 4.8 & 2.2 & 0.0 & 0.6 & 87.7 \\
\hline$\left(\mathrm{H}_{3} \mathrm{O}\right)_{2}\left[\left(\mathrm{Mo}_{6} \mathrm{Cl}_{8}\right) \mathrm{Cl}_{6}\right] \cdot 6 \mathrm{H}_{2} \mathrm{O}^{\mathrm{e}}$ & 5.5 & 34.6 & 7.3 & 4.1 & 7.9 & 20.8 & 25.5 \\
\hline$\left(\mathrm{H}_{3} \mathrm{O}\right)_{2}\left[\left(\mathrm{Mo}_{6} \mathrm{Cl}_{8}\right) \mathrm{Cl}_{6}\right] \cdot 6 \mathrm{H}_{2} \mathrm{O} / \mathrm{SiO}_{2}{ }^{\mathrm{f}}$ & 83.2 & 66.2 & 2.5 & 15.7 & 0.0 & 5.5 & 10.2 \\
\hline Mo metal ${ }^{\mathrm{g}}$ & 0.0 & & & & & & \\
\hline $\mathrm{SiO}_{2}$ & 0.0 & & & & & & \\
\hline
\end{tabular}

${ }^{a}$ After activation of supported cluster $(5 \mathrm{wt} \%$ on silica gel, $30 \mathrm{mg})$ in a helium stream $(600 \mathrm{~mL} / \mathrm{h})$ at $400{ }^{\circ} \mathrm{C}$ for $1 \mathrm{~h}$, reaction was started by introduction of cyclohexanone $(50 \mu \mathrm{L} / \mathrm{h}, 0.48 \mathrm{mmol} / \mathrm{h})$ to the stream without changing the temperature; ${ }^{\mathrm{b}}$ Conversion $=$ products/(products + recovered cyclohexanone $\times 100(\%)$ at 4-5 h after reaction started; ${ }^{\mathrm{c}}$ Selectivity $=$ product/(total amount of products) $\times 100(\%)$ at $4-5 \mathrm{~h}$ after reaction started; ${ }^{\mathrm{d}}$ Cyclohexylbenzene and cyclohex-1-enylbenzene with a small amount of trimers; ${ }^{\mathrm{e}}$ Unsupported crushed crystalline cluster (150-200 mesh, $\left.30 \mathrm{mg}\right){ }^{\mathrm{f}}$ In a stream of hydrogen; ${ }^{\mathrm{g}}$ Mo metal (150-200 mesh) 30 mg. 
Figure 7. Reaction scheme of (a) cyclohexanone; (b) 2-cyclohexen-1-one; and (c) cyclohexene over $\left(\mathrm{H}_{3} \mathrm{O}\right)_{2}\left[\left(\mathrm{Mo}_{6} \mathrm{Cl}_{8}\right) \mathrm{Cl}_{6}\right] \cdot 6 \mathrm{H}_{2} \mathrm{O} / \mathrm{SiO}_{2}$ in a hydrogen stream at $400{ }^{\circ} \mathrm{C}$ at $4-5 \mathrm{~h}$ after the start of the reaction. Other conditions are the same as in Figure 6. Conversion of each starting material is shown in brackets. The selectivity for each product is shown as a numerical value (\%), and the thickness of the arrow from the starting material is proportional to the corresponding selectivity value for the reaction. A leftward shift corresponds to hydrogen consumption, and a rightward shift corresponds to hydrogen release.

(a)

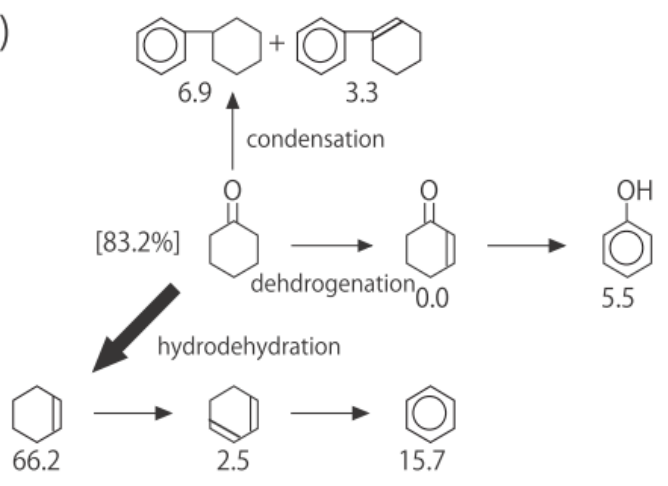

(b)

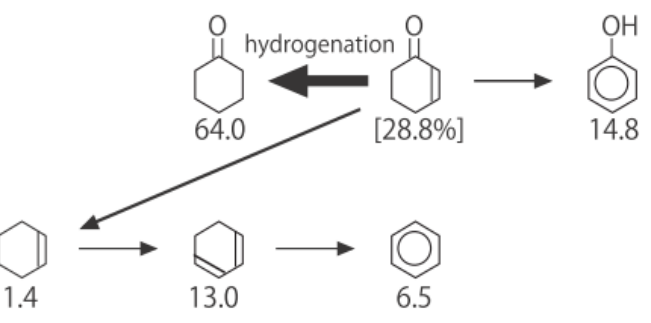

(c)

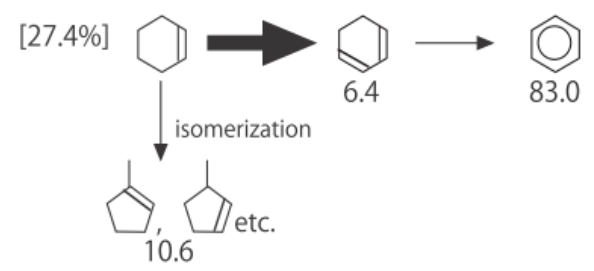

As Figure 7b shows, 2-cyclohexen-1-one was hydrogenated to cyclohexanone with $64 \%$ selectivity. In this reaction, the amount of hydrogen that is liberated from the dehydrogenation of 2-cyclohexen-1-one to phenol is insufficient for the production of cyclohexanone. Atmospheric hydrogen was incorporated into cyclohexanone.

Over evaporated film of molybdenum metal, the hydrogenation of ethylene has been reported, but the activity was quite low compared with that on the platinum metals [29,30]. Propylene was not hydrogenated over the molybdenum metal. Reduced $\mathrm{Mo}(0) / \mathrm{Al}_{2} \mathrm{O}_{3}[31,32]$ or $\mathrm{Mo}(\leq \mathrm{VI}) / \mathrm{Al}_{2} \mathrm{O}_{3}[32]$ has been reported as a hydrogenation catalyst for propylene. However, its application to other olefins has not been reported; nor has its application to oxygen-containing olefins been reported.

The product selectivity from cyclohexene under hydrogen is practically the same as that under helium, with benzene being produced with $\sim 83 \%$ selectivity (Figures $5 \mathrm{c}$ and $7 \mathrm{c}$ ). Accordingly, the 
molybdenum cluster catalyzed the dehydrogenation of cyclohexene irrespective of the atmosphere. Oxidative dehydrogenation of cyclohexene to benzene has been reported over several metal oxide catalysts, but dehydrogenation without oxidizing agents is catalyzed by the platinum metals [33-36].

Consequently, the molybdenum cluster catalyzed hydrodehydration and hydrogenation using atmospheric hydrogen, and catalyzed dehydrogenation like the platinum metals do. These similar reactivities of $\mathrm{Mo}$ atom in the halide cluster $\left(\mathrm{H}_{3} \mathrm{O}\right)_{2}\left[\left(\mathrm{Mo}_{6} \mathrm{Cl}_{8}\right) \mathrm{Cl}_{6}\right] \cdot 6 \mathrm{H}_{2} \mathrm{O}$ to those of the platinum metals can be interpreted in terms of the isoelectronic status of the Mo atom in the cluster and the platinum metals [1].

\section{Simple Acid Catalysis}

\subsection{Decomposition of Phenyl Acetate (Equation (3)) [37]}

Aromatic acylation is an important process in the fine chemical industries and has been intensively investigated. The reaction of phenyl acetate to $o$ - and $p$-hydroxyacetophenone is well known as the Fries rearrangement [38], and usually Lewis acids such as $\mathrm{AlCl}_{3}, \mathrm{BF}_{3}, \mathrm{FeCl}_{3}$, and $\mathrm{TiCl}_{4}$ are used stoichiometrically. Because the carbonyl oxygen strongly coordinates to the Lewis acid center [39], hydrolysis of the Lewis acid is necessary for the isolation of the products. In order to overcome this disadvantage, solid Brønsted acids such as H-Beta zeolite [40-43], H-Y zeolite [42,44,45], H-ZSM-5 [40-42,44-47], $\mathrm{HF} / \mathrm{Al}_{2} \mathrm{O}_{3}$ [44], and Nafion-H [48], a resin containing the $-\mathrm{CF}_{2} \mathrm{CF}_{2} \mathrm{SO}_{3} \mathrm{H}$ group, are used as the catalyst. However, the selectivity for $o$ - and $p$-hydroxyacetophenone is not high, and in almost all cases the main product is the decomposition product, phenol. Application of the halide cluster catalyst to the Fries rearrangement was unsuccessful; however, decomposition of phenyl acetate to phenol and ketene unexpectedly proceeded exclusively at as low as $150{ }^{\circ} \mathrm{C}$, and no other catalysts for the selective decomposition at lower temperature have been reported.

\subsubsection{Development of Catalytic Activity}

Crushed and screened (150-200 mesh) crystal powder of niobium halide cluster $\left[\left(\mathrm{Nb}_{6} \mathrm{Cl}_{12}\right) \mathrm{Cl}_{2}\left(\mathrm{H}_{2} \mathrm{O}\right)_{4}\right] \cdot 4 \mathrm{H}_{2} \mathrm{O}$ was initially activated in a helium stream for $1 \mathrm{~h}$ at an elevated temperature, and then reaction was commenced by introducing phenyl acetate into the gas flow without changing the temperature. The reaction profiles at various temperatures are plotted in Figure 8. No catalytic activity was observed below $100{ }^{\circ} \mathrm{C}$, and slight activity was evident at $150{ }^{\circ} \mathrm{C}$. Activation above $200{ }^{\circ} \mathrm{C}$ resulted in substantial catalytic activity and the activity increased with increasing temperature, reaching a maximum at $300{ }^{\circ} \mathrm{C}$. The products were solely phenol and ketene, and no by-products such as $o$ - and $p$-hydroxyacetophenone were detected throughout the reactions.

As can be seen from Figure 8, the catalytic activity decreased very rapidly during the first $2 \mathrm{~h}$ of the reaction and leveled off after $3 \mathrm{~h}$ of the reaction. This is probably because of fouling by carbonaceous compounds or coke on the catalyst $[15,16]$. The deactivation was increased by an increase in the reaction temperature. 
Figure 8. Typical reaction profiles of decomposition of phenyl acetate to phenol and ketene catalyzed by $\left[\left(\mathrm{Nb}_{6} \mathrm{Cl}_{12}\right) \mathrm{Cl}_{2}\left(\mathrm{H}_{2} \mathrm{O}\right)_{4}\right] \cdot 4 \mathrm{H}_{2} \mathrm{O}$ at different temperatures. Following activation of the cluster $(30 \mathrm{mg}, 25 \mu \mathrm{mol})$ in a helium stream $(2.4 \mathrm{~L} / \mathrm{h})$ for $1 \mathrm{~h}$, reaction was initiated by introduction of phenyl acetate $(0.1 \mathrm{~mL} / \mathrm{h}, 0.79 \mathrm{mmol} / \mathrm{h})$ to the helium stream without changing the temperature. Decomposition proceeded exclusively. Conversion $=\mathrm{phenol} /($ phenyl acetate + phenol $) \times 100(\%)$.

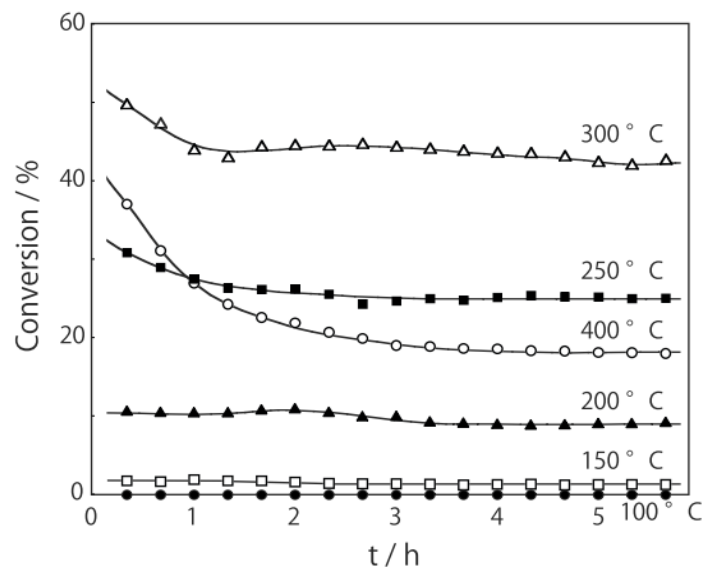

The effect of the preliminary activation temperature on the cluster and successive reaction temperature was examined, and the results are summarized in Figure 9. When both temperatures were changed concomitantly, the maximum activity appeared at $300{ }^{\circ} \mathrm{C}$. On the other hand, when the subsequent reactions were performed at $150{ }^{\circ} \mathrm{C}$, the maximum activity appeared at around $250{ }^{\circ} \mathrm{C}$. Hence, preliminary activation at $250^{\circ} \mathrm{C}$ induced the highest catalytic activity for the niobium cluster.

Figure 9. Effect of preliminary activation temperature and reaction temperature on catalytic activity of $\left[\left(\mathrm{Nb}_{6} \mathrm{Cl}_{12}\right) \mathrm{Cl}_{2}\left(\mathrm{H}_{2} \mathrm{O}\right)_{4}\right] \cdot 4 \mathrm{H}_{2} \mathrm{O}$ at $3 \mathrm{~h}$ after the start of the reaction. After activation of the cluster in a helium stream at a different temperature for $1 \mathrm{~h}$, reaction was initiated by introduction of phenyl acetate to the helium stream at the activation temperature $(\bullet)$; or at $150{ }^{\circ} \mathrm{C}(\circ)$. Other conditions are the same as in Figure 8.

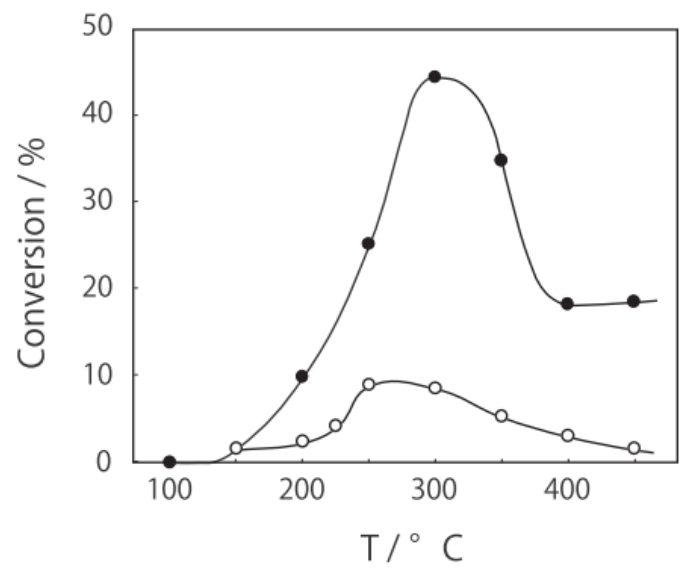

The catalytic activities of various halide clusters and the related compound are tested. Crushed and screened crystals of bromide cluster of niobium, $\left[\left(\mathrm{Nb}_{6} \mathrm{Br}_{12}\right) \mathrm{Br}_{2}\left(\mathrm{H}_{2} \mathrm{O}\right)_{4}\right] \cdot 4 \mathrm{H}_{2} \mathrm{O}$, and chloride clusters of molybdenum, tantalum, and tungsten also exhibited similar catalytic activities. Under a hydrogen 
stream, the clusters of niobium and molybdenum catalyzed the decomposition of phenyl acetate similarly. However, hydrogenolysis to benzene proceeded in around $20 \%$ selectivity, which could be attributable to the platinum-like property of the cluster catalysts [1].

Figure 10 shows the catalytic activity of crushed and screened (150-200 mesh) crystal powder of $\left(\mathrm{H}_{3} \mathrm{O}\right)_{2}\left[\left(\mathrm{Mo}_{6} \mathrm{Cl}_{8}\right) \mathrm{Cl}_{6}\right] \cdot 6 \mathrm{H}_{2} \mathrm{O}$, which underwent preliminary activation at various temperatures in a helium stream for $1 \mathrm{~h}$ and was then reacted at $150{ }^{\circ} \mathrm{C}$. The activity emerged with activation above $200{ }^{\circ} \mathrm{C}$ and reached a maximum with activation at $400{ }^{\circ} \mathrm{C}$. The temperature which resulted in the maximum activity for $\left(\mathrm{H}_{3} \mathrm{O}\right)_{2}\left[\left(\mathrm{Mo}_{6} \mathrm{Cl}_{8}\right) \mathrm{Cl}_{6}\right] \cdot 6 \mathrm{H}_{2} \mathrm{O}$ differed from that for $\left[\left(\mathrm{Nb}_{6} \mathrm{Cl}_{12}\right) \mathrm{Cl}_{2}\left(\mathrm{H}_{2} \mathrm{O}\right)_{4}\right] \cdot 4 \mathrm{H}_{2} \mathrm{O}$.

Figure 10. Effect of preliminary activation temperature on catalytic activity of $\left(\mathrm{H}_{3} \mathrm{O}\right)_{2}\left[\left(\mathrm{Mo}_{6} \mathrm{Cl}_{8}\right) \mathrm{Cl}_{6}\right] \cdot 6 \mathrm{H}_{2} \mathrm{O}$ at $3 \mathrm{~h}$ after the start of the reaction. Following the activation of the cluster $(30 \mathrm{mg}, 25 \mu \mathrm{mol})$ in a helium stream $(2.4 \mathrm{~L} / \mathrm{h})$ for $1 \mathrm{~h}$, reaction was initiated by introduction of phenyl acetate $(0.1 \mathrm{~mL} / \mathrm{h}, 0.79 \mathrm{mmol} / \mathrm{h})$ to the stream at $150{ }^{\circ} \mathrm{C}$. Other conditions are the same as in Figure 8.

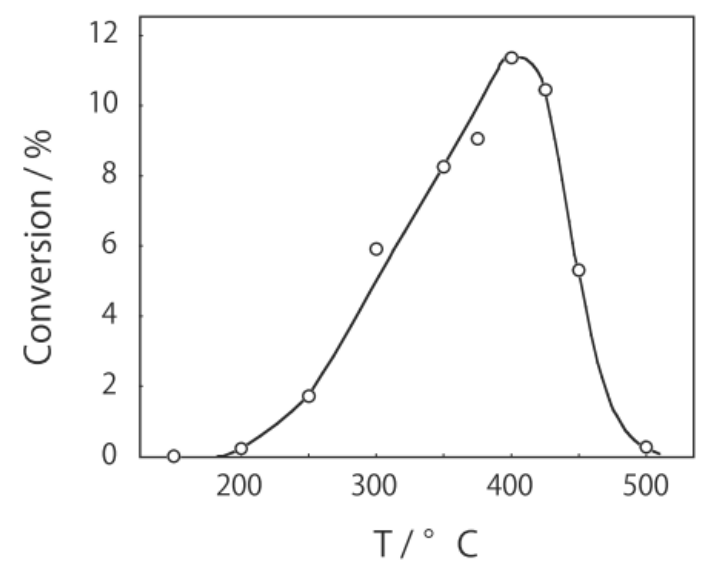

\subsubsection{Reaction Mechanism}

A mechanism for phenyl acetate transformation over solid Brønsted acids has been proposed [42,45,49]. Phenyl acetate is adsorbed on the protic center and then either rearranges into $o$-hydroxyacetophenone (intramolecular Fries rearrangement) or desorbs as phenol. In the latter case, the residual acetyl cation on the Brønsted base can react with the produced phenol to form $o$ - and $p$-hydroxyacetophenone (intermolecular Fries rearrangement), or afford ketene (decomposition) regenerating the Brønsted acid site. The stability of the adsorbed species would determine the selectivity for the products. Consequently, a high-performance catalyst for the Fries rearrangement is expected to have a stabilizing capacity for the cations. Liquid phase reaction exhibited better selectivity for the Fries rearrangement compared with the gas phase reaction [41], in which no solvation for the cations is present. Oxide catalysts generally have both acidic and basic characters. Alumina has been classified as a solid acid; however, it has both acidic and basic sites, namely: incompletely coordinated aluminum ions (strong Lewis acids) and oxide ions (weak Lewis bases) [50-53]. Both of the sites are small and have high charge densities for participation in reactions. Over conventional solid Brønsted acids such as H-Beta, H-Y, H-ZSM-5, and $\mathrm{HF} / \mathrm{Al}_{2} \mathrm{O}_{3}$, the Fries rearrangement proceeds to some extent, as mentioned above. In contrast, halide clusters are characterized by very weak basicity, great softness, 
and a large polyhedral anion structure, and hence have very low charge densities on their surface. The anion would not participate in the reactions nor stabilize the counter cation. Thus, protonated phenyl acetate and acetyl cation, which are not stabilized by the large cluster counter anion, would rapidly disproportionate into phenol, ketene, and proton exclusively.

\subsection{Isomerization of Olefin (Equation (4)) [54]}

Platinum group metals and $\mathrm{Ni}$ are used practically for the isomerization and hydrogenation of olefins in heterogeneous systems [27,55,56]. Both acids and bases also catalyze the isomerization of olefins. No metal halides, except $\mathrm{TiCl}_{3}$ [57], have been reported as isomerization catalysts of olefins in heterogeneous systems, although metal sulfides and oxides of Group 5 and 6 metal compounds have been reported to catalyze the reaction. Halide clusters were applied as catalysts for the isomerization of olefin.

\subsubsection{Catalysis over $\left[\left(\mathrm{Nb}_{6} \mathrm{Cl}_{12}\right) \mathrm{Cl}_{2}\left(\mathrm{H}_{2} \mathrm{O}\right)_{4}\right] \cdot 4 \mathrm{H}_{2} \mathrm{O}$}

Pulverized and screened (150-200 mesh) crystals of $\left[\left(\mathrm{Nb}_{6} \mathrm{Cl}_{12}\right) \mathrm{Cl}_{2}\left(\mathrm{H}_{2} \mathrm{O}\right)_{4}\right] \cdot 4 \mathrm{H}_{2} \mathrm{O}$ were thermally activated in a stream of hydrogen for $1 \mathrm{~h}$. Reaction was initiated by introduction of 1-hexene into the stream of hydrogen. A typical reaction profile at $350{ }^{\circ} \mathrm{C}$ is plotted in Figure 11 . The niobium cluster catalyzed isomerization and slightly catalyzed hydrogenation of the olefinic bond to yield cis- and trans-2-hexene and hexane. Although the catalytic activity decreased with time, the cis/trans selectivity of the isomerized product 2-hexene remained constant. The effect of the temperature is shown in Figure 12. When both the preliminary-activation and following reaction temperatures were changed concurrently, the catalytic activity developed slightly at $150{ }^{\circ} \mathrm{C}$. The activity increased with increasing temperature with a local maximum at $300{ }^{\circ} \mathrm{C}$. Then, the effect of the preliminary-activation temperature on the catalytic activity was examined. The cluster samples were given a preliminary activation by changing the temperature for $1 \mathrm{~h}$, followed by reaction with 1 -hexene at $150{ }^{\circ} \mathrm{C}$. As Figure 12 shows, preliminary activation at around $200{ }^{\circ} \mathrm{C}$ gave the maximum activity.

Figure 11. Typical reaction profile of 1-hexene under hydrogen over $\left[\left(\mathrm{Nb}_{6} \mathrm{Cl}_{12}\right) \mathrm{Cl}_{2}\left(\mathrm{H}_{2} \mathrm{O}\right)_{4}\right] \cdot 4 \mathrm{H}_{2} \mathrm{O}$. Following activation of the cluster $(30 \mathrm{mg}, 25 \mu \mathrm{mol})$ in a hydrogen stream $(2.4 \mathrm{~L} / \mathrm{h})$ at $350{ }^{\circ} \mathrm{C}$ for $1 \mathrm{~h}$, reaction was initiated by introduction of 1 -hexene $(0.8 \mathrm{~mL} / \mathrm{h}, 7.1 \mathrm{mmol} / \mathrm{h})$ to the hydrogen stream without changing the temperature.

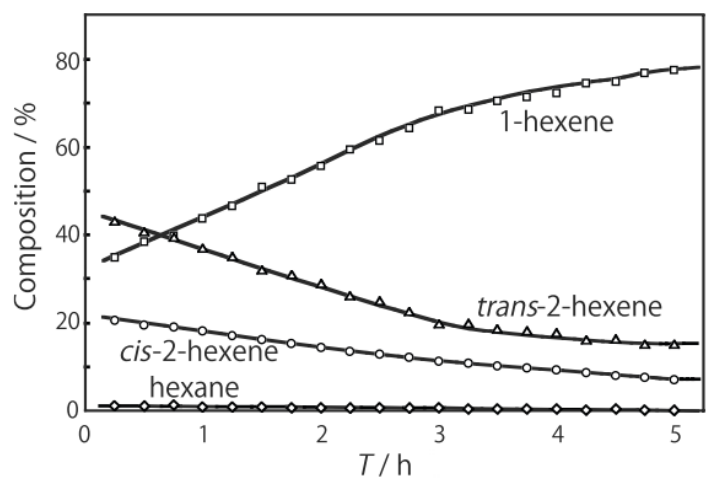


Figure 12. Effect of preliminary activation temperature on catalytic activity of $\left[\left(\mathrm{Nb}_{6} \mathrm{Cl}_{12}\right) \mathrm{Cl}_{2}\left(\mathrm{H}_{2} \mathrm{O}\right)_{4}\right] \cdot 4 \mathrm{H}_{2} \mathrm{O}$. Following the activation of the cluster in a hydrogen stream at a different temperature for $1 \mathrm{~h}$, reaction was initiated by introduction of 1-hexene to the stream at the activation temperature $(\square)$; or $150{ }^{\circ} \mathrm{C}(\bullet)$. Other conditions are the same as in Figure 11. Conversion $=(2$-hexene + hexane $) /(1$-hexene +2 -hexene + hexane $) \times 100(\%)$ at $4 \mathrm{~h}$ after the starat of the reaction.

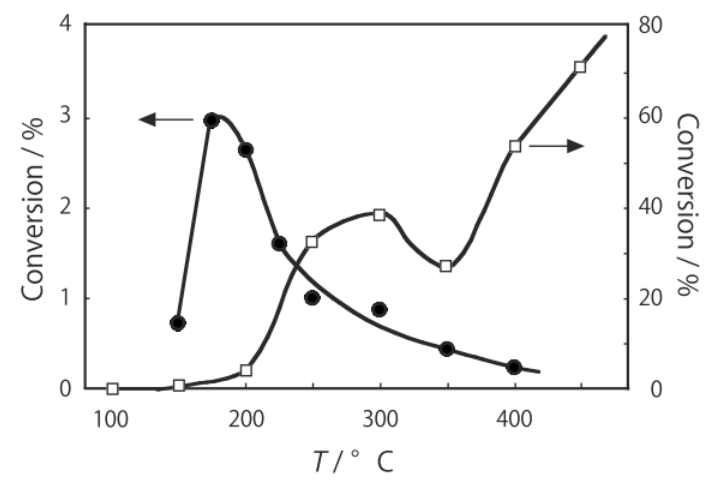

Table 4 lists the catalytic activity of various halide clusters and related compounds treated at $250{ }^{\circ} \mathrm{C}$. This table shows that the niobium cluster activated in a stream of helium exhibited almost the same activity as that treated in a stream of hydrogen. The cluster bromide of niobium and chlorides of molybdenum, tantalum, and tungsten also showed catalytic activity for the isomerization of olefin. Although rhenium metal [58] and rhenium sulfides [59] have been reported to be hydrogenation catalysts, a rhenium cluster, $\mathrm{Re}_{3} \mathrm{Cl}_{9}$, had no catalytic activity under the same reaction conditions. The catalytic activity varied with the cluster catalyst employed; however, the cis/trans selectivities of 2-hexene remained in a relatively narrow range and the ratios are approximately in accord with that of thermal equilibrium $\left(0.77\right.$ at $\left.250{ }^{\circ} \mathrm{C}\right)$. Isomerization of 1-butene to cis- and trans-2-butenes has been extensively studied over many heterogeneous basic and acidic catalysts. High cis/trans ratios have been observed over basic catalysts [60] such as $\mathrm{MgO}$ (3.2-7.0), $\mathrm{ZrO}_{2}$ (7.3), and $\mathrm{ThO}_{2}$ (3.1-3.4), and low ratios over acidic catalysts such as $\mathrm{Nb}_{2} \mathrm{O}_{5} \cdot n \mathrm{H}_{2} \mathrm{O}$ (2) [61], $\mathrm{WO}_{2}$ (1.4) [62], and $\mathrm{WO}_{3}$ (1.4) [62]. The corresponding cis/trans ratio of 2-hexene has not been reported on basic catalysts; however, on acidic catalysts the values reported are low: 0.83 on HY zeolite [63] and 0.5 on H-ZSM-5 [64]. Thus, the halide clusters should be classified as acidic catalysts.

\subsubsection{Catalysis over $\left(\mathrm{H}_{3} \mathrm{O}\right)_{2}\left[\left(\mathrm{~W}_{6} \mathrm{Cl}_{8}\right) \mathrm{Cl}_{6}\right] \cdot 6 \mathrm{H}_{2} \mathrm{O}$}

Figure 13 presents the catalytic activities of the pluverized and screened (150-200 mesh) crystals of tungsten cluster, $\left(\mathrm{H}_{3} \mathrm{O}\right)_{2}\left[\left(\mathrm{~W}_{6} \mathrm{Cl}_{8}\right) \mathrm{Cl}_{6}\right] \cdot 6 \mathrm{H}_{2} \mathrm{O}$, after preliminary activation at varying temperatures for $1 \mathrm{~h}$, followed by reaction without changing the temperature. The activity commenced when the reaction were carried out at $300{ }^{\circ} \mathrm{C}$, and the activity markedly increased with increasing temperature. On the other hand, while the samples activated at various temperatures react at $150{ }^{\circ} \mathrm{C}$ and $250{ }^{\circ} \mathrm{C}$, the maximum activities appeared around $450{ }^{\circ} \mathrm{C}$ and $480{ }^{\circ} \mathrm{C}$, respectively. Mononuclear and dinuclear tungsten chlorides $-\mathrm{WCl}_{4},\left(\mathrm{WCl}_{5}\right)_{2}$, and $\mathrm{WCl}_{6}-$ cannot be used as catalysts under the reaction conditions, as they decompose or boil below $347^{\circ} \mathrm{C}$. High thermal stability, high melting point, high boiling point, and low vapor pressure of the cluster permitted the utilization for a solid catalyst at high temperatures. 
Table 4. Isomerization of 1-hexene over halide clusters ${ }^{\text {a }}$.

\begin{tabular}{cccc}
\hline \multirow{2}{*}{ Catalyst } & \multicolumn{3}{c}{ Conversion/\% } \\
\cline { 2 - 4 } & Isomerization $^{\mathbf{b}}$ & (cis/trans) & Hydrogenation $^{\mathbf{c}}$ \\
\hline$\left[\left(\mathrm{Nb}_{6} \mathrm{Cl}_{12}\right) \mathrm{Cl}_{2}\left(\mathrm{H}_{2} \mathrm{O}\right)_{4}\right] \cdot 4 \mathrm{H}_{2} \mathrm{O}$ & 31.3 & $(0.47)$ & 0.3 \\
{$\left[\left(\mathrm{Nb}_{6} \mathrm{Cl}_{12}\right) \mathrm{Cl}_{2}\left(\mathrm{H}_{2} \mathrm{O}\right)_{4}\right] \cdot 4 \mathrm{H}_{2} \mathrm{O}{ }^{\mathrm{d}}$} & 25.5 & $(0.60)$ & 0.0 \\
{$\left[\left(\mathrm{Nb}_{6} \mathrm{Br}_{12}\right) \mathrm{Br}_{2}\left(\mathrm{H}_{2} \mathrm{O}\right)_{4}\right] \cdot 4 \mathrm{H}_{2} \mathrm{O}$} & 0.75 & $(0.47)$ & 0.0 \\
{$\left[\left(\mathrm{Nb}_{6} \mathrm{Br}_{12}\right) \mathrm{Br}_{2}\left(\mathrm{H}_{2} \mathrm{O}\right)_{4}\right] \cdot 4 \mathrm{H}_{2} \mathrm{O}{ }^{\mathrm{e}}$} & 35.9 & $(0.45)$ & 0.4 \\
$\left(\mathrm{H}_{3} \mathrm{O}\right)_{2}\left[\left(\mathrm{Mo}_{6} \mathrm{Cl}_{8}\right) \mathrm{Cl}_{6}\right] \cdot 6 \mathrm{H}_{2} \mathrm{O}$ & 1.8 & $(0.78)$ & 0.1 \\
{$\left[\left(\mathrm{Ta}_{6} \mathrm{Cl}_{12}\right) \mathrm{Cl}_{2}\left(\mathrm{H}_{2} \mathrm{O}\right)_{4}\right] \cdot 4 \mathrm{H}_{2} \mathrm{O}$} & 1.4 & $(0.45)$ & 0.1 \\
$\left(\mathrm{H}_{3} \mathrm{O}\right)_{2}\left[\left(\mathrm{~W}_{6} \mathrm{Cl}_{8}\right) \mathrm{Cl}_{6}\right] \cdot 6 \mathrm{H}_{2} \mathrm{O}$ & 1.8 & $(0.62)$ & 0.1 \\
$\mathrm{Re}_{3} \mathrm{Cl}_{9}$ & 0.0 & - & 0.0 \\
$\mathrm{Pt}$ metal $^{\mathrm{f}}$ & 2.3 & $(0.75)$ & 4.8 \\
$\mathrm{Pd} \mathrm{metal}^{\mathrm{f}}$ & 5.4 & $(0.56)$ & 1.1 \\
$\mathrm{Nb}$ metal & 0.0 & - & 0.0 \\
\hline
\end{tabular}

${ }^{\text {a }}$ After activation of catalyst $(30 \mathrm{mg})$ in a hydrogen stream $(2.4 \mathrm{~L} / \mathrm{h})$ at $250{ }^{\circ} \mathrm{C}$ for $1 \mathrm{~h}$, reaction was started by introduction of 1-hexene $(0.8 \mathrm{~mL} / \mathrm{h}, 7.1 \mathrm{mmol} / \mathrm{h})$ to the stream without changing the temperature. At $4 \mathrm{~h}$ after the start of the reaction; ${ }^{b}$ Isomerization $=2$-hexene/(1-hexene +2 -hexene + hexane $) \times 100(\%)$ at $4 \mathrm{~h}$; ${ }^{\mathrm{c}}$ Hydrogenation $=$ hexane $/(1$-hexene +2 -hexene + hexane $) \times 100(\%)$ at $4 \mathrm{~h} ;{ }^{\mathrm{d}}$ Helium $(2.4 \mathrm{~L} / \mathrm{h})$ was used; ${ }^{\mathrm{e}}$ Catalyst activation and reaction was performed at $350 \mathrm{~mm} ;{ }^{\mathrm{f}}$ Unsupported metal black powder.

Figure 13. Effect of preliminary activation temperature on catalytic activity of $\left(\mathrm{H}_{3} \mathrm{O}\right)_{2}\left[\left(\mathrm{~W}_{6} \mathrm{Cl}_{8}\right) \mathrm{Cl}_{6}\right] \cdot 6 \mathrm{H}_{2} \mathrm{O}$. Following the activation of the cluster $(30 \mathrm{mg}, 17 \mu \mathrm{mol})$ in a hydrogen stream at a different temperature for $1 \mathrm{~h}$, reaction was initiated by introduction of 1-hexene to the stream at the activation temperature $(\square)$; at $150{ }^{\circ} \mathrm{C}(\bullet)$; or at $250{ }^{\circ} \mathrm{C}(\mathrm{O})$. Other conditions are the same as in Figures 11 and 12.

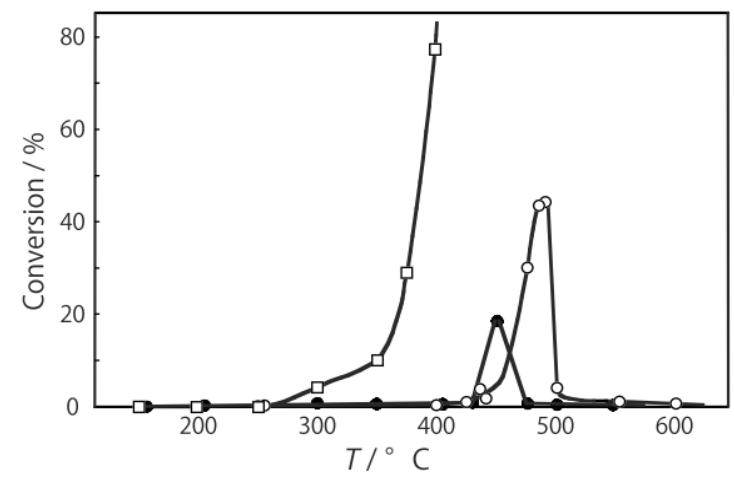

Thus, when molecular halide clusters of Group 5 and 6 metals were activated at $150-250{ }^{\circ} \mathrm{C}$, catalytic activity for double bond isomerization of the olefin developed. In the case of tungsten cluster, the catalytic activity was enhanced with increasing temperature up to the decay at around $450{ }^{\circ} \mathrm{C}$.

\subsection{Reaction of Alcohol (Equation (5)) [65]}

Dehydration of alcohols is a well-known simple reaction, and hence, various types of catalysts have been applied to it [66]. Liquid acids, such as sulfuric acid and $p$-toluenesulfonic acid, are known to catalyze this reaction. Solid acids, such as alumina [66,67] and Nafion-H [68], also catalyze this reaction. Heteropoly acids are also used to carry out this reaction [68-71], and occasionally these are 
used as supported catalysts. On the other hand, thorium oxide, a solid base, also catalyzes the reaction. Halide clusters were applied to this reaction.

Pulverized and screened (150-200 mesh) crystals of $\left[\left(\mathrm{Nb}_{6} \mathrm{Cl}_{12}\right) \mathrm{Cl}_{2}\left(\mathrm{H}_{2} \mathrm{O}\right)_{4}\right] \cdot 4 \mathrm{H}_{2} \mathrm{O}$ or $\left(\mathrm{H}_{3} \mathrm{O}\right)_{2}\left[\left(\mathrm{~W}_{6} \mathrm{Cl}_{8}\right) \mathrm{Cl}_{6}\right] \cdot 6 \mathrm{H}_{2} \mathrm{O}$ were activated at an elevated temperature in flowing helium gas for $1 \mathrm{~h}$. The reaction was initiated by introducing ethanol into the helium without changing the temperature. Figure 14 shows the effect of the temperature. The catalytic activity appeared in a narrow temperature range of $225-350{ }^{\circ} \mathrm{C}$, with the activity increasing with increasing temperature, and the maximum activity occurring at a temperature of $300-330^{\circ} \mathrm{C}$. Both clusters catalyzed the dehydration of ethanol to yield ethylene as a major product. The selectivity for ethyl ether decreased with increasing temperature. The cluster bromide of niobium $\left[\left(\mathrm{Nb}_{6} \mathrm{Br}_{12}\right) \mathrm{Br}_{2}\left(\mathrm{H}_{2} \mathrm{O}\right)_{4}\right] \cdot 4 \mathrm{H}_{2} \mathrm{O}$ and chlorides of tantalum and tungsten also showed the catalytic activity, and ethylene was the major product at $300{ }^{\circ} \mathrm{C}$.

Figure 14. Effect of temperature on the dehydration of ethanol over (a) $\left[\left(\mathrm{Nb}_{6} \mathrm{Cl}_{12}\right) \mathrm{Cl}_{2}\left(\mathrm{H}_{2} \mathrm{O}\right)_{4}\right] \cdot 4 \mathrm{H}_{2} \mathrm{O}$; and $(\mathbf{b})\left(\mathrm{H}_{3} \mathrm{O}\right)_{2}\left[\left(\mathrm{~W}_{6} \mathrm{Cl}_{8}\right) \mathrm{Cl}_{6}\right] \cdot 6 \mathrm{H}_{2} \mathrm{O}$. Following the activation of the cluster ( $30 \mathrm{mg} ; 25 \mu \mathrm{mol}$ and $17.1 \mu \mathrm{mol}$, respectively) in a helium stream $(1.2 \mathrm{~L} / \mathrm{h}$ ) for

$1 \mathrm{~h}$, reaction was initiated by introduction of ethanol $(0.24 \mathrm{~mL} / \mathrm{h}, 4.2 \mathrm{mmol} / \mathrm{h})$ to the helium stream without changing the temperature. Conversion of ethanol $(\bullet)$; selectivity for ethylene (०); selectivity for ethyl ether $(\Delta)$; and selectivity for 1,1-diethoxyethane ( $\square$ ); at $5 \mathrm{~h}$ after the start of the reaction.
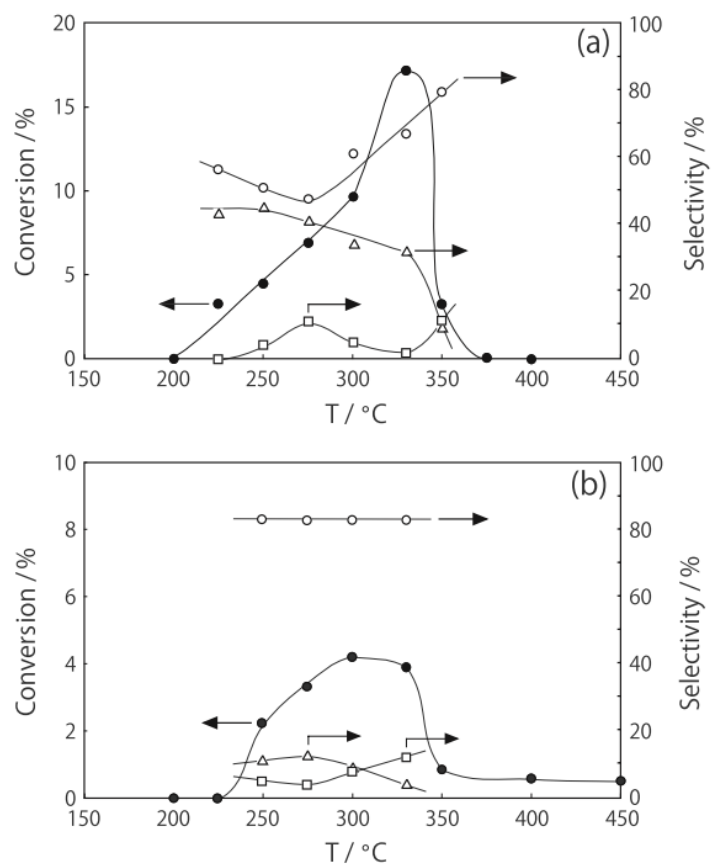

Table 5 summarizes the catalytic activity for $\mathrm{C}_{3}-\mathrm{C}_{5}$ alcohols at $300{ }^{\circ} \mathrm{C}$. All the alcohols tested yielded the corresponding olefins almost exclusively, and no ethers were afforded. In the case of primary alcohols, the selectivity for ether has been reported to decrease with increasing length of the carbon chain in the alcohol [72]. Secondary and tertiary alcohols are reported to yield the olefins, but no ethers [66]. The activity of the primary alcohols decreased as the length of the carbon chain increased, and the secondary alcohol exhibited higher activity than the corresponding primary alcohol 
over each catalyst. The same order of reactivity of alcohols has been reported over heteropoly acid [71], metal sulfates [73], and $\mathrm{La}_{2} \mathrm{O}_{3}$ [74]. This order of reactivity is interpreted in terms of the relative ease of formation of the carbenium ion by rupturing of the $\mathrm{C}-\mathrm{O}$ bond [71]. As Table 5 shows, when 2-butanol was applied to the reaction, the selectivity for 2-butene (inner olefin) was higher than that for 1-butene (outer olefin), and the selectivity for cis-2-butene was higher than that for trans-2-butene over both niobium and tungsten clusters. The same product selectivities have been reported over solid acid catalysts, such as $\mathrm{Al}_{2} \mathrm{O}_{3}, \mathrm{SiO}_{2}$, and $\mathrm{ZnS}$, where 2-olefins were the major products rich in the cis-isomers when 2-hydroxyalkanes were dehydrated [75]. In contrast, solid base catalysts, such as $\mathrm{ThO}_{2}, \mathrm{La}_{2} \mathrm{O}_{3}$, and $\mathrm{CeO}_{2}$, mainly afford 1-olefins and 2-olefins are the by-products rich in the trans-isomer [76]. Consequently, the halide clusters showed the same product selectivity as the solid acid catalysts rather than the solid base catalysts.

Table 5. Dehydration of alcohols over halide clusters ${ }^{\mathrm{a}}$.

\begin{tabular}{|c|c|c|c|c|c|c|}
\hline \multirow{2}{*}{ Alcohol } & \multirow{2}{*}{ Catalyst } & \multirow{2}{*}{$\begin{array}{c}\text { Conversion } \\
(\%)^{b} \\
\end{array}$} & \multicolumn{4}{|c|}{ Selectivity $(\%)^{\mathrm{c}}$} \\
\hline & & & 1-Olefin & cis-2-Olefin & trans-2-Olefin & Others $^{d}$ \\
\hline \multirow[t]{4}{*}{ 1-Propanol } & {$\left[\left(\mathrm{Nb}_{6} \mathrm{Cl}_{12}\right) \mathrm{Cl}_{2}\left(\mathrm{H}_{2} \mathrm{O}\right)_{4}\right] \cdot 4 \mathrm{H}_{2} \mathrm{O}$} & 61.3 & 97.7 & - & - & 2.3 \\
\hline & $\left(\mathrm{H}_{3} \mathrm{O}\right)_{2}\left[\left(\mathrm{Mo}_{6} \mathrm{Cl}_{8}\right) \mathrm{Cl}_{6}\right] \cdot 6 \mathrm{H}_{2} \mathrm{O}$ & 2.3 & 94.0 & - & - & 6.0 \\
\hline & {$\left[\left(\mathrm{Ta}_{6} \mathrm{Cl}_{12}\right) \mathrm{Cl}_{2}\left(\mathrm{H}_{2} \mathrm{O}\right)_{4}\right] \cdot 4 \mathrm{H}_{2} \mathrm{O}$} & 9.0 & 98.9 & - & - & 1.1 \\
\hline & $\left(\mathrm{H}_{3} \mathrm{O}\right)_{2}\left[\left(\mathrm{~W}_{6} \mathrm{Cl}_{8}\right) \mathrm{Cl}_{6}\right] \cdot 6 \mathrm{H}_{2} \mathrm{O}$ & 9.7 & 98.6 & - & - & 1.4 \\
\hline \multirow[t]{2}{*}{ 1-Butanol } & {$\left[\left(\mathrm{Nb}_{6} \mathrm{Cl}_{12}\right) \mathrm{Cl}_{2}\left(\mathrm{H}_{2} \mathrm{O}\right)_{4}\right] \cdot 4 \mathrm{H}_{2} \mathrm{O}$} & 27.6 & 56.2 & 26.1 & 14.6 & 3.1 \\
\hline & $\left(\mathrm{H}_{3} \mathrm{O}\right)_{2}\left[\left(\mathrm{~W}_{6} \mathrm{Cl}_{8}\right) \mathrm{Cl}_{6}\right] \cdot 6 \mathrm{H}_{2} \mathrm{O}$ & 2.7 & 41.6 & 32.1 & 25.4 & 0.9 \\
\hline \multirow[t]{2}{*}{ 1-Pentanol } & {$\left[\left(\mathrm{Nb}_{6} \mathrm{Cl}_{12}\right) \mathrm{Cl}_{2}\left(\mathrm{H}_{2} \mathrm{O}\right)_{4}\right] \cdot 4 \mathrm{H}_{2} \mathrm{O}$} & 4.8 & 53.0 & 26.2 & 17.4 & 3.4 \\
\hline & $\left(\mathrm{H}_{3} \mathrm{O}\right)_{2}\left[\left(\mathrm{~W}_{6} \mathrm{Cl}_{8}\right) \mathrm{Cl}_{6}\right] \cdot 6 \mathrm{H}_{2} \mathrm{O}$ & 2.3 & 32.1 & 28.9 & 17.1 & 21.9 \\
\hline \multirow[t]{4}{*}{ 2-Propanol } & {$\left[\left(\mathrm{Nb}_{6} \mathrm{Cl}_{12}\right) \mathrm{Cl}_{2}\left(\mathrm{H}_{2} \mathrm{O}\right)_{4}\right] \cdot 4 \mathrm{H}_{2} \mathrm{O}$} & 100.0 & 99.9 & 0.0 & 0.0 & 0.1 \\
\hline & $\left(\mathrm{H}_{3} \mathrm{O}\right)_{2}\left[\left(\mathrm{Mo}_{6} \mathrm{Cl}_{8}\right) \mathrm{Cl}_{6}\right] \cdot 6 \mathrm{H}_{2} \mathrm{O}$ & 81.2 & 99.6 & 0.0 & 0.0 & 0.4 \\
\hline & {$\left[\left(\mathrm{Ta}_{6} \mathrm{Cl}_{12}\right) \mathrm{Cl}_{2}\left(\mathrm{H}_{2} \mathrm{O}\right)_{4}\right] \cdot 4 \mathrm{H}_{2} \mathrm{O}$} & 16.2 & 99.7 & 0.0 & 0.0 & 0.3 \\
\hline & $\left(\mathrm{H}_{3} \mathrm{O}\right)_{2}\left[\left(\mathrm{~W}_{6} \mathrm{Cl}_{8}\right) \mathrm{Cl}_{6}\right] \cdot 6 \mathrm{H}_{2} \mathrm{O}$ & 87.1 & 99.8 & 0.0 & 0.0 & 0.2 \\
\hline \multirow[t]{2}{*}{ 2-Butanol } & {$\left[\left(\mathrm{Nb}_{6} \mathrm{Cl}_{12}\right) \mathrm{Cl}_{2}\left(\mathrm{H}_{2} \mathrm{O}\right)_{4}\right] \cdot 4 \mathrm{H}_{2} \mathrm{O}^{\mathrm{e}}$} & 73.6 & 25.5 & 40.2 & 34.2 & 0.1 \\
\hline & $\left(\mathrm{H}_{3} \mathrm{O}\right)_{2}\left[\left(\mathrm{~W}_{6} \mathrm{Cl}_{8}\right) \mathrm{Cl}_{6}\right] \cdot 6 \mathrm{H}_{2} \mathrm{O}$ & 29.5 & 24.8 & 42.9 & 31.9 & 0.4 \\
\hline
\end{tabular}

${ }^{\text {a }}$ After activation of cluster $(30 \mathrm{mg})$ in a helium stream $(1.2 \mathrm{~L} / \mathrm{h})$ at $300{ }^{\circ} \mathrm{C}$ for $1 \mathrm{~h}$, reaction was started by introduction of alcohol $(4.2 \mathrm{mmol} / \mathrm{h})$ to the stream without changing the temperature;

${ }^{\mathrm{b}}$ Conversion $=$ products $/($ products + recovered alcohol $) \times 100(\%)$ at $5 \mathrm{~h}$ after the start of the reaction;

${ }^{\mathrm{c}}$ Scelectivity $=$ product $/$ combined products $\times 100(\%)$ at $5 \mathrm{~h}$ after the start of the reaction; ${ }^{\mathrm{d}}$ Ether and acetal were not formed; ${ }^{\mathrm{e}}$ Catalyst $=10 \mathrm{mg}$.

As Figure 14 shows, 1,1-diethoxyethane was produced with a selectivity of $12 \%$. Direct formation of 1,1-diethoxyethane from ethanol alone over some catalysts has been reported, in which a dehydrogenating agent, such as dioxygen, hydrogen peroxide, or $t$-butyl hydroperoxide, was used to produce acetaldehyde as an intermediate. Nevertheless, there have been no reports on the formation of 1,1-diethoxyethane from ethanol alone without using such oxidizing agents. The selectivity for 1,1-diethoxyethane increased to $19 \%-25 \%$ when the niobium or tungsten clusters were used in flowing hydrogen gas. A notable feature of halide clusters is that the clusters catalyze the hydrogenation and dehydrogenation of olefins, as the platinum metals do (Section 2), and accordingly, the dehydrogenation to acetaldehyde was enhanced by the activation of the clusters under hydrogen. Condensation of 
acetaldehyde with ethanol is catalyzed by acid catalysts. Thus, the halide clusters exhibited a unique bifunctional catalyst functionality: dehydrogenation and acid catalysis.

\section{Alkylation}

\subsection{Methylation of Toluene (Equation (6)) [77]}

Alkylation of the aromatic ring has been widely studied using ether, olefin, halogenated hydrocarbon, or alcohol as an alkylating reagent, and inter alia methylation of toluene with methanol has been studied extensively owing to the commercial demand for $p$-xylene. Friedel-Crafts catalysts such as $\mathrm{AlCl}_{3}$ [78] and $\mathrm{BF}_{3}$ [79] are employed for the reaction using alcohol, however they serve as stoichiometric reagents. Solid acids such as $\mathrm{Al}_{13}$-pillared montmorillonite [80], $\mathrm{AlPO}_{4}-\mathrm{Al}_{2} \mathrm{O}_{3}$, [81,82], $\mathrm{TiO}_{4} /$ and $\mathrm{MoO}_{3} /$ silica-alumina [83], and Nafion-H [84] have been utilized for the reaction as catalysts. Detailed research has been focused particularly on zeolite catalysts such as ZSM-5 and mordenite with micro-pore structures $[85,86]$. For toluene methylation with methanol over zeolite, the commonly accepted reaction scheme suggests that an activated form of methanol, the methyl cation, reacts with weakly adsorbed toluene $[87,88]$. In the cluster catalysis, this intermediate was expected by replacing the silica-alumina catalyst with the cluster moiety. The fundamental reactivity of methylbenzenes over cluster with or without methanol was studied.

In order to enhance catalyst efficiency, halide clusters were supported on silica gel (Aerosil, $380 \mathrm{~m}^{2} / \mathrm{g}$ ) in $5.0 \mathrm{wt}-\%$ followed by screening to 150-200 mesh. The supported clusters of tungsten, $\left(\mathrm{H}_{3} \mathrm{O}\right)_{2}\left[\left(\mathrm{~W}_{6} \mathrm{Cl}_{8}\right) \mathrm{Cl}_{6}\right] \cdot 6 \mathrm{H}_{2} \mathrm{O} / \mathrm{SiO}_{2}$, were initially activated in a hydrogen stream for $1 \mathrm{~h}$ at an elevated temperature, and then reaction was commenced by introducing a mixture of toluene and methanol into the gas flow without changing the temperature. The reaction profiles at various temperatures are plotted in Figure 15. Activation above $300{ }^{\circ} \mathrm{C}$ resulted in substantial catalytic activity and the activity increased with increasing temperature, reaching a maximum at $450{ }^{\circ} \mathrm{C}$. Above $475{ }^{\circ} \mathrm{C}$, the decomposition of methanol was too high, and accordingly it was not utilized effectively for the methylation. At $450{ }^{\circ} \mathrm{C}$ the cluster catalyzed methylation of toluene to yield xylenes in higher than $80 \%$ selectivity, and successively, trimethylbenzenes with $13 \%$ selectivity, as listed in Table 6 . On the other hand, the selectivity for side chain alkylation to produce ethylbenzene was as low as $0.8 \%$. Demethylation proceeded to a small extent, producing benzene in $3 \%$ selectivity.

Table 6 summarizes the catalytic activity of various clusters of Group 5-7 metals and related compounds. This table shows that the chloride clusters of niobium, molybdenum, and tantalum also catalyzed the reaction. Unsupported crushed crystals of tungsten cluster also catalyzed the reaction regardless of the low activity. The rhenium chloride cluster catalyzed methylation and demethylation under helium; however, the metallic rhenium that resulted from the rhenium chloride cluster by hydrogen reduction under the reaction conditions [1] had no catalytic activity. 
Table 6. Methylation of toluene with methanol over halide clusters ${ }^{\text {a }}$.

\begin{tabular}{|c|c|c|c|c|c|c|c|c|c|}
\hline \multirow[b]{2}{*}{ Catalyst } & \multirow[b]{2}{*}{ Conversion $(\%)$} & \multicolumn{8}{|c|}{ Selectivity (\%) } \\
\hline & & Benzene & $o$-Xylene & $m$-Xylene & p-Xylene & $1,2,3-\mathrm{Me}_{3} \mathrm{C}_{6} \mathrm{H}_{3}$ & $1,2,4-\mathrm{Me}_{3} \mathrm{C}_{6} \mathrm{H}_{3}$ & $1,3,5-\mathrm{Me}_{3} \mathrm{C}_{6} \mathrm{H}_{3}$ & Ethylbenzene \\
\hline$\left[\left(\mathrm{Nb}_{6} \mathrm{Cl}_{12}\right) \mathrm{Cl}_{2}\left(\mathrm{H}_{2} \mathrm{O}\right)_{4}\right] \cdot 4 \mathrm{H}_{2} \mathrm{O} / \mathrm{SiO}_{2}$ & 3.0 & 3.9 & 45.7 & 20.5 & 23.7 & 1.9 & 2.7 & 0.0 & 1.7 \\
\hline$\left(\mathrm{H}_{3} \mathrm{O}\right)_{2}\left[\left(\mathrm{Mo}_{6} \mathrm{Cl}_{8}\right) \mathrm{Cl}_{6}\right] \cdot 6 \mathrm{H}_{2} \mathrm{O} / \mathrm{SiO}_{2}$ & 1.8 & 33.8 & 16.7 & 19.1 & 17.4 & 0.0 & 0.0 & 0.0 & 12.9 \\
\hline$\left[\left(\mathrm{Ta}_{6} \mathrm{Cl}_{12}\right) \mathrm{Cl}_{2}\left(\mathrm{H}_{2} \mathrm{O}\right)_{4}\right] \cdot 4 \mathrm{H}_{2} \mathrm{O} / \mathrm{SiO}_{2}$ & 2.2 & 2.8 & 44.5 & 20.5 & 26.5 & 1.3 & 2.4 & 0.0 & 2.1 \\
\hline$\left(\mathrm{H}_{3} \mathrm{O}\right)_{2}\left[\left(\mathrm{~W}_{6} \mathrm{Cl}_{8}\right) \mathrm{Cl}_{6}\right] \cdot 6 \mathrm{H}_{2} \mathrm{O} / \mathrm{SiO}_{2}$ & 10.5 & 3.2 & 37.7 & 21.4 & 24.2 & 5.0 & 7.3 & 0.4 & 0.8 \\
\hline$\left(\mathrm{H}_{3} \mathrm{O}\right)_{2}\left[\left(\mathrm{~W}_{6} \mathrm{Cl}_{8}\right) \mathrm{Cl}_{6}\right] \cdot 6 \mathrm{H}_{2} \mathrm{O}^{\mathrm{b}}$ & 1.0 & 50.9 & 14.9 & 13.4 & 10.6 & 3.6 & 1.4 & 2.1 & 3.2 \\
\hline$\left(\mathrm{H}_{3} \mathrm{O}\right)_{2}\left[\left(\mathrm{~W}_{6} \mathrm{Cl}_{8}\right) \mathrm{Cl}_{6}\right] \cdot 6 \mathrm{H}_{2} \mathrm{O} / \mathrm{SiO}_{2}{ }^{\mathrm{c}}$ & 4.2 & 6.9 & 41.1 & 21.0 & 23.5 & 2.3 & 3.6 & 0.0 & 1.6 \\
\hline$\left(\mathrm{H}_{3} \mathrm{O}\right)_{2}\left[\left(\mathrm{~W}_{6} \mathrm{Cl}_{8}\right) \mathrm{Cl}_{6}\right] \cdot 6 \mathrm{H}_{2} \mathrm{O} / \mathrm{SiO}_{2}{ }^{\mathrm{d}}$ & 7.2 & 0.0 & 43.5 & 20.9 & 24.2 & 3.9 & 6.5 & 0.0 & 1.0 \\
\hline $\mathrm{Re}_{3} \mathrm{Cl}_{9} / \mathrm{SiO}_{2}$ & 0.0 & & & & & & & & \\
\hline $\mathrm{Re}_{3} \mathrm{Cl}_{9} / \mathrm{SiO}_{2}{ }^{\mathrm{c}}$ & 1.7 & 79.5 & 2.2 & 6.0 & 4.0 & 0.0 & 0.0 & 0.0 & 8.3 \\
\hline $\mathrm{SiO}_{2}$ & 0.0 & & & & & & & & \\
\hline
\end{tabular}

${ }^{\mathrm{a}}$. After activation of supported cluster ( $5 \mathrm{wt} \%$ on silica gel, $\left.200 \mathrm{mg}\right)$ in a hydrogen stream $(120 \mathrm{~mL} / \mathrm{h})$ at $450{ }^{\circ} \mathrm{C}$ for $1 \mathrm{~h}$, reaction was started by introduction of toluene $(10.6 \mathrm{~mL} / \mathrm{h}, 0.1 \mathrm{mmol} / \mathrm{h})$ and methanol $(27.5 \mathrm{~mL} / \mathrm{h}, 0.68 \mathrm{mmol} / \mathrm{h})$ to the stream, without changing the temperature. At $4 \mathrm{~h}$ after the start of reaction; ${ }^{\mathrm{b}}$ Unsupported crushed crystalline cluster (150-200 mesh, $200 \mathrm{mg}) ;{ }^{\mathrm{c}}$ Under helium; ${ }^{\mathrm{d}}$ Under nitrogen. 
Figure 15. Effect of temperature on the reaction of toluene with methanol over $\left(\mathrm{H}_{3} \mathrm{O}\right)_{2}\left[\left(\mathrm{~W}_{6} \mathrm{Cl}_{8}\right) \mathrm{Cl}_{6}\right] \cdot 6 \mathrm{H}_{2} \mathrm{O} / \mathrm{SiO}_{2}$. Following the activation of the supported cluster $(200 \mathrm{mg}$, $5.7 \mu \mathrm{mol})$ in a hydrogen stream $(120 \mathrm{~mL} / \mathrm{h})$ for $1 \mathrm{~h}$, reaction was initiated by introduction of toluene $(10.6 \mathrm{~mL} / \mathrm{h}, 0.1 \mathrm{mmol} / \mathrm{h})$ and methanol $(27.5 \mathrm{~mL} / \mathrm{h}, 0.68 \mathrm{mmol} / \mathrm{h})$ to the stream without changing the temperature. Conversion $=$ products $($ products + recovered toluene $) \times$ $100(\%)$, selectivity $=$ product/total amount of products $\times 100(\%)$ based on aromatic compounds at $4 \mathrm{~h}$ after the start of the reaction.

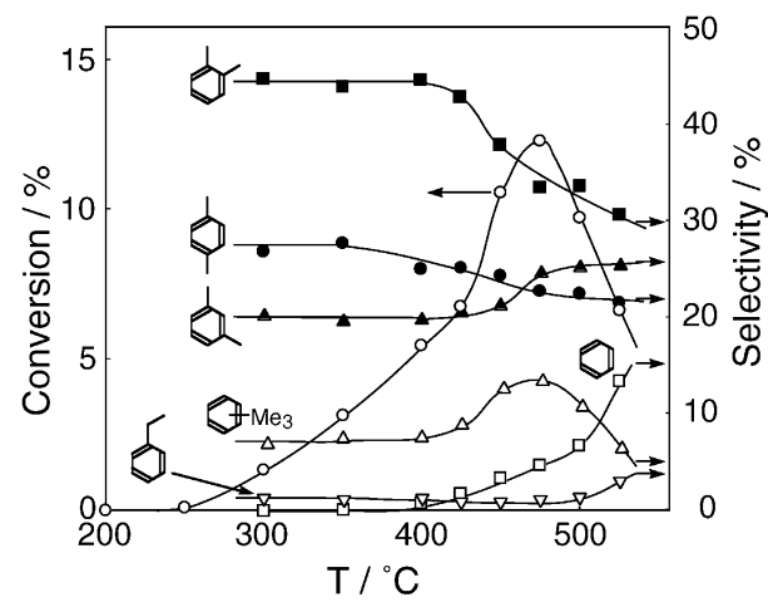

It is generally accepted that the alkylation of toluene with methanol proceeds via electrophilic substitution [85], and that a Brønsted acid site on zeolite catalysts is the active center and is covered with methanol [89]. The strongly adsorbed methanol [90] is activated to a carbenium ion, which reacts with weakly adsorbed toluene [91]. In contrast, side chain alkylation to yield ethylbenzene is generally accepted over base catalysts such as basic Y-zeolite [92], potassium-cation-exchanged zeolite [93], Cs-exchanged zeolite, alkali-impregnated carbon [94], and magnesia [95]. Thus, clusters exhibited acidic character in the catalysis.

Methylations of methyl-substituted benzenes were tested over $\left(\mathrm{H}_{3} \mathrm{O}\right)_{2}\left[\left(\mathrm{~W}_{6} \mathrm{Cl}_{8}\right) \mathrm{Cl}_{6}\right] \cdot 6 \mathrm{H}_{2} \mathrm{O} / \mathrm{SiO}_{2}$. Unsubstituted benzene did not react under the conditions; however, methylation of methylbenzenes other than hexamethylbenzene proceeded. The increasing reactivity order of toluene, xylenes and trimethylbenzenes accords with the increasing proton affinity order of polymethyl-substituted benzenes [96]. The same reactivity order is reported on Nafion-H catalyst [84]. In methylation of xylenes over the tungsten cluster, trimethylbenzenes were obtained with 58\%-63\% selectivity with isomerization and demethylation products in 10\%-20\% and 4\%-9\% selectivity, respectively. Methylation of pentamethylbenzene was difficult and demethylation proceeded almost exclusively, even in the presence of methanol. Demethylation of hexamethylbenzene also proceeded under hydrogen, both in the presence and absence of methanol. The same catalytic activities, methylation and demethylation, have been reported on an acidic large-pore zeolite. H-Beta catalyzed methylation of toluene with methanol [97,98] and demethylation of hexamethylbenzene under nitrogen [99] or polymethylbenzenes under helium [100]. Reaction of hexamethylbenzene with benzene over the tungsten cluster in the absence of methanol yielded toluene with $9 \%$ selectivity; indicating intermolecular transfer of the methyl substituents. Superimposition of these reactions complicated the methylation. 


\subsection{N-Alkylation of Amine (Equation (7)) [101]}

$N$-Methylation of Amine: Alkylation of ammonia and amines has been studied for the production of a variety of amines. The methylation of amines has been extensively studied using various methylating reagents: methyl carbonates, formaldehyde, diazomethane, dimethyl ether, carbon monoxide/hydrogen, or methanol. In particular, methanol has been widely used because of its ready availability and ease of handling. Conventional liquid acids such as sulfuric, hydrochloric, hydrobromic, and hydroiodic acids have been reported to catalyze the methylation of amines [102]. On the other hand, solid acids such as alumina [103-106], silica-alumina [107], faujasite [108], beta zeolite, EMT zeolites [109], $\mathrm{AlPO}_{4}-5$ [110,111], and niobic acid [112] have been used as catalysts in the gas-phase flow system, which requires no solvent, circumvents tedious separation procedures, and recycles the catalyst. These catalysts are chiefly used for the alkylation of aniline, because this reaction proceeds smoothly. There are fewer examples of the alkylation of aliphatic amines with alcohols [106]; Y zeolite, beta zeolite, [113], and alumina [114] have been used in the gas-flow system. Over halide cluster catalysts, methyl cation was produced from methanol as an intermediate for the methylation of toluene, as described above. Then attempts were made for the methylation of amines with alcohols over halide cluster catalysts.

Supported clusters $\left(\mathrm{H}_{3} \mathrm{O}\right)_{2}\left[\left(\mathrm{~W}_{6} \mathrm{Cl}_{8}\right) \mathrm{Cl}_{6}\right] \cdot 6 \mathrm{H}_{2} \mathrm{O} / \mathrm{SiO}_{2}$ were activated in a hydrogen stream for $1 \mathrm{~h}$. The reaction was commenced immediately by introduction of an equimolar mixture of piperidine and methanol into the hydrogen stream without changing the temperature. Figure 16 shows the effect of the reaction temperature. Practically catalytic activity developed above $200{ }^{\circ} \mathrm{C}$. The activity was enhanced with increasing temperature. Over the temperature range $250-350{ }^{\circ} \mathrm{C}$, the cluster catalyzed the methylation of piperidine to yield $N$-methylpiperidine in more than $89 \%$ selectivity. A significant side reaction was dehydrogenation, yielding 2,3,4,5-tetrahydropyridine with a selectivity as low as $4.6 \%$. Above $400{ }^{\circ} \mathrm{C}$, selectivity for dehydrogenation to yield 2,3,4,5-tetrahydropyridine and pyridine was conspicuous and increased with increasing temperature. Above $450{ }^{\circ} \mathrm{C}$, the decomposition of methanol was too high to utilize effectively for the methylation. Thus, the selectivity strongly depends on the reaction temperature.

Various clusters of Group 5-7 metals and related compounds were tested for this reaction at $300{ }^{\circ} \mathrm{C}$. Supported chloride clusters of niobium, molybdenum, and tantalum also catalyzed the reaction in $4 \%-15 \%$ conversion. The selectivities over these cluster catalysts were similar: $N$-methylpiperidine was the main product in above $95 \%$ selectivity with 2,3,4,5-tetrahydropyridine resulting from dehydrogenation in $4 \%$ selectivity. Unsupported crushed crystals of $\left(\mathrm{H}_{3} \mathrm{O}\right)_{2}\left[\left(\mathrm{~W}_{6} \mathrm{Cl}_{8}\right) \mathrm{Cl}_{6}\right] \cdot 6 \mathrm{H}_{2} \mathrm{O}$ (150-200 mesh) exhibited a slight lower selectivity ( $86 \%$ selectivity for $N$-methylpiperidine), although the reactivity was low $(2.4 \%$ conversion) because of its low surface area. Thus, Group 5 and 6 metal halide clusters exhibited good catalytic properties for the $N$-methylation of piperidine with methanol. Over rhenium chloride cluster the selectivity for $N$-methylpiperidine was low (19\% selectivity). 
Figure 16. Effect of temperature on the reaction of piperidine with methanol over $\left(\mathrm{H}_{3} \mathrm{O}\right)_{2}\left[\left(\mathrm{~W}_{6} \mathrm{Cl}_{8}\right) \mathrm{Cl}_{6}\right] \cdot 6 \mathrm{H}_{2} \mathrm{O} / \mathrm{SiO}_{2}$. Following the activation of the supported cluster $(30 \mathrm{mg}$, $0.86 \mu \mathrm{mol})$ in a hydrogen stream $(600 \mathrm{~mL} / \mathrm{h})$ for $1 \mathrm{~h}$, reaction was initiated by introduction of piperidine $(99 \mu \mathrm{L} / \mathrm{h}, 1.0 \mathrm{mmol} / \mathrm{h})$ and methanol $(41 \mu \mathrm{L} / \mathrm{h}, 1.0 \mathrm{mmol} / \mathrm{h})$ to the stream without changing the temperature. Conversion and selectivities are based on piperidine at $3 \mathrm{~h}$ after the start of the reaction. Conversion of piperidine $(\bullet)$; selectivity for $N$-methylpiperidine (O); selectivity for 2,3,4,5-tetrahydropyridine $(\Delta)$; selectivity for pyridine $(\nabla)$; and selectivity for the other nitrogen containing products $(\square)$.

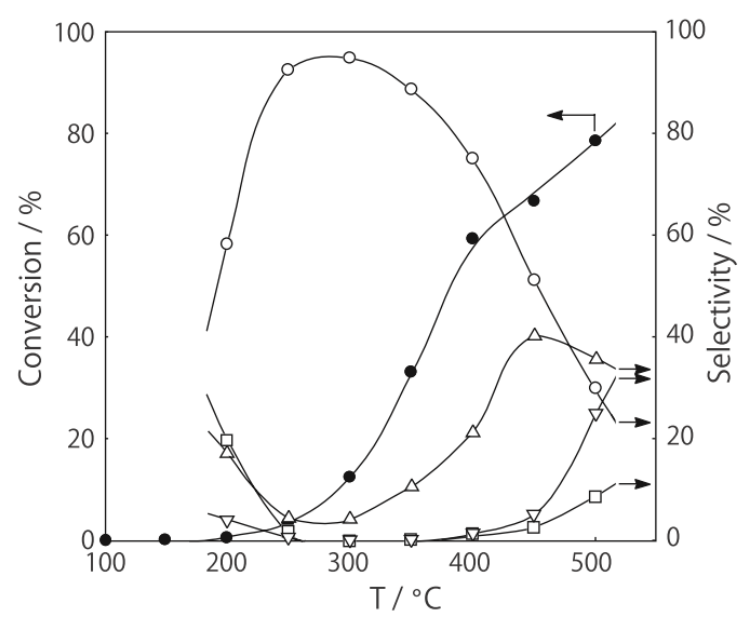

Silica-alumina and H-beta exhibited high activities (19 and 29\% conversion, respectively) and high selectivities for $\mathrm{N}$-methylation (95\%, each), comparable to those over a halide cluster, which accords with the reported results $[107,113]$. On the other hand, H-mordenite and H-ZSM-5 exhibited quite low activities (4 and 1.6\% conversion, respectively) and low selectivities (46 and 35\%, respectively) for this reaction. The catalytic activities of the latter zeolites have not been reported for this reaction. Reports on the application of solid acids to this reaction are few [106].

$N$-Alkylation of Amine: Over $\left(\mathrm{H}_{3} \mathrm{O}\right)_{2}\left[\left(\mathrm{~W}_{6} \mathrm{Cl}_{8}\right) \mathrm{Cl}_{6}\right] \cdot 6 \mathrm{H}_{2} \mathrm{O} / \mathrm{SiO}_{2}$, selective $N$-alkylation of piperidine with primary alcohols (methanol, ethanol, and propanol) proceeded; the longer the alkyl chain, the lower the reactivity. However, alkylation with secondary and tertiary alcohols (2-propanol and 2-methyl-2-propanol) did not proceed. Although many examples of the alkylation with primary alcohols have been reported, examples of the alkylation with secondary alcohols are sparse owing to steric effects: 2-propanol over alumina [106] and 2-butanol over ruthenium trichloride [115] give rise to poor conversions compared with the primary alcohols. In the latter case, dehydrogenation of alcohol followed by attack of amine is suggested. Alkylation with tertiary alcohol has not been reported, as far as we know.

Five- to seven-membered alicyclic amines (pyrrolidine, piperidine, and azepane) were exclusively $N$-methylated with methanol. They exhibited equal reactivity. Butylamine, a primary amine, was $N$-methylated with higher reactivity. Diethylamine was also $N$-methylated. Consequently, a halide cluster is an effective catalyst for the $N$-alkylation of aliphatic amines. $N$-Methylation of an aromatic amine, aniline, with methanol proceeded over tungsten cluster. Although $N$-methylation is not selective, producing both $\mathrm{N}$-methyl- and $\mathrm{N}, \mathrm{N}$-dimethylanilines, $\mathrm{C}$-methylation of the aromatic ring did not proceed at all. Oxide catalysts such as $\mathrm{V}_{2} \mathrm{O}_{5}, \mathrm{Cr}_{2} \mathrm{O}_{3}$ [116], and $\mathrm{Fe}_{2} \mathrm{O}_{3}$ [117] have been reported 
to afford $C$-methylation products, 2-methyl- and 2,6-dimethylanilines, exclusively in the methylation of aniline with methanol. Zeolites $\mathrm{X}$ and $\mathrm{Y}$ exchanged with $\mathrm{Li}$ and $\mathrm{Na}$ cations give rise to $C$-methylation products in this reaction [108]. ZSM-5 catalyzes both $C$ - and $N$-methylation of aniline [118]. Thus, a halide cluster proved to be a selective catalyst for the $N$-methylation of an aromatic amine with methanol.

\subsection{Alkylation of Pyridine (Equation (8)) [119]}

To utilize the methyl cation intermediate over halide cluster catalysts and, furthermore, to expand the scope for the application of halide cluster catalysis, alkylations of other compounds with alcohols were attempted. Methylation of pyridine has been extensively studied, and conventional liquid acids such as hydrochloric acid [120], metal exchanged zeolites [121], and metallic nickel [122] are reported to catalyze the reaction. Methanol is predominantly used in these methylations, and in many cases, the formation of a methyl cation is suggested as an intermediate in the presence of acid catalysts.

After $\left(\mathrm{H}_{3} \mathrm{O}\right)_{2}\left[\left(\mathrm{~W}_{6} \mathrm{Cl}_{8}\right) \mathrm{Cl}_{6}\right] \cdot 6 \mathrm{H}_{2} \mathrm{O} / \mathrm{SiO}_{2}$ was activated under hydrogen stream at an elevated temperature for $1 \mathrm{~h}$, a mixture of pyridine and methanol was introduced to the stream without changing the temperature. The effect of the reaction temperature is presented in Figure 17. Catalytic activity developed above $200{ }^{\circ} \mathrm{C}$ and increased with increasing temperature, having a local maximum at $400{ }^{\circ} \mathrm{C}$. At $400{ }^{\circ} \mathrm{C}$, the cluster catalyzed $\alpha$-methylation of pyridine to yield 2-methylpyridine with $61 \%$ selectivity. A significant side reaction was methylation yielding 3- and 4-methylpyridines with 9 and $21 \%$ selectivity, respectively. Total selectivity for monomethylpyridines was $92 \%$. Above $450{ }^{\circ} \mathrm{C}$ the decomposition of methanol was too high. Similar temperature effect has been reported for this reaction: the maximum activity was attained at $400{ }^{\circ} \mathrm{C}$ over $\mathrm{H}-\mathrm{X}$ and $\mathrm{H}-\mathrm{Y}$ zeolites [121], and at $400-440{ }^{\circ} \mathrm{C}$ over $\mathrm{H}-\mathrm{Y}$ and $\mathrm{H}-\mathrm{ZSM}-5$ zeolites [123]. As basic pyridine would be strongly adsorbed on the acid site of the catalyst, considerably higher temperatures were required for the reaction over acidic catalysts.

Over the low temperature range $200-300{ }^{\circ} \mathrm{C}$, selectivities for 3- and 4-methylpyridines were high (totally $81 \%-68 \%$ ), whereas the main product was 2 -methylpyridine above $350{ }^{\circ} \mathrm{C}$. The equilibrium distribution for methylpyridine isomers has been reported at $400{ }^{\circ} \mathrm{C}: 71 \%$ 2-methylpyridine, $16 \%$ 3-methylpyridine, and 13\% 4-methylpyridine. This distribution roughly accords with the selectivity for methylpyridines as shown in Figure 17.

Various clusters of Group 5-7 metals were used as catalysts at $400{ }^{\circ} \mathrm{C}$. Unsupported $\left(\mathrm{H}_{3} \mathrm{O}\right)_{2}\left[\left(\mathrm{~W}_{6} \mathrm{Cl}_{8}\right) \mathrm{Cl}_{6}\right] \cdot 6 \mathrm{H}_{2} \mathrm{O}$ exhibited a similar product selectivity (82\% for combined methylpyridines) to that of $\left(\mathrm{H}_{3} \mathrm{O}\right)_{2}\left[\left(\mathrm{~W}_{6} \mathrm{Cl}_{8}\right) \mathrm{Cl}_{6}\right] \cdot 6 \mathrm{H}_{2} \mathrm{O} / \mathrm{SiO}_{2}$, and the lower activity of the unsupported cluster $(8.1 \%$ conversion with $200 \mathrm{mg}$ of crushed crystals of the cluster) is attributable to its low surface area. The supported clusters of niobium, molybdenum, and tantalum with an octahedrally arranged $\mathrm{M}_{6}$ metal core also catalyzed the methylation, and the combined selectivities for methylpyridines were $78 \%-92 \%$. 
Figure 17. Effect of temperature on the reaction of pyridine with methanol over $\left(\mathrm{H}_{3} \mathrm{O}\right)_{2}\left[\left(\mathrm{~W}_{6} \mathrm{Cl}_{8}\right) \mathrm{Cl}_{6}\right] \cdot 6 \mathrm{H}_{2} \mathrm{O} / \mathrm{SiO}_{2}$. Following the activation of the supported cluster $(200 \mathrm{mg}$, $5.7 \mu \mathrm{mol})$ in a hydrogen stream $(300 \mathrm{~mL} / \mathrm{h})$ for $1 \mathrm{~h}$, reaction was initiated by introduction of pyridine $(20 \mu \mathrm{L} / \mathrm{h}, 0.25 \mathrm{mmol} / \mathrm{h})$ and methanol $(203 \mu \mathrm{L} / \mathrm{h}, 5.0 \mathrm{mmol} / \mathrm{h})$ to the stream without changing the temperature. Conversion and selectivities are based on pyridine at $3 \mathrm{~h}$ after the start of the reaction. Conversion of pyridine $(\bullet)$; selectivity for 2-methylpyridine $(\circ)$; selectivity for 3-methylpyridine (ם); selectivity for 4-methylpyridine ( $\square$ ); selectivity for dimethylpyridines $(\Delta)$; and selectivity for ethylpyridines $(\boldsymbol{\Delta})$.

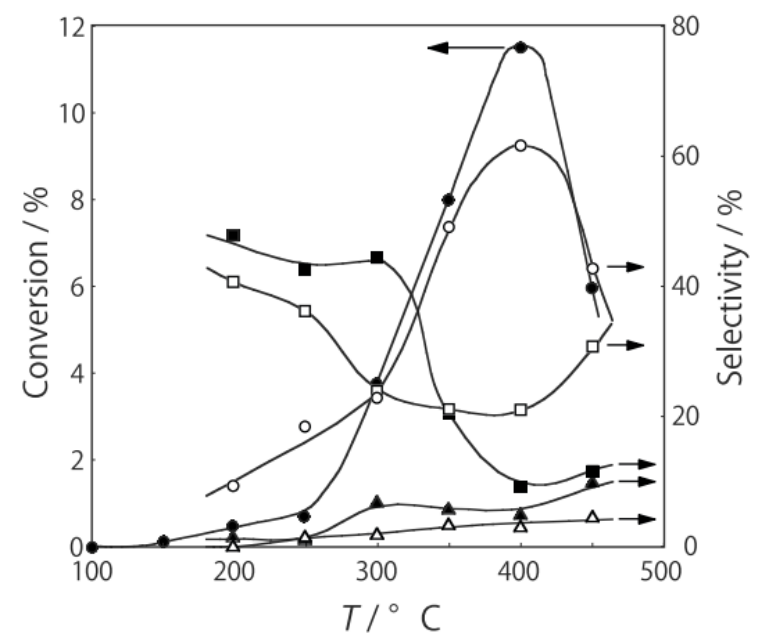

In the same reactions at $400{ }^{\circ} \mathrm{C}$, the main product has been reported to be 3-methylpyridine over $\mathrm{H}-\mathrm{Y}$ and $\mathrm{H}-\mathrm{X}$ [121], and 2-methylpyridine over $\mathrm{H}-\mathrm{Y}$ and 3-methylpyridine over $\mathrm{H}-\mathrm{Y}, \mathrm{H}-\mathrm{X}$ and $\mathrm{H}-\mathrm{ZSM}-5$ [123]. In these reactions combined selectivities for methylpyridines were $63 \%-100 \%$. Over these Brønsted acids, the main reaction was methylation of the pyridine ring, but the selectivity differed. Consequently, proton determined the reaction pathway, and the conjugate bases played an important role for the determination of the selectivity. Basic supports such as $\mathrm{MgO}$ and $\mathrm{ZnO}$ were used as the support of $\left(\mathrm{H}_{3} \mathrm{O}\right)_{2}\left[\left(\mathrm{~W}_{6} \mathrm{Cl}_{8}\right) \mathrm{Cl}_{6}\right] \cdot 6 \mathrm{H}_{2} \mathrm{O}$, but the reactivity for the methylation significantly decreased (3.4 and 1.9\% conversion, respectively). The Brønsted acid site developed on the cluster can react with the basic supports. Ethanol was an effective reagent for the alkylation of pyridine affording ethylpyridines with $98 \%$ selectivity, but the other alcohols tested did not afford the alkylation products.

\subsection{Alkylation of Phenol (Equation (9)) [119]}

Methylation of phenols has been widely investigated, and Brønsted acids such as Nafion-H [124], metal oxides such as $\mathrm{CeO}_{2}-\mathrm{MgO}$ [125], and $\mathrm{KF}$-zeolite [126] are reported to catalyze the reaction. Methanol is predominantly used in these methylations, and in many cases, the formation of a methyl cation is suggested as an intermediate in the presence of acid catalysts.

The methylation of phenol with methanol was examined over $\left(\mathrm{H}_{3} \mathrm{O}\right)_{2}\left[\left(\mathrm{Mo}_{6} \mathrm{Cl}_{8}\right) \mathrm{Cl}_{6}\right] \cdot 6 \mathrm{H}_{2} \mathrm{O} / \mathrm{SiO}_{2}$. Figure 18 presents the effect of temperature. Catalytic activity developed above $150{ }^{\circ} \mathrm{C}$ and increased with increasing temperature with a local maximum at $300{ }^{\circ} \mathrm{C}$. The supported cluster catalyzed $C$-methylation of phenol to yield $o$-cresol with $67 \%$ selectivity. Side reactions were methylation 
yielding $m$ - and $p$-cresols, anisole, dimethylphenols, and ethylphenols, with 5, 7, 8, and 4\% selectivity, respectively. Total selectivity for cresols was $73 \%$. Similar temperature effect has been reported for this reaction: maximum activities were observed at $300{ }^{\circ} \mathrm{C}$ over $\mathrm{Al}_{2} \mathrm{O}_{3}$ [127] and at 280-330 ${ }^{\circ} \mathrm{C}$ over $\mathrm{Al}_{2} \mathrm{O}_{3}$ [128]. At temperatures to $200{ }^{\circ} \mathrm{C}$, the main reaction is $O$-methylation yielding anisole. Similar results of $O$-methylation at relatively low temperatures have been reported for many acid and base catalysts: $\mathrm{H}-\mathrm{Y}$ zeolite [129], ZSM-5 [130], $\mathrm{Al}_{2} \mathrm{O}_{3}, \mathrm{SiO}_{2}-\mathrm{Al}_{2} \mathrm{O}_{3}$ [127], $\mathrm{AlPO}_{4}, \mathrm{AlPO}_{4}-\mathrm{TiO}_{2}$ [131], basic X zeolites [132], Nafion-H [124], phosphoric acid/Kieselguhr [127], and tungstophosphoric $\mathrm{acid} / \mathrm{SiO}_{2}$ [133], the last three of which are typical Brønsted acids without a Lewis acid site. When anisole was allowed to react alone at $300{ }^{\circ} \mathrm{C}$, the conversion was $13 \%$, and phenol was obtained with $48 \%$ selectivity with $o$-, $m$ - and $p$-cresols with $18 \%$ selectivity, indicating that $O$-methylation is reversible. Cresols are formed by direct $C$-alkylation of phenol or by conversion of anisole intermediate on acid catalysts [134]. The same elimination and migration of the methyl group has been reported over $\mathrm{AlPO}_{4}-\mathrm{Al}_{2} \mathrm{O}_{3}$ at $250-400{ }^{\circ} \mathrm{C}$ [135] and $\mathrm{Al}_{2} \mathrm{O}_{3}$ at 200-300 ${ }^{\circ} \mathrm{C}$ [127]. Anisole is thermodynamically far less stable than $o$-cresol below $500{ }^{\circ} \mathrm{C}$.

Figure 18. Effect of temperature on the methylation of phenol with methanol over $\left(\mathrm{H}_{3} \mathrm{O}\right)_{2}\left[\left(\mathrm{Mo}_{6} \mathrm{Cl}_{8}\right) \mathrm{Cl}_{6}\right] \cdot 6 \mathrm{H}_{2} \mathrm{O} / \mathrm{SiO}_{2}$. Following the activation of the supported cluster $(200 \mathrm{mg}, 8.2 \mu \mathrm{mol})$ in a hydrogen stream $(300 \mathrm{~mL} / \mathrm{h})$ for $1 \mathrm{~h}$, reaction was initiated by introduction of phenol $(17.8 \mu \mathrm{L} / \mathrm{h}, 0.20 \mathrm{mmol} / \mathrm{h})$ and methanol $(82.2 \mu \mathrm{L} / \mathrm{h}, 2.0 \mathrm{mmol} / \mathrm{h})$ to the stream without changing the temperature. Conversion and selectivities are based on phenol. Conversion of phenol $(\bullet)$; selectivity for $o$-cresol $(\circ)$; selectivity for $m$ - and $p$-cresols $(\square)$; selectivity for anisole ( $\square)$; selectivity for dimethylphenols $(\Delta)$; and selectivity for ethylphenols $(\boldsymbol{\Delta})$; at $3 \mathrm{~h}$ after the start of the reaction. Decomposition products are omitted for clarity.

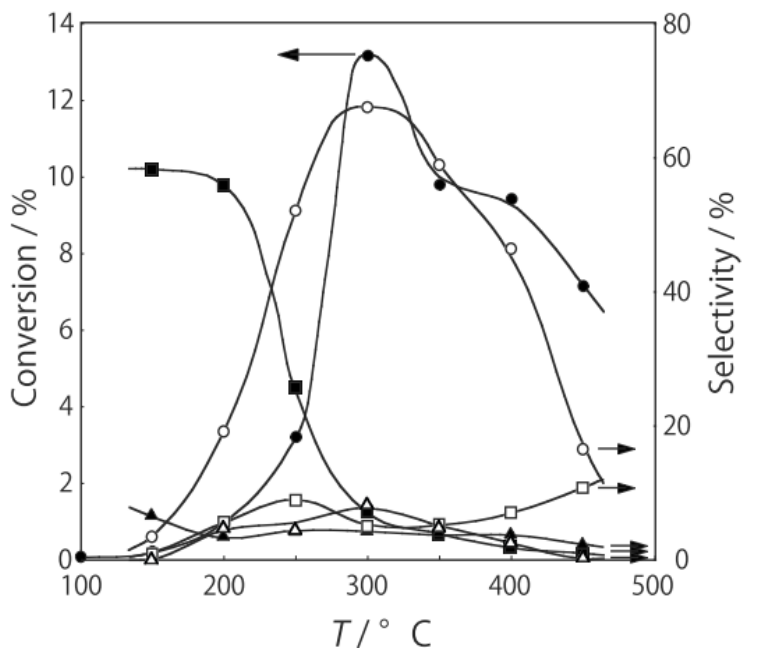

Niobium, tantalum, and tungsten chloride clusters also catalyzed the $C$-methylation of phenol predominantly (44\%-53\% selectivity). Selective $C$-alkylation of phenol with ethanol and 1-propanol proceeded (62 and 53\% selectivity, respectively). Although many examples of alkylation with methanol have been reported, examples of alkylation with other alcohols are sparse, probably because dehydration of the alcohol to olefin or ether proceeds faster over conventional strong solid acids. Thus, halide clusters exhibited $C$-methylation of phenol as Brønsted acid catalyst. 


\subsection{Alkylation of Benzenethiol (Equation (10)) [136]}

Alkyl phenyl sulfides are useful synthetic intermediates for medicines, pesticides and agricultural chemicals, and are used as solvents. Many synthetic methods have been reported. In the case of $S$-alkylation of benzenethiol, several alkylating reagents have been reported: alcohols, ethers, alkyl carbonates, alkyl halides, olefins and, in rare cases, alkyl carboxylates. Alumina, NaX zeolite and $\mathrm{NaY}$ zeolite were used with methanol at $270{ }^{\circ} \mathrm{C}$ [137]. Alumina, silica-alumina and activated charcoal have been reported for the alkylation with alcohols and ethers at 250-400 ${ }^{\circ} \mathrm{C}$ [138]. The phase-transfer catalyst, $\mathrm{K}_{2} \mathrm{CO}_{3}$ /poly(ethylene glycol), has been reported for the alkylation with dialkyl carbonates [139]. With alkyl halides, NaX zeolite was used at $220{ }^{\circ} \mathrm{C}$ [140], and hydrotalcite was used as a basic catalyst at $80{ }^{\circ} \mathrm{C}$ for the alkylation [141]. A zeolite of hydrogen-type faujasite catalyzed the $S$-alkylation with 1-decene at $182{ }^{\circ} \mathrm{C}$ [142]. Methyl esters are also used under continuous-flow conditions in the presence of base/phase-transfer catalysts such as $\mathrm{AcONa} / \mathrm{Bu}_{4} \mathrm{P}^{+} \mathrm{Br}^{-}$ and $\mathrm{K}_{2} \mathrm{CO}_{3}$ /poly(ethylene glycol) at $180{ }^{\circ} \mathrm{C}$ [143]. As has been shown above, halide clusters served as alkylation catalysts for some functional groups. Attempts to use halide cluster as the alkylation catalyst for benzenethiol proved that all of those alkylating reagents are applicable to the $S$-alkylation.

Alkylation with alcohol: After activation of supported niobium cluster, $\left[\left(\mathrm{Nb}_{6} \mathrm{Cl}_{12}\right) \mathrm{Cl}_{2}\left(\mathrm{H}_{2} \mathrm{O}\right)_{4}\right] \cdot 4 \mathrm{H}_{2} \mathrm{O} / \mathrm{SiO}_{2}$, at various temperatures in a stream of hydrogen for $1 \mathrm{~h}$, reaction was initiated by introduction of a mixture of benzenethiol and methanol into the hydrogen stream without changing the temperature. The effect of the reaction temperature is presented in Figure 19. Practically no catalytic activity for the methylation was observed below $200{ }^{\circ} \mathrm{C}$, although there was considerable coupling of benzenethiol by spontaneous reaction. Catalytic activity for the methylation developed above $250{ }^{\circ} \mathrm{C}$ and increased with increasing temperature, having a local maximum at $400{ }^{\circ} \mathrm{C}$. At $400{ }^{\circ} \mathrm{C}$, the cluster catalyzed $S$-methylation of benzenethiol to yield methyl phenyl sulfide almost exclusively. Side reactions were the coupling of benzenethiol yielding diphenyl sulfide and diphenyl disulfide with $0.2 \%$ and $1.8 \%$ selectivity, respectively. Above $450{ }^{\circ} \mathrm{C}$, the decomposition of methanol was too high, and hence it was not utilized effectively for the methylation. The turnover frequency per cluster during a period of $2-4 \mathrm{~h}$ at $400{ }^{\circ} \mathrm{C}$ was $95.6 \mathrm{~h}^{-1}$, assuming that all of the cluster molecules were active. The supported clusters of molybdenum, tantalum and tungsten also selectively catalyzed the methylation exclusively.

Alcohols with $\mathrm{C}_{1}-\mathrm{C}_{6}$ alkyls were applied to the reaction at $400{ }^{\circ} \mathrm{C}$. $S$-Alkylation of benzenethiol with primary alcohols proceeded; the longer the alkyl chain, the lower the reactivity and selectivity for the alkyl phenyl sulfide. Practically no branched alkyl sulfides were formed, when 1-propanol and higher primary alcohols were used. Alkyl cations seem not to be produced as intermediates. The reactivity of a secondary alcohol was low, and a tertiary alcohol did not react. Although several examples of alkylation with methanol have been reported, examples with longer chain alcohols [144] or secondary alcohols [145] are rare, probably because of steric effects. Acidic catalysts, namely activated alumina [144], silica-alumina and cation-exchanged sulfonic acid resin [145], were used for the reaction. Protonation of the hydroxy group of the alcohol would facilitate nucleophilic attack of benzenethiol to yield alkyl phenyl sulfide. 
Figure 19. Effect of temperature on the $S$-methylation of benzenethiol with methanol over $\left[\left(\mathrm{Nb}_{6} \mathrm{Cl}_{12}\right) \mathrm{Cl}_{2}\left(\mathrm{H}_{2} \mathrm{O}\right)_{4}\right] \cdot 4 \mathrm{H}_{2} \mathrm{O} / \mathrm{SiO}_{2}$. Following the activation of the supported cluster $(10 \mathrm{mg}$, $0.42 \mu \mathrm{mol})$ in a hydrogen stream $(300 \mathrm{~mL} / \mathrm{h})$ for $1 \mathrm{~h}$, reaction was initiated by introduction of benzenethiol $(22 \mu \mathrm{L} / \mathrm{h}, 0.20 \mathrm{mmol} / \mathrm{h})$ and methanol $(64 \mu \mathrm{L} / \mathrm{h}, 2.0 \mathrm{mmol} / \mathrm{h})$ to the stream without changing the temperature. Conversion and selectivities are based on benzenethiol. Conversion of benzenethiol $(\bullet)$; selectivity for methyl phenyl sulfide $(\circ)$; selectivity for diphenyl sulfide $(\Delta)$; and selectivity for diphenyl disulfide ( $\square$ ); at $3 \mathrm{~h}$ after the start of the reaction.

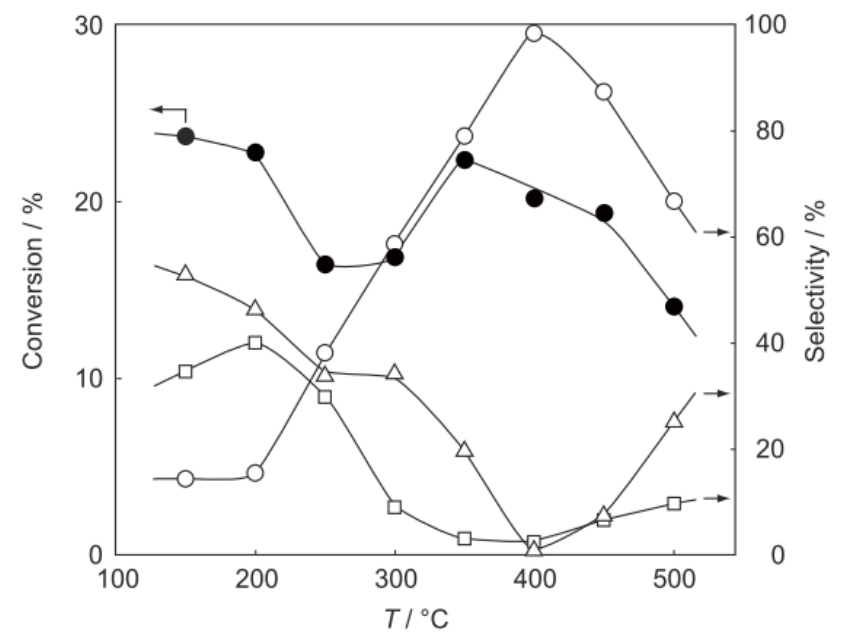

Alkylation with ether: Some ethers with $\mathrm{C}_{2}-\mathrm{C}_{4}$ alkyls were applied to the alkylation over $\left[\left(\mathrm{Nb}_{6} \mathrm{Cl}_{12}\right) \mathrm{Cl}_{2}\left(\mathrm{H}_{2} \mathrm{O}\right)_{4}\right] \cdot 4 \mathrm{H}_{2} \mathrm{O} / \mathrm{SiO}_{2}$ at $400{ }^{\circ} \mathrm{C}$; ethers acted as $S$-alkylating reagents for benzenethiol. Shorter alkyl chains exhibited higher selectivity for the alkyl phenyl sulfide. Unsymmetrical ether afforded two corresponding alkyl phenyl sulfides, preferentially yielding the shorter alkyl phenyl sulfide. The reactivities of the ethers were higher than the alcohols of the same alkyl groups. Activated alumina and silica-alumina have been reported to catalyze the $S$-alkylation with ethers as well as alcohols in the vapor phase at $200-450{ }^{\circ} \mathrm{C}$ [138].

Alkylation with carbonate and orthoester: Methyl and ethyl carbonates also provided the corresponding alkyl phenyl sulfides over $\left[\left(\mathrm{Nb}_{6} \mathrm{Cl}_{12}\right) \mathrm{Cl}_{2}\left(\mathrm{H}_{2} \mathrm{O}\right)_{4}\right] \cdot 4 \mathrm{H}_{2} \mathrm{O} / \mathrm{SiO}_{2}$ at $400{ }^{\circ} \mathrm{C}$. The reactivities of the carbonates were much higher than the reactivities of the alcohols or ethers bearing the same alkyl groups, and the selectivities for alkyl phenyl sulfide were high. In the case of the unsymmetrical carbonate, the two expected alkyl phenyl sulfides were obtained, with the shorter alkyl phenyl sulfide predominating. The phase-transfer catalyst, $\mathrm{K}_{2} \mathrm{CO}_{3} /$ poly(ethylene glycol), has been reported for the $S$-alkylation with dimethyl carbonate as an inexpensive reagent [143].

When methyl and ethyl orthoesters were employed at $400{ }^{\circ} \mathrm{C}$ over the niobium cluster, the productivities of the alkyl phenyl sulfides were quite high: the conversions were higher than $93 \%$ and the selectivities were higher than 94\%. Except for methyl orthoformate (trimethoxymethane), there are no precedents for the use of orthoesters for the $S$-alkylation. Protonation of the alkoxy group in ethers or orthoesters and protonation of the carbonyl group in carbonates would lead to the nucleophilic attack of benzenethiol to yield the sulfides. The higher reactivity of the orthoesters with higher selectivity for the $S$-alkylation is ascribable to the electron-withdrawing effect of the other two or three alkoxy groups. 
Alkylation with halogenated alkane: Some 1-halogenated alkanes with $\mathrm{C}_{4}-\mathrm{C}_{6}$ alkyls were applied to the $S$-acetylation of benzenethiol over $\left[\left(\mathrm{Nb}_{6} \mathrm{Cl}_{12}\right) \mathrm{Cl}_{2}\left(\mathrm{H}_{2} \mathrm{O}\right)_{4}\right] \cdot 4 \mathrm{H}_{2} \mathrm{O} / \mathrm{SiO}_{2}$ at $400{ }^{\circ} \mathrm{C}$. When the reaction temperature of 1-chlorobutane with benzenethiol was raised to $300{ }^{\circ} \mathrm{C}$, butyl phenyl sulfide was obtained with $58 \%$ selectivity. The longer the alkyl chain of the chloroalkane, the lower both the conversion and the selectivity for the alkylation. Bromoalkanes were also effective reagents for the $S$-alkylation. Few or no secondary alkyl phenyl sulfides were formed on either cluster catalyst. Protonation or interaction of a proton with an electronegative halogen atom should facilitate the nucleophilic attack of the sulfur atom to yield the sulfide. $\mathrm{NaX}$ zeolite is reported to catalyze $S$-alkylation of benzenethiol with $\mathrm{C}_{2}-\mathrm{C}_{6}$ alkyl bromides with maximum activity at $220{ }^{\circ} \mathrm{C}$ [140]. The reactivity of the bromide decreased similarly with increasing alkyl chain length.

Alkylation with olefin: Olefins were applied to the alkylation of benzenethiol. Figure 20 shows the temperature effect of the alkylation with 1-hexene. Below $150{ }^{\circ} \mathrm{C}$, the reactions proceeded similarly in both the presence and the absence of $\left[\left(\mathrm{Nb}_{6} \mathrm{Cl}_{12}\right) \mathrm{Cl}_{2}\left(\mathrm{H}_{2} \mathrm{O}\right)_{4}\right] \cdot 4 \mathrm{H}_{2} \mathrm{O} / \mathrm{SiO}_{2}$ to yield mainly diphenyl disulfide, suggesting that the cluster did not operate as a catalyst. Above $200{ }^{\circ} \mathrm{C}$, the reactivity of 1-hexene increased, in both the presence and the absence of the catalyst, and the main reaction changed to the $S$-alkylation, yielding $n$-hexyl phenyl sulfide. About half of the $n$-hexyl phenyl sulfide was produced by spontaneous reaction in the presence of $\left[\left(\mathrm{Nb}_{6} \mathrm{Cl}_{12}\right) \mathrm{Cl}_{2}\left(\mathrm{H}_{2} \mathrm{O}\right)_{4}\right] \cdot 4 \mathrm{H}_{2} \mathrm{O} / \mathrm{SiO}_{2}$, as Figure 20 shows. Thus, $S$-alkylation with olefin at temperatures above $200{ }^{\circ} \mathrm{C}$ proceeds even in the absence of any catalysts; nevertheless, $\left[\left(\mathrm{Nb}_{6} \mathrm{Cl}_{12}\right) \mathrm{Cl}_{2}\left(\mathrm{H}_{2} \mathrm{O}\right)_{4}\right] \cdot 4 \mathrm{H}_{2} \mathrm{O} / \mathrm{SiO}_{2}$ was an effective catalyst for the alkylation at higher temperatures. In these reactions, the formation of branched alkyl phenyl sulfide was not detected.

There are few reports of the use of an olefin as the reagent: propene, 2-methylpropene and cyclohexene are reported to add benzenethiol to yield phenyl 2-propyl sulfide, $t$-butyl phenyl sulfide and cyclohexyl phenyl sulfide, respectively, according to Markovnikov's rule by a carbenium-ion mechanism over cation-exchange sulfonated resin at $135-160{ }^{\circ} \mathrm{C}$ [145]. 1-Decene is reported to add benzenethiol to yield decyl phenyl sulfide with $92 \%$ selectivity in the presence of HY zeolite at $182{ }^{\circ} \mathrm{C}$. In this reaction, sec-decyl phenyl sulfide was the main product, probably by a free-radical mechanism [142]. Both reactions were performed in batch reactors over periods of more than $2 \mathrm{~h}$, which afforded thermodynamically stable secondary alkyl products. In contrast, Lewis acids such as boron trifluoride and aluminum trichloride promoted Friedel-Crafts-type aromatic alkylation of benzenethiol with propene or 2-methylpropene [146,147]. 
Figure 20. Effect of temperature on the $S$-alkylation of benzenethiol with 1-hexene in the presence and absence of $\left[\left(\mathrm{Nb}_{6} \mathrm{Cl}_{12}\right) \mathrm{Cl}_{2}\left(\mathrm{H}_{2} \mathrm{O}\right)_{4}\right] \cdot 4 \mathrm{H}_{2} \mathrm{O} / \mathrm{SiO}_{2}$. Following the activation of the supported cluster $(10 \mathrm{mg}, 0.42 \mu \mathrm{mol})$ in a hydrogen stream $(300 \mathrm{~mL} / \mathrm{h})$ for $1 \mathrm{~h}$, reaction was initiated by introduction of benzenethiol $(22 \mu \mathrm{L} / \mathrm{h}, 0.20 \mathrm{mmol} / \mathrm{h})$ and 1-hexene $(250 \mu \mathrm{L} / \mathrm{h}, 2.0 \mathrm{mmol} / \mathrm{h})$ to the stream without changing the temperature. Other conditions are the same as in Figure 19. Yield of $n$-hexyl phenyl sulfide $=$ conversion $\times$ (selectivity for $n$-hexyl phenyl sulfide)/100 (mol\%) based on benzenethiol. Conversion of benzenethiol in the presence $(\bullet)$; and absence of the supported cluster $(\boldsymbol{\square})$; and yield of $n$-hexyl phenyl sulfide in the presence ( $\circ)$; and absence of the supported cluster ( $\square$ ); at $3 \mathrm{~h}$ after the start of the reaction.

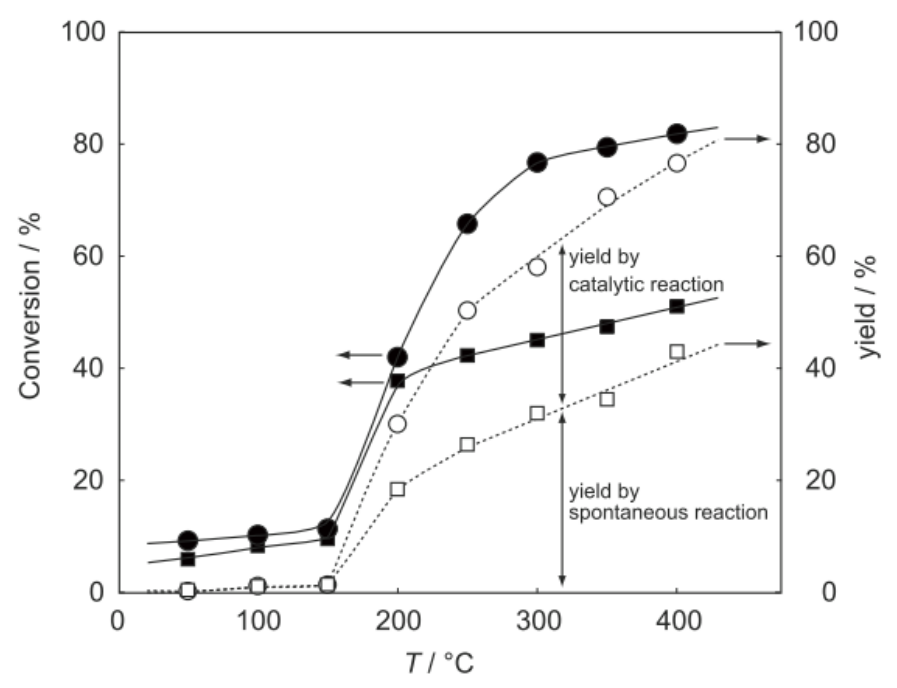

Alkylation with ester: Some acetates were applied to the reaction at $400{ }^{\circ} \mathrm{C}$. Over $\left[\left(\mathrm{Nb}_{6} \mathrm{Cl}_{12}\right) \mathrm{Cl}_{2}\left(\mathrm{H}_{2} \mathrm{O}\right)_{4}\right] \cdot 4 \mathrm{H}_{2} \mathrm{O} / \mathrm{SiO}_{2}$, the main reaction was $S$-acetylation: methyl, ethyl and propyl acetate provided $S$-phenyl thioacetate with $50 \%-75 \%$ selectivity. The acylation of thiols will be discussed in Section 6.4. On the other hand, over $\left(\mathrm{H}_{3} \mathrm{O}\right)_{2}\left[\left(\mathrm{Mo}_{6} \mathrm{Cl}_{8}\right) \mathrm{Cl}_{6}\right] \cdot 6 \mathrm{H}_{2} \mathrm{O} / \mathrm{SiO}_{2}$, the main reaction was $S$-alkylation to afford methyl, ethyl and propyl phenyl sulfide almost exclusively. The tantalum and tungsten halide clusters supported on $\mathrm{SiO}_{2}$ also selectively catalyzed the $S$-alkylation. The $S$-alkylation of thiol with esters is quite rare: when methyl formate, methyl acetate or methyl propionate were reacted with benzenethiol in the presence of $\mathrm{CH}_{3} \mathrm{CO}_{2} \mathrm{Na} / \mathrm{Bu}_{4} \mathrm{PBr}$ under continuous-flow phase-transfer catalytic conditions at $180{ }^{\circ} \mathrm{C}$, only methyl phenyl sulfide was obtained [139]. Thus, halide clusters exhibited $S$-alkylation catalysis of benzenethiol for a wide variety of alkylating reagents: alcohols, ethers, dialkyl carbonates, orthoseters, alkyl halides, olefins, halogenated alkanes, and alkyl acetates.

\section{Ring Closure Reaction}

\subsection{Quinoline Synthesis (Equation (11)) [148]}

Various types of quinolines have been synthesized for application to pharmaceuticals, dyes, and feed additives. The Skraup synthesis is of great general utility and has been applied to many aromatic amines combined with glycerol or acrolein [149], because the route is straightforward, readily available 
starting material are used, and the procedure is simple. Reaction of aniline with acetone to yield 1,2-dihydro-2,2,4-trimethylquinoline is a modification of the Skraup synthesis, in which strong acids $(\mathrm{pKa}<2)$ or halogens are used as the catalyst. Volatile catalysts, such as hydrogen chloride [150-155], bromine [150], and iodine $[150,153,154]$ are used near the boiling point of aniline $\left(184{ }^{\circ} \mathrm{C}\right)$ or lower temperature at around $100{ }^{\circ} \mathrm{C}$. Nonvolatile homogeneous acids, such as $p$-aminobenzenesulfonic acid [150], benzenesulfonic acid [152,155], and $p$-toluenesulfonic acid [151-153,156-158] have also been used in liquid phase batch reaction systems. These liquid-phase systems have some disadvantages, and removal of the homogeneous catalysts after the reaction is a crucial problem. Vapor-phase reaction utilizing a solid acid catalyst would circumvent these issues. However, there has been only one report on the reaction: solid acid catalysts, such as silica-alumina and zeolite were used for a modified quinoline synthesis in which $o$-toluidine with excess amounts of acetaldehyde and formaldehyde in methanol/water solution was used [159]. Catalytic synthesis of quinolines over halide clusters which have no micropore structure has been developed.

Unsupported powdered crystals of $\left[\left(\mathrm{Nb}_{6} \mathrm{Cl}_{12}\right) \mathrm{Cl}_{2}\left(\mathrm{H}_{2} \mathrm{O}\right)_{4}\right] \cdot 4 \mathrm{H}_{2} \mathrm{O}(150-200$ mesh) were activated in a hydrogen stream at an elevated temperature for $1 \mathrm{~h}$, and then the reaction was commenced by introduction of aniline and acetone in the 1:2 reaction stoichiometry into the hydrogen stream without changing the temperature. The effect of the reaction temperature is presented in Figure 21. Practically no catalytic activity was observed below $200{ }^{\circ} \mathrm{C}$; the formation of $N$-isopropylideneaniline, a Schiff base, is a non catalytic reaction (Equation (29)).

$$
\mathrm{C}_{6} \mathrm{H}_{5}-\mathrm{NH}_{2}+\mathrm{Me}-\mathrm{CO}-\mathrm{Me} \rightarrow \mathrm{C}_{6} \mathrm{H}_{5}-\mathrm{N}=\mathrm{CMe}_{2}+\mathrm{H}_{2} \mathrm{O}
$$

Figure 21. Effect of temperature on quinoline synthesis catalyzed by $\left[\left(\mathrm{Nb}_{6} \mathrm{Cl}_{12}\right) \mathrm{Cl}_{2}\left(\mathrm{H}_{2} \mathrm{O}\right)_{4}\right] \cdot 4 \mathrm{H}_{2} \mathrm{O}$. Following activation of the supported cluster $(30 \mathrm{mg}$, $25 \mu \mathrm{mol})$ in a hydrogen stream $(120 \mathrm{~mL} / \mathrm{h})$ for $1 \mathrm{~h}$, reaction was commenced by feeding aniline $(0.091 \mathrm{~mL} / \mathrm{h}, 1.0 \mathrm{mmol} / \mathrm{h})$ and acetone $(0.147 \mathrm{~mL} / \mathrm{h}, 2.0 \mathrm{mmol} / \mathrm{h})$ to the hydrogen stream. Both activation and reaction temperatures were altered concomitantly. Conversion and selectivities are based on aniline at $3 \mathrm{~h}$ after reaction started. Conversion of aniline $(\bullet)$; selectivity for 1,2-dihydro-2,2,4-trimethylquinoline (०); selectivity for 1,2,3,4-tetrahydro-2,2,4-trimethylquinoline $(\Delta)$; and selectivity for $N$-isopropylideneaniline ( $\square$ ).

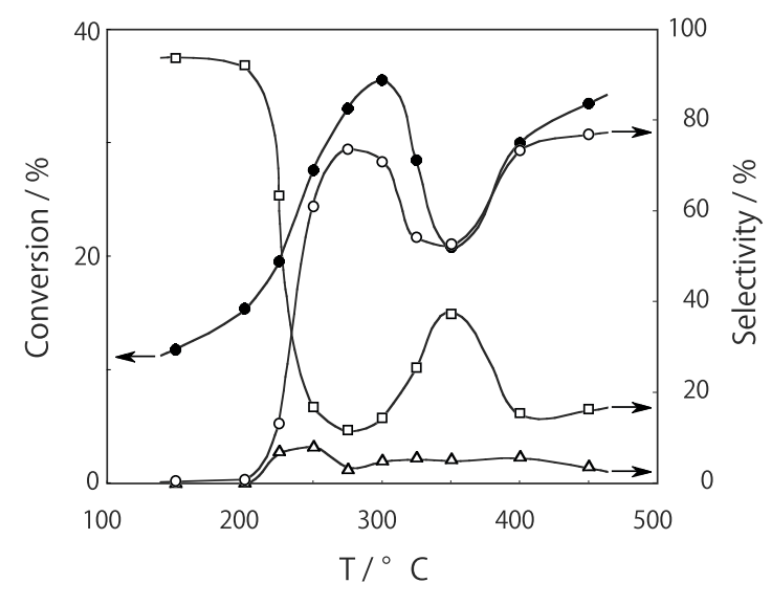


The catalytic activity for the formation of 1,2-dihydro-2,2,4-trimethylquinoline developed when the activation as well as the reaction was performed above $200{ }^{\circ} \mathrm{C}$. Both the activity and the selectivity for the quinoline increased with increasing temperature, having a local maximum at around $300{ }^{\circ} \mathrm{C}$ with $72 \%$ selectivity.

The catalytic activity of some clusters and solid acid compounds were performed at $300{ }^{\circ} \mathrm{C}$. A bromide cluster of niobium and chloride clusters of tantalum and rhenium exhibited moderate selectivities $(30 \%-60 \%)$ for the quinoline. On the other hand, clusters of Group 6 metals, molybdenum and tungsten, produced only a small amount of the quinoline. Conventional solid acid catalysts such as $\mathrm{NH}_{4}-\mathrm{Y}$ and $\mathrm{H}$-mordenite exhibited low selectivities for the quinoline (23 and 17\% selectivity, respectively), and silica-alumina and H-ZSM-5 had practically no selectivities for the quinoline synthesis under identical conditions.

Three toluidine isomers were reacted with acetone over $\left[\left(\mathrm{Nb}_{6} \mathrm{Cl}_{12}\right) \mathrm{Cl}_{2}\left(\mathrm{H}_{2} \mathrm{O}\right)_{4}\right] \cdot 4 \mathrm{H}_{2} \mathrm{O}$ at $300{ }^{\circ} \mathrm{C}$. All of the toluidines produced the corresponding quinolines. Both the reactivities of $m$ - and $p$-toluidines (35 and 48 conversion, respectively) and the selectivities for the methyl substituted quinolines (67\% and 63\% selectivity, respectively) were high, and were practically the same as for the corresponding unsubstituted aniline. In contrast, the reactivity $o$-toluidine (22\% conversion) and its selectivity for the methyl-substituted quinoline (29\% selectivity) were not high. The methyl group of $o$-toluidine should hinder the reaction.

When 3-buten-2-one or 4-Methyl-3-penten-2-one was reacted combined with aniline, the corresponding aniline was produced with 49 or $25 \%$ selectivity, respectively. Thus, halide clusters demonstrated efficient heterogeneous catalysis for the quinoline syntheses based on their Brønsted acidity, high thermal stability, and non micropore structure.

\subsection{Benzofuran Synthesis (Equation (12)) [160]}

Benzofurans including 3-methylbenzofuran are used as raw materials for pharmaceuticals, fluorescent dyes, and photoreceptors. Although more than 1100 reports on syntheses of benzofurans were published prior to 1973 [161], there have been no precedents for the direct synthesis of benzofurans from phenols and ketones. Halide clusters catalyzed the novel direct synthesis of 3-methylbenzofuran from phenol and acetone (Equation (12)), in which Brønsted acidity and platinum-like metallic behavior operated concurrently.

Supported tantalum cluster, $\left[\left(\mathrm{Ta}_{6} \mathrm{Cl}_{12}\right) \mathrm{Cl}_{2}\left(\mathrm{H}_{2} \mathrm{O}\right)_{4}\right] \cdot 4 \mathrm{H}_{2} \mathrm{O} / \mathrm{SiO}_{2}$, was activated at various temperatures in a helium stream for $1 \mathrm{~h}$, and the reaction was initiated by introduction of a mixture of phenol with acetone into the helium stream without changing the temperature. The effect of the temperature is shown in Figure 22. The catalytic activity developed above $150{ }^{\circ} \mathrm{C}$, and increased with increasing temperature, having a maximum around $300{ }^{\circ} \mathrm{C}$. Over the temperature range $150-300{ }^{\circ} \mathrm{C}$, condensation yielding 2-isopropenylphenol selectively proceeded. The condensation activity can be attributed to the weak Brønsted acidity of the hydroxo ligand [1]. Above $350{ }^{\circ} \mathrm{C}$, subsequent cyclodehydrogenation of 2-isopropenylphenol proceeded to yield 3-methylbenzofuran as the main product. According to Le Chatelier's principle, a reaction that increases the number of product molecules is thermodynamically favorable at higher temperatures under constant pressure. Thus, the higher reaction temperatures promoted the cyclodehydrogenation of 2-isopropenylphenol to 3-methylbenzofuran. Above $350{ }^{\circ} \mathrm{C}$, 
the selectivity for 3-methylbenzofuran decreased, and the selectivity for decomposition products such as cresol and ethylphenol increased.

Figure 22. Effect of temperature on the reaction of phenol with acetone over $\left[\left(\mathrm{Ta}_{6} \mathrm{Cl}_{12}\right) \mathrm{Cl}_{2}\left(\mathrm{H}_{2} \mathrm{O}\right)_{4}\right] \cdot 4 \mathrm{H}_{2} \mathrm{O} / \mathrm{SiO}_{2}$. After activation of the supported cluster $(100 \mathrm{mg}$, $2.9 \mu \mathrm{mol})$ in a helium stream $(600 \mathrm{~mL} / \mathrm{h})$ for $1 \mathrm{~h}$, reaction was commenced by feeding a mixture of phenol $(10 \mathrm{mg} / \mathrm{h}, 0.11 \mathrm{mmol} / \mathrm{h})$ and acetone $(40 \mu \mathrm{L} / \mathrm{h}, 0.55 \mathrm{mmol} / \mathrm{h})$ into the helium stream without changing the temperature. Conversion of phenol $(\bullet)$; selectivity for 3-methylbenzofuran (०); selectivity for 2-isopropenylphenol ( $\square$ ); and selectivity for the other aromatic products such as cresol and ethylphenol $(\Delta)$ at $3 \mathrm{~h}$ after the reaction started.

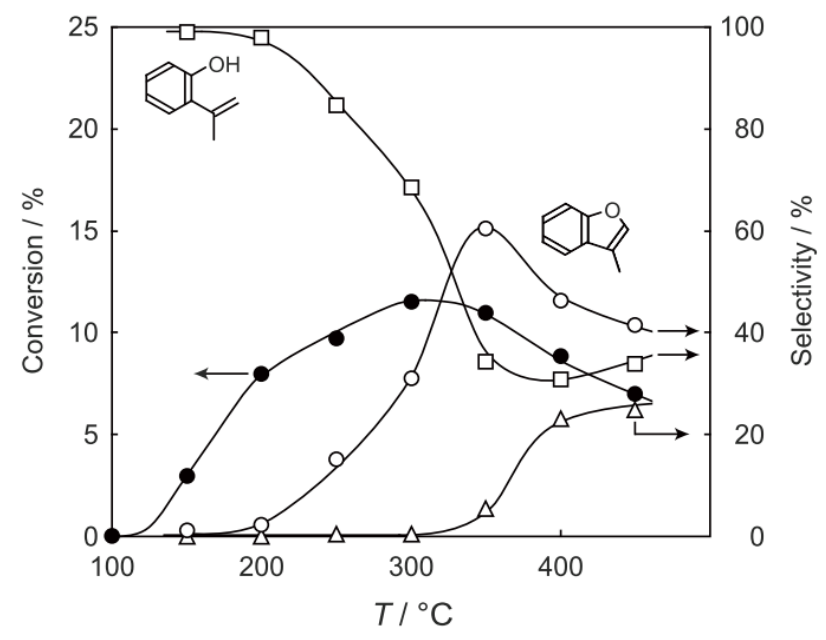

As listed in Table 7, supported chloride clusters of niobium, molybdenum and tungsten, and bromide cluster of tantalum, $\left[\left(\mathrm{Ta}_{6} \mathrm{Br}_{12}\right) \mathrm{Br}_{2}\left(\mathrm{H}_{2} \mathrm{O}\right)_{4}\right] \cdot 4 \mathrm{H}_{2} \mathrm{O} / \mathrm{SiO}_{2}$, also catalyzed the reaction selectively (entries 1,2,5,6). In contrast, no catalytic activity was observed over $\mathrm{Re}_{3} \mathrm{Cl}_{9} / \mathrm{SiO}_{2}$, which has no coordinated water to produce hydroxo ligands (entry 7). When $p$-cresol was used in place of phenol over $\left[\left(\mathrm{Ta}_{6} \mathrm{Cl}_{12}\right) \mathrm{Cl}_{2}\left(\mathrm{H}_{2} \mathrm{O}\right)_{4}\right] \cdot 4 \mathrm{H}_{2} \mathrm{O} / \mathrm{SiO}_{2}$, the corresponding benzofuran, 3,5-dimethylbenzofuran, was obtained with $64 \%$ selectivity (entry 4 ).

Bisphenol A, 2,2-bis(4-hydroxyphenyl)propane, is commercially produced from phenol and acetone in the presence of $\mathrm{HCl}$ [162] or ion exchange resins [163] at around $70{ }^{\circ} \mathrm{C}$ (Scheme 1). $\mathrm{SiO}_{2}-\mathrm{Al}_{2} \mathrm{O}_{3}$, $\mathrm{H}$-beta, $\mathrm{H}$-mordenite, and $\mathrm{H}_{3} \mathrm{PW}_{12} \mathrm{O}_{40}$ are also reported to catalyze the reaction in the temperature range $90-180{ }^{\circ} \mathrm{C}$. At $250{ }^{\circ} \mathrm{C}$, bisphenol $\mathrm{A}$ is reported to be decomposed to phenol and $p$-isopropenylphenol in the presence of $\mathrm{HCl}$ [164]. These catalysts are strong acids with a Hammett acidity function $\left(H_{0}\right)$ less than $-8[165,166]$, in contrast to the weak acidity of the halide clusters $\left(H_{0} \approx+1.3\right)$ [1]. As Table 7 shows, formation of 3-methylbenzofuran scarcely proceeded over the conventional solid acids under identical conditions (entries 8-11), and there have been no reports on cyclodehydrogenation of alkenylphenols to benzofurans over solid acid catalysts. On the other hand, the platinum group metal catalysts such as $\mathrm{Pd}$ metal [167] and $\mathrm{RuCl}_{3}$ [168] are reported to catalyze cyclodehydrogenation of 2-allylphenol to yield 2-methylbenzofuran. Similar cyclodehydrogenation is reported for $\mathrm{Pd} / \mathrm{C}, \mathrm{PdCl}_{2}$, and $\mathrm{Pd}(\mathrm{OAc})_{2}$ [169]. The cyclodehydrogenation would be promoted by the coordinatively unsaturated platinum-like metal atom of the cluster [1]. Thus, the halide clusters acted 
as acidic and metallic bifunctional catalysts, leading to direct synthesis of benzofurans from phenols and acetone.

Table 7. Synthesis of 3-methylbenzofuran over halide clusters ${ }^{\text {a }}$.

\begin{tabular}{cccccc}
\hline \multirow{2}{*}{ Entry } & \multirow{2}{*}{ Catalyst } & \multirow{3}{*}{ Conversion (\%) } & \multicolumn{3}{c}{ Selectivity (\%) } \\
\cline { 4 - 6 } & & & 2-Isopropenylphenol & 3-Methylbenzofuran & Others $^{\mathbf{b}}$ \\
\hline 1 & {$\left[\left(\mathrm{Nb}_{6} \mathrm{Cl}_{12}\right) \mathrm{Cl}_{2}\left(\mathrm{H}_{2} \mathrm{O}\right)_{4}\right] \cdot 4 \mathrm{H}_{2} \mathrm{O} / \mathrm{SiO}_{2}$} & 20.4 & 19.7 & 27.5 & 52.7 \\
2 & $\left(\mathrm{H}_{3} \mathrm{O}\right)_{2}\left[\left(\mathrm{Mo}_{6} \mathrm{Cl}_{8}\right) \mathrm{Cl}_{6}\right] \cdot 6 \mathrm{H}_{2} \mathrm{O} / \mathrm{SiO}_{2}$ & 4.4 & 30.4 & 56.8 & 12.9 \\
3 & {$\left[\left(\mathrm{Ta}_{6} \mathrm{Cl}_{12}\right) \mathrm{Cl}_{2}\left(\mathrm{H}_{2} \mathrm{O}\right)_{4}\right] \cdot 4 \mathrm{H}_{2} \mathrm{O} / \mathrm{SiO}_{2}$} & 10.9 & 34.1 & 60.4 & 5.5 \\
4 & {$\left[\left(\mathrm{Ta}_{6} \mathrm{Cl}_{12}\right) \mathrm{Cl}_{2}\left(\mathrm{H}_{2} \mathrm{O}\right)_{4}\right] \cdot 4 \mathrm{H}_{2} \mathrm{O} / \mathrm{SiO}_{2}{ }^{\mathrm{c}}$} & 3.6 & $11.2^{\mathrm{d}}$ & $64.1^{\mathrm{e}}$ & 24.7 \\
5 & {$\left[\left(\mathrm{Ta}_{6} \mathrm{Br}_{12}\right) \mathrm{Br}_{2}\left(\mathrm{H}_{2} \mathrm{O}\right)_{4}\right] \cdot 4 \mathrm{H}_{2} \mathrm{O} / \mathrm{SiO}_{2}$} & 13.1 & 40.4 & 47.5 & 12.1 \\
6 & $\left(\mathrm{H}_{3} \mathrm{O}\right)_{2}\left[\left(\mathrm{~W}_{6} \mathrm{Cl}_{8}\right) \mathrm{Cl}_{6}\right] \cdot 6 \mathrm{H}_{2} \mathrm{O} / \mathrm{SiO}_{2}$ & 7.2 & 47.9 & 42.0 & 10.1 \\
7 & $\mathrm{Re}_{3} \mathrm{Cl}_{9} / \mathrm{SiO}_{2}$ & 0.0 & & & \\
8 & $\mathrm{SiO}_{2}-\mathrm{Al}_{2} \mathrm{O}_{3}\left(\right.$ high alumina) $^{\mathrm{f}}$ & 25.9 & 9.2 & 7.8 & 83.0 \\
9 & $\mathrm{H}-$ beta & & & & \\
10 & $\mathrm{f}$ & 8.6 & 1.1 & 1.4 & 97.5 \\
11 & $\mathrm{H}-\mathrm{ZSM}-5-25 \mathrm{H}^{\mathrm{f}}$ & 7.0 & 1.5 & 0.9 & 97.6 \\
\hline
\end{tabular}

${ }^{\text {a }}$ After activation of catalyst $(100 \mathrm{mg})$ in a helium stream $(600 \mathrm{~mL} / \mathrm{h})$ at $350{ }^{\circ} \mathrm{C}$ for $1 \mathrm{~h}$, reaction was started by introduction of phenol $(10 \mathrm{mg} / \mathrm{h}, 0.11 \mathrm{mmol} / \mathrm{h})$ and acetone $(40 \mu \mathrm{L} / \mathrm{h}, 0.55 \mathrm{mmol} / \mathrm{h})$ to the stream without changing the temperature. At $3 \mathrm{~h}$ after the start of the reaction. Other conditions are the same as in Figure 22; ${ }^{\mathrm{b}}$ Cresol, ethylphenol, etc.; ${ }^{\mathrm{c}} \mathrm{p}$-Cresol $(12 \mathrm{mg} / \mathrm{h}, 0.11 \mathrm{mmol} / \mathrm{h})$ was used in place of phenol; d 2-Isopropenyl-4-methylphenol; ${ }^{\text {e }}$ 3,5-Dimethylbenzofuran; ${ }^{\mathrm{f}}$ Reference catalyst, The Catalysis Society of Japan.

Scheme 1. Bisphenol A, 2,2-bis(4-hydroxyphenyl)propane, is commercially produced at around $70{ }^{\circ} \mathrm{C}$.

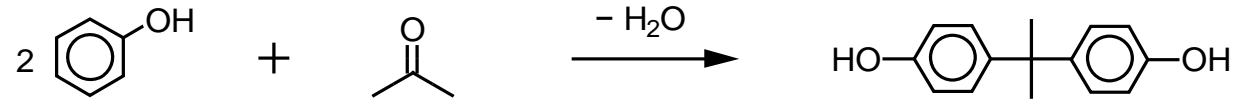

\subsection{Aldol Condensation to Yield Indene (Equation (13)) [170]}

The aldol condensation is well investigated and is catalyzed by acids and bases, the latter being more frequently employed [171]. Sulfuric acid, Nafion-H, Amberlite IR-120, and $\mathrm{RuCl}_{3}$ have been used as acid catalysts, and $\mathrm{NaOH}, \mathrm{Ba}(\mathrm{OH})_{2}$, choline hydroxide/MgO, hydrotalcite, guanidine, and the basic sites of alumina have been used as base catalysts. When halide clusters were applied to the aldol condensation of benzaldehyde with aliphatic ketones above $350{ }^{\circ} \mathrm{C}$, successive cyclization reactions proceeded to create indenes by taking advantage of the thermal stability.

Supported tantalum cluster, $\left[\left(\mathrm{Ta}_{6} \mathrm{Cl}_{12}\right) \mathrm{Cl}_{2}\left(\mathrm{H}_{2} \mathrm{O}\right)_{4}\right] \cdot 4 \mathrm{H}_{2} \mathrm{O} / \mathrm{SiO}_{2}$, was initially activated at elevated temperatures for $1 \mathrm{~h}$ in a helium stream, and then reaction was commenced by introduction of an equimolar mixture of benzaldehyde and acetone without changing the temperature. The effect of the reaction temperature is presented in Figure 23. The catalytic activity developed slightly when the reaction was performed at $200{ }^{\circ} \mathrm{C}$, and increased with increasing temperature. The activity had a maximum at around $425{ }^{\circ} \mathrm{C}$. At $400{ }^{\circ} \mathrm{C}$, the cluster catalyzed the cross aldol condensation to yield E-4-phenyl-3-buten-2-one with around 75\% selectivity (Equation (30)), with some decomposition to 
benzene, toluene, and styrene. No $Z$ isomer of the condensation product was detected as reported in other cases of the aldol condensation [171]. Even more remarkable is the formation of indenes, 1-methyleneindene and 3-methylindene with 6\% selectivity (Equation (13)). Above $400{ }^{\circ} \mathrm{C}$, the selectivity for decomposition to principally benzene increased with increasing temperature.

Figure 23. Effect of temperature on the reaction of benzaldehyde with acetone over $\left[\left(\mathrm{Ta}_{6} \mathrm{Cl}_{12}\right) \mathrm{Cl}_{2}\left(\mathrm{H}_{2} \mathrm{O}\right)_{4}\right] \cdot 4 \mathrm{H}_{2} \mathrm{O} / \mathrm{SiO}_{2}$ in a helium stream. Following activation of the supported cluster $(100 \mathrm{mg}, 2.9 \mu \mathrm{mol})$ in a helium stream $(300 \mathrm{~mL} / \mathrm{h})$ for $1 \mathrm{~h}$, reaction was started by introduction of a mixture of benzaldehyde $(58 \mu \mathrm{L} / \mathrm{h}, 0.57 \mathrm{mmol} / \mathrm{h})$ and acetone $(42 \mu \mathrm{L} / \mathrm{h}$, $0.57 \mathrm{mmol} / \mathrm{h}$ ) to the stream without changing the temperature. Conversion and selectivities are based on aromatic compounds. Conversion of benzaldehyde $(\bullet)$; selectivity for aldol condensation to E-4-phenyl-3-buten-2-one (०); selectivity for hydrogenolysis to benzene, toluene, and styrene $(\Delta)$; and selectivity for indenes $(\square)$; at $3 \mathrm{~h}$ after the reaction started.

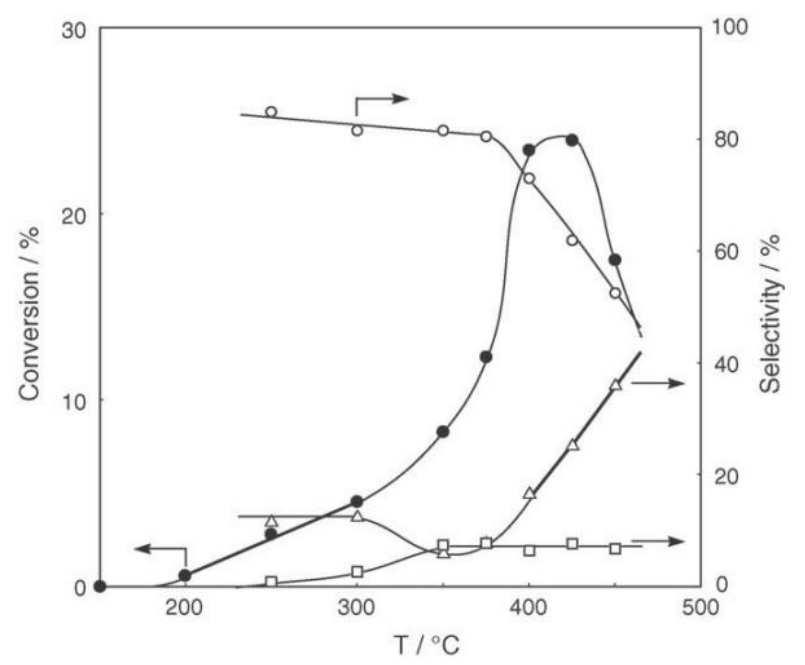

$$
\mathrm{C}_{6} \mathrm{H}_{5} \mathrm{CHO}+\mathrm{CH}_{3} \mathrm{COCH}_{3} \rightarrow \mathrm{C}_{6} \mathrm{H}_{5}-\mathrm{CH}=\mathrm{CH}-\mathrm{CO}-\mathrm{CH}_{3}+\mathrm{H}_{2} \mathrm{O}
$$

The catalytic activity of various clusters of Group 5-7 metals and related compounds were examined at $400{ }^{\circ} \mathrm{C}$. Supported tantalum bromide cluster exhibited considerably higher activity ( $12 \%$ conversion) and selectivity (62\% selectivity) for the aldol condensation. Supported niobium and tungsten chloride clusters also demonstrated moderate selectivities (48 and 47\% selectivity, respectively). These clusters afforded the indenes with 3\%-9\% selectivity. However, the trinuclear rhenium chloride cluster catalyzed hydrogenolysis to yield benzene preferentially.

Some acyclic ketones were subjected to reaction with benzaldehyde in the presence of $\left[\left(\mathrm{Ta}_{6} \mathrm{Cl}_{12}\right) \mathrm{Cl}_{2}\left(\mathrm{H}_{2} \mathrm{O}\right)_{4}\right] \cdot 4 \mathrm{H}_{2} \mathrm{O} / \mathrm{SiO}_{2}$, and the results are summarized in Table 8. 3,3-Dimethyl-2-butanone, which has no $\alpha$-hydrogen at one side, was effectively converted to the cross aldol condensation product, E-4,4-dimethyl-1-phenyl-1-penten-3-one. In contrast, 3-pentanone that has hydrogens at the $\alpha$ - and $\alpha^{\prime}$-positions afforded substituted indenes (1) with as high as $78 \%$ selectivity (Scheme 2). Similarly, butanone and 2-pentanone provided the corresponding indenes (2b and 2c) (Scheme 3). When E-4-Phenyl-3-buten-2-one (3a), the aldol condensation product of benzaldehyde with acetone, was subjected to the reaction under identical conditions, the corresponding indenes (2a) were obtained with $36 \%$ selectivity, which is much higher than that starting from acetone with benzaldehyde (Table 8). 
Table 8. Reaction of ketones with benzaldehyde over $\left[\left(\mathrm{Ta}_{6} \mathrm{Cl}_{12}\right) \mathrm{Cl}_{2}\left(\mathrm{H}_{2} \mathrm{O}\right)_{4}\right] \cdot 4 \mathrm{H}_{2} \mathrm{O} / \mathrm{SiO}_{2}{ }^{\mathrm{a}}$.

\begin{tabular}{|c|c|c|c|c|c|}
\hline \multirow{2}{*}{ Ketone } & \multirow{2}{*}{ Conversion $(\%)$} & \multicolumn{4}{|c|}{ Selectivity (\%) } \\
\hline & & $E-\mathrm{C}_{6} \mathrm{H}_{5} \mathrm{CHCR}_{1} \mathrm{COR}_{2}$ & Indenes & $\mathrm{C}_{6} \mathrm{H}_{5} \mathrm{R}\left(\mathrm{R}=\mathrm{H}, \mathrm{CH}_{3}, \mathrm{CHCH}_{2}\right)$ & Others \\
\hline Acetone & 23.3 & $72.3\left(\mathrm{R}_{1}=\mathrm{H}, \mathrm{R}_{2}=\mathrm{CH}_{3}\right)$ & $6.4^{\mathrm{b}}$ & 16.3 & 5.0 \\
\hline Butanone & 8.4 & $9.6\left(\mathrm{R}_{1}=\mathrm{H}, \mathrm{R}_{2}=\mathrm{C}_{2} \mathrm{H}_{5}\right)$ & $23.4^{\mathrm{c}}$ & 47.9 & 19.1 \\
\hline 2-Pentanone & 13.8 & $17.9\left(\mathrm{R}_{1}=\mathrm{H}, \mathrm{R}_{2}=\mathrm{C}_{3} \mathrm{H}_{7}\right)$ & $31.4^{\mathrm{d}}$ & 15.7 & 16.0 \\
\hline 3-Pentanone & 29.7 & $0.0\left(\mathrm{R}_{1}=\mathrm{CH}_{3}, \mathrm{R}_{2}=\mathrm{C}_{2} \mathrm{H}_{5}\right)$ & $78.4^{\mathrm{e}}$ & 10.2 & 11.4 \\
\hline 3,3-Dimethyl-2-butanone (6) & 20.0 & $81.1\left(\mathrm{R}_{1}=\mathrm{H}, \mathrm{R}_{2}=t-\mathrm{Bu}\right)$ & 0.0 & 8.1 & 10.8 \\
\hline E-4-Phenyl-3-buten-2-one (3a) ${ }^{\mathrm{f}}$ & 21.6 & - & $35.8^{\mathrm{g}}$ & 13.9 & $50.3^{j}$ \\
\hline
\end{tabular}

${ }^{a}$ After activation of cluster $(100 \mathrm{mg}, 2.9 \mu \mathrm{mol})$ in a helium stream $(300 \mathrm{~mL} / \mathrm{h})$ at $400{ }^{\circ} \mathrm{C}$ for $1 \mathrm{~h}$, reaction was started by introduction of ketone $(0.57 \mathrm{mmol} / \mathrm{h})$ and benzaldehyde $(58 \mathrm{iL} / \mathrm{h}, 0.57 \mathrm{mmol} / \mathrm{h})$ to the stream without changing the temperature. At $3 \mathrm{~h}$ after the start of the reaction. Other conditions are the same as in Figure 23.; ${ }^{\mathrm{b}}$ 1-Methyleneindene (2.2\%) and 3-methylindene (4.2\%); ${ }^{\mathrm{c}}$ 2-Methyl-1-methyleneindene (4.5\%) and 2,3-dimethylindene (18.9\%); ${ }^{\mathrm{d}}$ 2-Ethyl-1-methyleneindene (13.6\%) and 2-ethyl-3-methylindene (17.8\%).; ${ }^{\mathrm{e}}$ Z-1-Ethylidene-2-methylindene (45.9\%), E-1-ethylidene-2-methylindene (14.7\%), 2-methyl-3-vinylindene (6.1\%), and 3-ethyl-2-methylindene (11.7\%).; ${ }^{\mathrm{f}}$ Butyl ether solution (15\%) in the absence of benzaldehyde; ${ }^{\mathrm{g}}$ 1-Methyleneindene (3.5\%) and 3-methylindene (32.3\%).;

h 4-Phenyl-2-butanone, 1-phenyl-1-butene, naphthalene, etc.

Scheme 2. Formation of indenes from benzaldehyde and 3-pentanone.

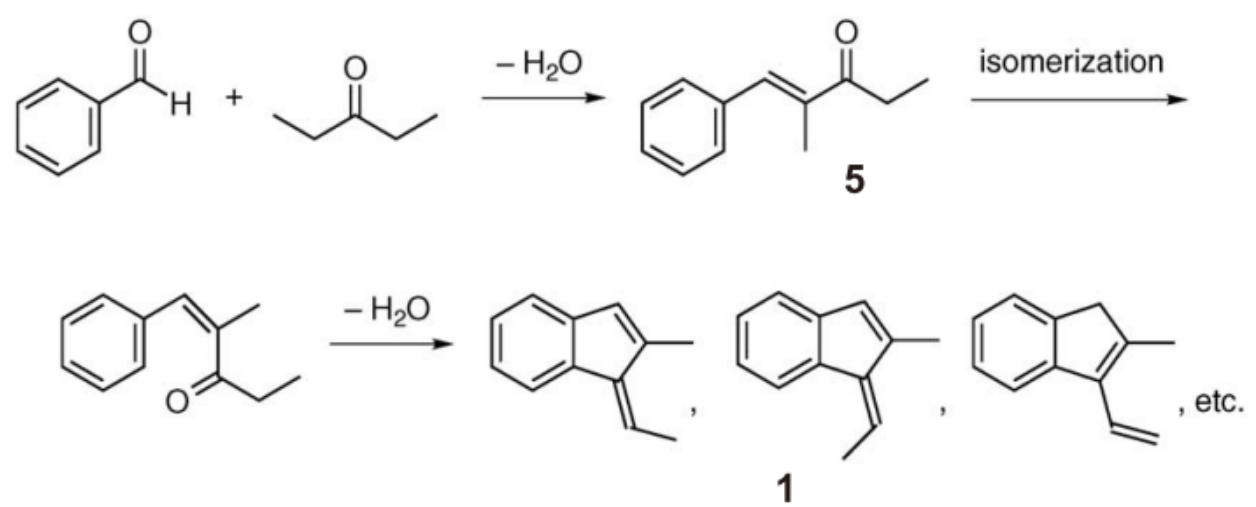


Scheme 3. Different regioselectivities for the aldol condensation of unsymmetrical aliphatic ketones over acid and base catalysts.

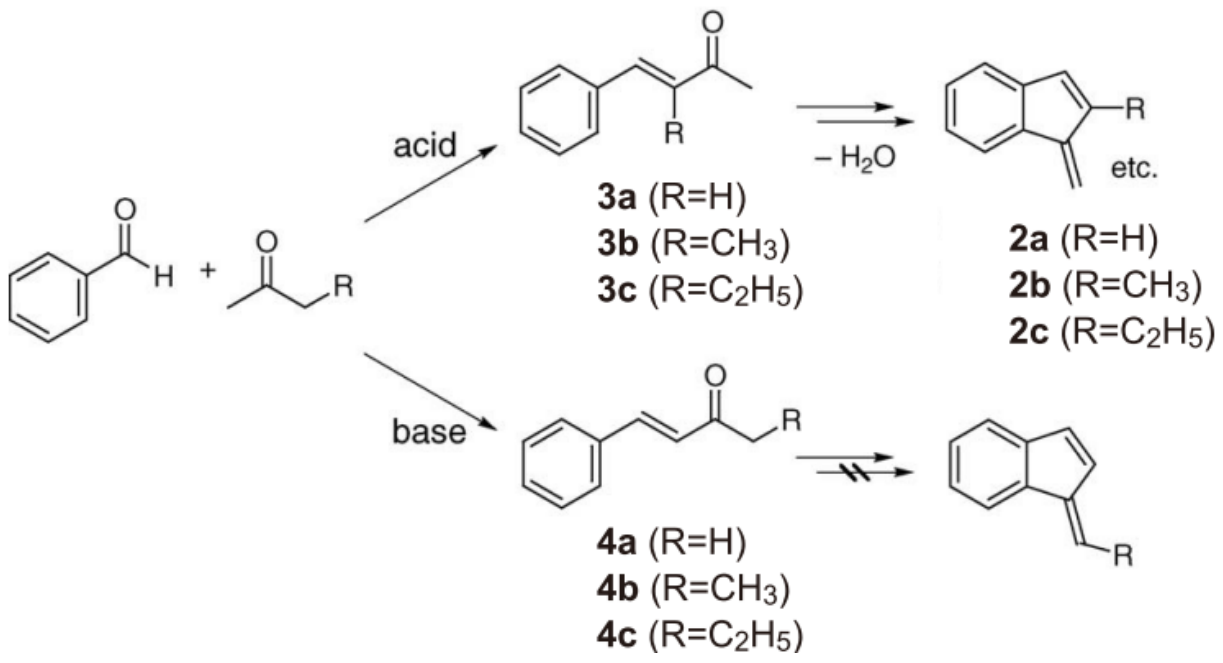

The aldol condensation is catalyzed by acids and bases. Different regioselectivities for the aldol condensation of unsymmetrical aliphatic ketones such as butanone and 2-pentanone have been well established: the acid-catalyzed reaction of butanone with benzaldehyde affords E-3-methyl-4-phenyl-3-buten-2-one (3b) by activation of the methylene group, while the base-catalyzed reaction yields E-1-phenyl-1-penten-3-one (4b) by activation of the methyl group [171-173] (Scheme 3). The methylene group of acyclic non-methyl ketones is hardly activated by base catalysts $[171,174]$.

The Brønsted acid site on the cluster catalyzed the aldol condensation to afford $\alpha, \beta$-unsaturated carbonyl compound 5 (Scheme 2). Halide clusters can isomerize olefins (Section 3.2) and abstract ortho-hydrogen of aromatic rings (Section 5.1 and 5.2). Then the carbonyl group is accessible to the ortho-hydrogen, leading to cyclodehydration to yield indenes. In the case of 3,3-dimethyl-2-butanone (6), there is no $\alpha$ '-hydrogen in the $t$-butyl group for dehydration, and hence indene was not formed (Table 8). Thus, carbonyl compound which has no $\alpha$-hydrogen at one side was effectively converted to the corresponding cross aldol condensation product, and carbonyl compound which has hydrogens at the $\alpha$ - and $\alpha$-positions afforded substituted indenes above $350{ }^{\circ} \mathrm{C}$. There have been no precedents for the one-step synthesis of indenes from an acyclic ketone and benzaldehyde, although more than 2300 reports on the aldol condensation were published prior to 1968 [171]. The aldol condensation is usually accomplished at room temperature and excessively high temperatures are generally unnecessary, since the rates are sufficiently rapid at room temperature [171]. Application of high temperatures, which is one of the advantages of halide cluster catalyses, caused the cyclodehydration to indenes, as the equilibrium shifts to yield cyclodehydration with increased temperature.

\subsection{Heterocyclic Rings Containing Oxygen, Sulfur and Nitrogen (Equation (14)) [175]}

Organic compounds that contain rings composed of carbon and other atoms including $\mathrm{O}, \mathrm{S}$ or $\mathrm{N}$ are termed heterocyclic compounds. The synthesis of heterocyclic compounds has a long and extensive history, but a broadly applicable catalytic method for the synthesis of simple, commonly occurring heterocyclic rings has not been developed. Halide cluster catalyzed some cyclization reactions, as has 
been described above. We have attempted to expand the scope of halide cluster catalysis, and 1,2-disubstituted benzenes containing $-\mathrm{OH},-\mathrm{SH}$, or $-\mathrm{NH}_{2}$ groups were employed as reactants (Equation (14)).

Supported niobium cluster, $\left[\left(\mathrm{Nb}_{6} \mathrm{Cl}_{12}\right) \mathrm{Cl}_{2}\left(\mathrm{H}_{2} \mathrm{O}\right)_{4}\right] \cdot 4 \mathrm{H}_{2} \mathrm{O} / \mathrm{SiO}_{2}$, was initially activated at an elevated temperature for $1 \mathrm{~h}$ in a helium stream, and then reaction was commenced by introduction of 1,2-benzenedimethanol into the stream without changing the temperature. The effect of the reaction temperature is presented in Figure 24. Substantial catalytic activity developed above $200{ }^{\circ} \mathrm{C}$. Cyclization was the main reaction at all of the temperatures tested. At $350{ }^{\circ} \mathrm{C}$, cyclization yielding 1,3-dihydroisobenzofuran proceeded with a selectivity of $92 \%$ at $31 \%$ conversion. Assuming that all of the cluster molecules were active, the turnover frequency per $\mathrm{Nb}_{6}$-cluster molecule was $0.10 \mathrm{~s}^{-1}$, which is a very large value for a molecular catalyst. In these eliminative ring-closure reactions, the number of product molecules increases, which is thermodynamically favorable at higher temperatures under constant pressure, according to Le Chatelier's principle.

Figure 24. Effect of temperature on the cyclization of 1,2-benzenedimethanol in a helium stream over $\left[\left(\mathrm{Nb}_{6} \mathrm{Cl}_{12}\right) \mathrm{Cl}_{2}\left(\mathrm{H}_{2} \mathrm{O}\right)_{4}\right] \cdot 4 \mathrm{H}_{2} \mathrm{O} / \mathrm{SiO}_{2}$. Following the activation of the supported cluster $(10 \mathrm{mg}, 0.42 \mu \mathrm{mol})$ in a helium stream $(600 \mathrm{~mL} / \mathrm{h})$ for $1 \mathrm{~h}$, reaction was started by introduction of 1,2-benzenedimethanol ( $10 \%$ aqueous solution, $0.69 \mathrm{~mL} / \mathrm{h}, 0.50 \mathrm{mmol} / \mathrm{h}$ ) to the helium stream without changing the temperature. Conversion of 1,2-benzenedimethanol $(\bullet)$; selectivity for 1,3-dihydroisobenzofuran (०); selectivity for 2-methylbenzyl alcohol ( $\square$ ); selectivity for 2-methylbenzaldehyde $(\Delta)$; and selectivity for combined amount of $o$-xylene and toluene $(\diamond)$ at $6-7 \mathrm{~h}$ after the start of the reaction.

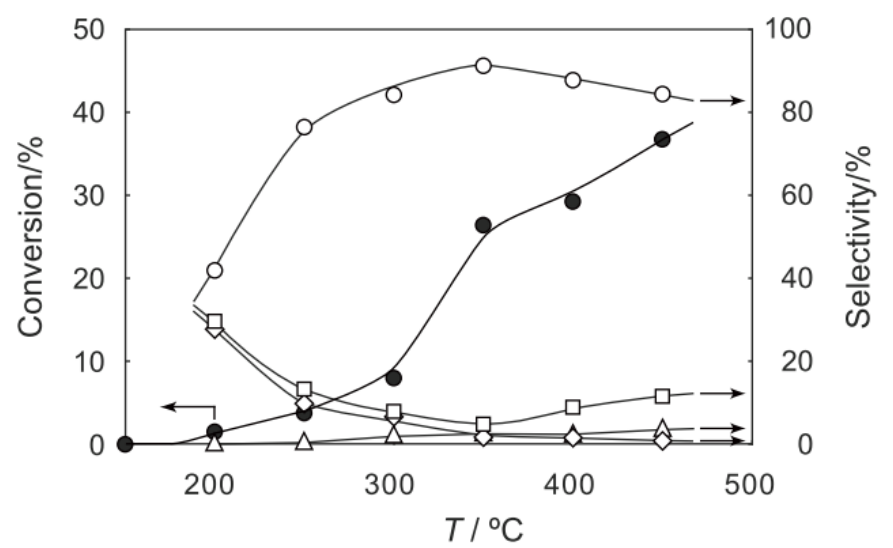

Some halide clusters and related compounds were applied to this reaction at $350{ }^{\circ} \mathrm{C}$. Supported niobium, tantalum, and tungsten halide clusters catalyzed the cyclization at 15-21 conversion with a selectivity of $81 \%-90 \%$. Unsupported crystalline niobium clusters also catalyzed the reaction with $69 \%$ selectivity, regardless of the low activity ( $3.3 \%$ conversion). In contrast, the selectivity was not so high over a supported molybdenum cluster (12\% conversion with $51 \%$ selectivity), which has platinum-like character to activate hydrogen, to yield the hydrogenolysis product 2-methylbenzylalcohol with $36 \%$ selectivity.

Some $\alpha, \delta$-disubstituted compounds were allowed to react, and the results are listed in Table 9. cis-1,2-Cyclohexanedimethanol, 1,4-butanediol, and 2-hydroxyphenethyl alcohol afforded the corresponding 
cyclization products selectively, although they have $\alpha$-hydrogens to yield olefins. On the other hand, cis-2-butene-1,4-diol scarcely afforded the corresponding cyclization product. Halide cluster catalyzes isomerization of olefins (Section 3.2), and hence most of the reactant would be changed to 4-hydroxybutylaldehyde followed by decomposition at high temperature. As Table 9 shows, 2-aminophenethyl alcohol exclusively produced 2,3-dihydroindole. In $\mathrm{N}$-alkylation of amines with alcohols over halide-cluster catalysts, the $\mathrm{C}-\mathrm{O}$ bonds of the alcohols were cleaved (Section 4.2). Not the $\mathrm{C}-\mathrm{N}$ but the $\mathrm{C}-\mathrm{O}$ bond of 2-aminophenethyl alcohol was cleaved in this case as well. Formation of a new stable $\mathrm{O}-\mathrm{H}$ bond, with resulting evolution of $\mathrm{H}_{2} \mathrm{O}$, is driving force for the formation of cyclic amines.

Table 9. Intramolecular cyclization over $\left[\left(\mathrm{Nb}_{6} \mathrm{Cl}_{12}\right) \mathrm{Cl}_{2}\left(\mathrm{H}_{2} \mathrm{O}\right)_{4}\right] \cdot 4 \mathrm{H}_{2} \mathrm{O} / \mathrm{SiO}_{2}{ }^{\mathrm{a}}$.

\begin{tabular}{|c|c|c|c|}
\hline Reactant & Conversion (\%) & Product & Selectivity (\%) \\
\hline (O) $\mathrm{OH}$ & 26.3 & & 91.0 \\
\hline & 100.0 & & 98.9 \\
\hline & 99.7 & & 1.1 \\
\hline & 99.9 & & 99.9 \\
\hline & 9.7 & & $73.0(1.7)$ \\
\hline & 100.0 & & $96.9(2.3)$ \\
\hline & 99.6 & & $94.3(4.5)$ \\
\hline $\mathrm{SH}_{\mathrm{SH}}$ & 56.8 & & $61.8(10.9)$ \\
\hline
\end{tabular}

\footnotetext{
${ }^{\text {a }}$ After activation of cluster $(10 \mathrm{mg}, 0.42 \mu \mathrm{mol})$ in a helium stream $(600 \mathrm{~mL} / \mathrm{h})$ at $350{ }^{\circ} \mathrm{C}$ for $1 \mathrm{~h}$, reaction was started by introduction of the reactant $(0.50 \mathrm{mmol} / \mathrm{h})$ to the helium stream without changing the temperature. Solvents such as water and tetrahydrofuran are used appropriately to introduce the reactants. At 6-7 $\mathrm{h}$ after the start of the reaction. Values shown in parentheses are the corresponding dehydrogenation products: benzofuran, indole, isoindole, and 2-benzothiophene, respectively.
}

When 1,2-benzenedimethaneamine was applied to the reaction, cyclization proceeded to yield isoindoline with $94 \%$ selectivity. 1,2-Benzenedimethanethiol afforded the cyclization product 1,2-dihydrothiophene with $62 \%$ selectivity. There have been many reports on the catalytic cyclization of 1,2-benzenedimethanol; however, as far as we know, there is no report on the catalytic cyclization of 1,2-benzenedimethaneamine or 1,2-benzenedimethanethiol. Thus, halide clusters exhibit unique functional group-insensitive and reactant structure-sensitive catalysts for intramolecular condensation to yield heterocyclic compounds.

We have attempted to expand the scope of this catalysis using simple $\alpha, \omega$-disubstituted aliphatic compounds containing $-\mathrm{OH},-\mathrm{SH}$, or $-\mathrm{NH}_{2}$ groups as reactants (Scheme 4). The cyclization of $\mathrm{HR}\left(\mathrm{CH}_{2}\right)_{n} \mathrm{RH}(\mathrm{R}=\mathrm{O}, \mathrm{S}$ or $\mathrm{NH} ; n=4-6)$ to $\left(\mathrm{CH}_{2}\right)_{n} \mathrm{R}$, with the elimination of $\mathrm{H}_{2} \mathrm{R}$, proceeded selectively over halide cluster catalysts at $\geq 200{ }^{\circ} \mathrm{C}[176]$. 
Scheme 4. Ring closure reactions to yield heterocyclic compounds.
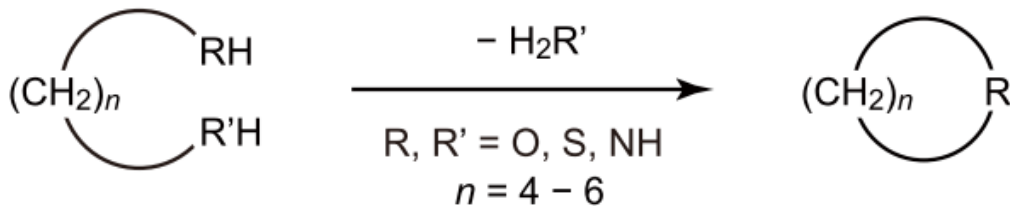

\section{Various Reactions}

\subsection{Isomerization of Diethylbenzene (Equation (15)) [177]}

Much literature has appeared on the catalytic ring-attachment isomerization of $o$ - and $m$-xylenes and the catalytic intermolecular transalkylation (disproportionation) of toluene to produce p-xylene $[90,178,179]$, which is used in its oxidation to form terephthalic acid. Mordenite and ZSM-5 are currently the best catalysts for those catalytic reactions [180-182]. On the other hand, very little has been reported on the reactions of diethylbenzenes, even though $p$-diethylbenzene is an industrial source of $p$-divinylbenzene. Diethylbenzenes disproportionated over solid catalysts, similarly. When Y-zeolite mixed with $\mathrm{SiO}_{2}-\mathrm{Al}_{2} \mathrm{O}_{3}$ was employed as a catalyst in a neat liquid of $o-, m$, or $p$-diethylbenzene at $170{ }^{\circ} \mathrm{C}$, disproportionation occurred, affording ethylbenzene and 1,2,4-triethylbenzene. Although small yields of $o-, m-$, and $p$-diethylbenzenes were formed, they were the secondary disproportionation products from ethylbenzene and 1,2,4-triethylbenzene [183]. Disproportionation of ethylbenzene to afford benzene and $m$ - and $p$-diethylbenzenes was reported over a ZSM-5 catalyst without yielding $o$-diethylbenzene [184].

Generally, in large-pore zeolites, such as Y-zeolites and mordenite, side chains disproportionate by way of bimolecular transalkylation. Conversely, in medium pore zeolites, such as ZSM-5, disproportionation proceeds by way of successive dealkylation and realkylation [185]. Thus, ring-attached ethyl groups do not migrate around the aromatic ring by an intramolecular 1,2-shift mechanism over conventional heterogeneous solid acid catalysts.

When crushed crystals of $\left(\mathrm{H}_{3} \mathrm{O}\right)_{2}\left[\left(\mathrm{Mo}_{6} \mathrm{Cl}_{8}\right) \mathrm{Cl}_{6}\right] \cdot 6 \mathrm{H}_{2} \mathrm{O}(150-200$ mesh) were activated in a stream of hydrogen for $1 \mathrm{~h}$, and then allowed to react with $p$-diethylbenzene, a catalytic reaction proceeded. The effect of temperature is shown in Figure 25 . Reactions above $200{ }^{\circ} \mathrm{C}$ showed substantial catalytic activity. At $300{ }^{\circ} \mathrm{C}$, the main reaction occurring was dehydrogenation (Equation (31)) to yield p-ethylstyrene in $90 \%$ selectivity. However, at $400-475{ }^{\circ} \mathrm{C}$ this changed to ring-attachment isomerization (Equation (32)) to afford $m$-diethylbenzene. At $400{ }^{\circ} \mathrm{C}, m$-diethylbenzene was formed with $74 \%$ selectivity, with a smaller yield of $o$-diethylbenzene in $8 \%$ selectivity. Dealkylation of the side chains (Equation (33)) to yield ethylbenzene and benzene and dehydrogenation (Equation (31)) to yield $p$-ethylstyrene proceeded to a small extent. However, no disproportionation (Equation (34)) to yield triethylbenzenes was observed. At higher temperatures, near $500{ }^{\circ} \mathrm{C}$, dealkylation of the side chain (Equation (33)) proceeded more to completion with increasing temperature, yielding ethylbenzene and benzene. Thus, selectivity depended strongly on temperature.

Dehydrogenation:

$$
\mathrm{Et}-\mathrm{C}_{6} \mathrm{H}_{4}-\mathrm{Et} \rightarrow \mathrm{Et}-\mathrm{C}_{6} \mathrm{H}_{4}-\mathrm{CH}=\mathrm{CH}_{2}+\mathrm{H}_{2}
$$


Ring-attachment isomerization:

$p$-Et- $\mathrm{C}_{6} \mathrm{H}_{4}-\mathrm{Et} \rightarrow o$-Et- $\mathrm{C}_{6} \mathrm{H}_{4}-\mathrm{Et}+m-\mathrm{Et}-\mathrm{C}_{6} \mathrm{H}_{4}-\mathrm{Et}$

Dealkylation of the side chain (dealkylation of the ring attached alkyl):

$\mathrm{Et}-\mathrm{C}_{6} \mathrm{H}_{4}-\mathrm{Et} \rightarrow \mathrm{Et}-\mathrm{C}_{6} \mathrm{H}_{5}+\mathrm{C}_{2} \mathrm{H}_{4} \rightarrow \mathrm{C}_{6} \mathrm{H}_{6}+2 \mathrm{C}_{2} \mathrm{H}_{4}$

Intermolecular transalkylation (disproportionation):

$2 \mathrm{Et}-\mathrm{C}_{6} \mathrm{H}_{4}-\mathrm{Et} \rightarrow \mathrm{Et}-\mathrm{C}_{6} \mathrm{H}_{5}+\mathrm{C}_{6} \mathrm{H}_{3} \mathrm{Et}_{3}$

Reductive dealkylation (hydrogenolysis ):

$\mathrm{Et}-\mathrm{C}_{6} \mathrm{H}_{4}-\mathrm{Et}+\mathrm{H}_{2} \rightarrow \mathrm{Et}-\mathrm{C}_{6} \mathrm{H}_{4}-\mathrm{Me}+\mathrm{C}_{6} \mathrm{H}_{5}-\mathrm{Et}+\mathrm{C}_{6} \mathrm{H}_{5}-\mathrm{Me}+\mathrm{C}_{6} \mathrm{H}_{6}+\mathrm{CH}_{4}+\mathrm{C}_{2} \mathrm{H}_{6}$

Figure 25. Effect of temperature on the reactivity of $p$-diethylbenzene and product distribution over $\left(\mathrm{H}_{3} \mathrm{O}\right)_{2}\left[\left(\mathrm{Mo}_{6} \mathrm{Cl}_{8}\right) \mathrm{Cl}_{6}\right] \cdot 6 \mathrm{H}_{2} \mathrm{O}$. After activation of the cluster $(200 \mathrm{mg}, 163 \mu \mathrm{mol})$ in a stream of hydrogen $(300 \mathrm{~mL} / \mathrm{h})$ for $1 \mathrm{~h}$, the reaction was initiated by introducing p-diethylbenzene $(0.62 \mu \mathrm{L} / \mathrm{h}, 0.40 \mathrm{mmol} / \mathrm{h})$ to the stream without changing the temperature. Conversion of $p$-diethylbenzene $(\bullet)$; selectivity for $m$-diethylbenzene $(\boldsymbol{\bullet})$; selectivity for $o$-diethylbenzene $(\boldsymbol{\Delta})$; selectivity for $p$-ethylstyrene $(0)$; selectivity for benzene $(\Delta)$; and selectivity for ethylbenzene ( $\square$ ); at $4 \mathrm{~h}$ after the start of the reaction.

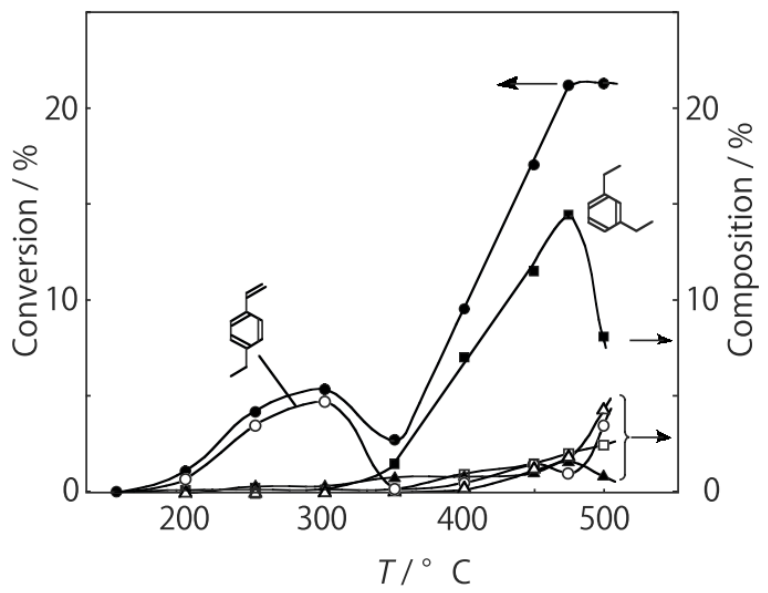

The effect of the activation and reaction temperature was examined. When a $400{ }^{\circ} \mathrm{C}$ activation of $\left(\mathrm{H}_{3} \mathrm{O}\right)_{2}\left[\left(\mathrm{Mo}_{6} \mathrm{Cl}_{8}\right) \mathrm{Cl}_{6}\right] \cdot 6 \mathrm{H}_{2} \mathrm{O}$ was applied to the reaction at $300{ }^{\circ} \mathrm{C}$, the selectivity was the same as that of $\left(\mathrm{H}_{3} \mathrm{O}\right)_{2}\left[\left(\mathrm{Mo}_{6} \mathrm{Cl}_{8}\right) \mathrm{Cl}_{6}\right] \cdot 6 \mathrm{H}_{2} \mathrm{O}$ treated at $300{ }^{\circ} \mathrm{C}$ throughout (Figure 25). Hence, selectivity does not depend on activation temperature, but on reaction temperature. When the reaction gas was changed from hydrogen to helium under identical conditions, catalytic activity decreased noticeably, and its selectivity changed. Dehydrogenation yielding $p$-ethylstyrene (59\% selectivity) replaced isomerization to yield $m$-diethylbenzene ( $77 \%$ selectivity) as the main reaction, indicating that hydrogen plays an important role in the reaction.

A halide cluster of tungsten, $\left(\mathrm{H}_{3} \mathrm{O}\right)_{2}\left[\left(\mathrm{~W}_{6} \mathrm{Cl}_{8}\right) \mathrm{Cl}_{6}\right] \cdot 6 \mathrm{H}_{2} \mathrm{O}$, exhibited almost the same catalytic activity and selectivity with $\left(\mathrm{H}_{3} \mathrm{O}\right)_{2}\left[\left(\mathrm{Mo}_{6} \mathrm{Cl}_{8}\right) \mathrm{Cl}_{6}\right] \cdot 6 \mathrm{H}_{2} \mathrm{O}$. On the other hand, a halide cluster of tantalum, $\left[\left(\mathrm{Ta}_{6} \mathrm{Cl}_{12}\right) \mathrm{Cl}_{2}\left(\mathrm{H}_{2} \mathrm{O}\right)_{4}\right] \cdot 4 \mathrm{H}_{2} \mathrm{O}$, selectively catalyzed the dehydrogenation to yield $p$-ethylstyrene and a small quantity of $p$-divinylbenzene. A cluster of niobium, $\left[\left(\mathrm{Nb}_{6} \mathrm{Cl}_{12}\right) \mathrm{Cl}_{2}\left(\mathrm{H}_{2} \mathrm{O}\right)_{4}\right] \cdot 4 \mathrm{H}_{2} \mathrm{O}$, showed intermediate selectivity with respect to the above clusters, forming both $m$-dimethylbenzene and $p$-ethylstyrene in significant quantities. 
Some $p$-substituted benzenes such as $p$-xylene, $p$-ethyltoluene, and $p$-propyltoluene were reacted over $\left(\mathrm{H}_{3} \mathrm{O}\right)_{2}\left[\left(\mathrm{Mo}_{6} \mathrm{Cl}_{8}\right) \mathrm{Cl}_{6}\right] \cdot 6 \mathrm{H}_{2} \mathrm{O}$ under hydrogen at $400{ }^{\circ} \mathrm{C}$. All substrates tested yielded the corresponding $m$-isomer as the main product by ring-attachment isomerization. Three diethylbenzene isomers were reacted over $\left(\mathrm{H}_{3} \mathrm{O}\right)_{2}\left[\left(\mathrm{Mo}_{6} \mathrm{Cl}_{8}\right) \mathrm{Cl}_{6}\right] \cdot 6 \mathrm{H}_{2} \mathrm{O}$ at $400{ }^{\circ} \mathrm{C}$ to achieve similar conversions, with the main reaction being ring-attachment isomerization, although the selectivity for the isomerization decreased in the order $p^{-}>m$ - $>o$-isomer. Even traces of triethylbenzenes (Equation (34)) were not detected in all the reactions. The selectivities for mutual interconversion of the three isomers are illustrated in Figure 26. One of the most striking features of the reactions is that $o$-diethylbenzene afforded the $m$-isomer in a selectivity that was three times that of the $p$-isomer, even though from a thermodynamical point of view, the $p$-isomer is more stable than the $m$-isomer. $p$-Diethylbenzene yielded predominantly its $m$-isomer, which was only twice as abundant as the equilibrium composition, compared with the $o$-isomer. On the other hand, the $m$-isomer afforded the sterically hindered $o$-isomer more abundantly than expected from the equilibrium composition, when compared with the formation of the $p$-isomer. Consequently, the ethyl group preferentially migrated to the neighboring position of the aromatic ring, irrespective of the equilibrium distribution.

Figure 26. Isomerization of diethylbenzenes over $\left(\mathrm{H}_{3} \mathrm{O}\right)_{2}\left[\left(\mathrm{Mo}_{6} \mathrm{Cl}_{8}\right) \mathrm{Cl}_{6}\right] \cdot 6 \mathrm{H}_{2} \mathrm{O}$, showing the selectivity values (in \%) at $400{ }^{\circ} \mathrm{C}, 4 \mathrm{~h}$ after the reaction was initiated. The other conditions are the same as those described in the caption to Figure 25. The thickness of each arrow is proportional to the corresponding selectivity. The equilibrium compositions of diethylbenzenes in the vapor phase at $400{ }^{\circ} \mathrm{C}$ are shown in brackets.

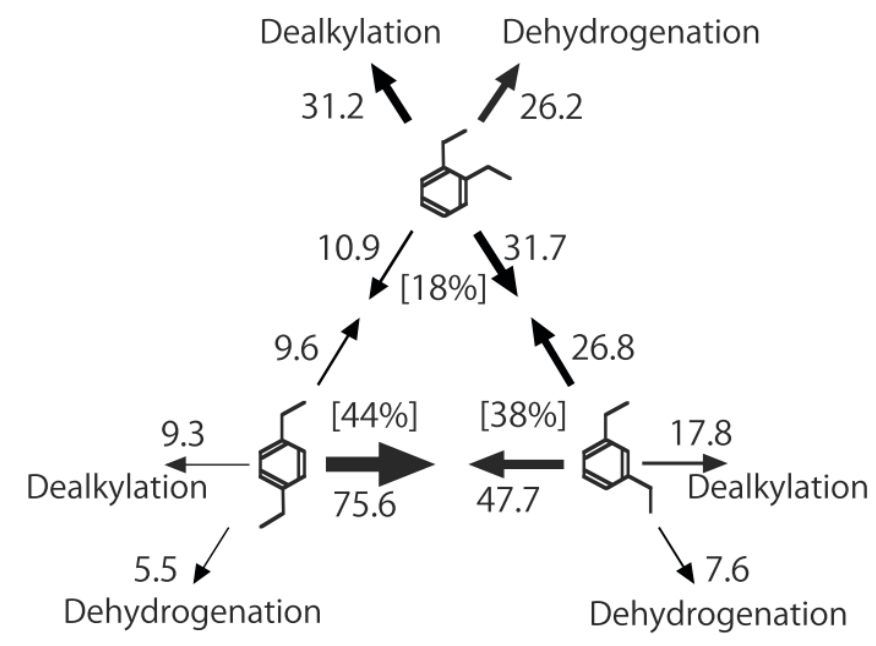

When a mixture of $p$-xylene and $p$-diethylbenzene was applied to the reaction, ring-attachment isomerization occurred to yield the corresponding $o$ - and $m$-isomers. However, the formation of $o$ - and $m$-ethyltoluenes, which would be expected from intermolecular alkyl transfer, was not detected. Furthermore, triethylbenzenes were not detected in any of the reactions. These results clearly demonstrate that the isomerization proceeded by way of an intramolecular 1,2-shift of the ethyl group around the aromatic ring. They are distinct from conventional strong acids. The catalytic disproportionation of ethylbenzene in the presence of $\mathrm{AlCl}_{3}$ yielded benzene, $m$ - and $p$-diethylbenzenes, and 1,2,4-triethylbenzene [186]. In an $\mathrm{AlCl}_{3}-\mathrm{HCl}$ catalytic system, the disproportionation of $\mathrm{m}$ and $p$-diethylbenzenes proceeded to yield ethylbenzene and 1,2,4-triethylbenzene [187]. A protic 
acid, $\mathrm{CF}_{3} \mathrm{COOH}$, also catalyzed the disproportionation of $m$-diethylbenzene to yield ethylbenzene and 1,2,4-triethylbenzene by an ethylcarbenium rearrangement [188]. All of these catalytic reactions were disproportionations. The disproportionation of trimethylbenzenes and toluene has been reported to occur on stronger acid sites, while the isomerization of trimethylbenzenes and xylenes have been reported to predominate on weaker acid sites [189]. In the case of the cluster catalysis, it would be difficult to abstract the ethyl substituent as an ethyl cation intermediate, because the charge density of the counter cluster anion is too low to stabilize the ethyl cation [1]. The isomerizations over cluster catalysts were always accompanied by an appreciable yield of dealkylation products, particularly over Group 6 metal clusters (Figure 26). Atmospheric hydrogen, as well as alkyl hydrogen, was activated over these cluster catalysts (Section 2.1 and 2.2), and used to carry out hydrogenolyses (Equation (35)), which have been reported over platinum group metal catalysts.

Conclusively, the halide clusters developed catalytic activity above $200{ }^{\circ} \mathrm{C}$ for $p$-diethylbenzene. The activity depended on reaction temperature, with dehydrogenation, ring-attachment isomerization, and dealkylation increasing with increasing temperature. At $400-475{ }^{\circ} \mathrm{C}$, halide clusters exhibited a characteristic selective ring-attachment isomerization of diethylbenzenes by the intramolecular 1,2-shift mechanism without yielding disproportionation products. They are distinct from conventional strong acids, isomerization of which is based on a disproportionation mechanism. Another characteristic feature of halide cluster catalysis is that the halide clusters have no micropore structures and, hence, they can be used to catalyze $o$-diethylbenzene, which is too large to enter the pores of zeolite $\mathrm{Y}$ and ZSM-5.

\subsection{Reaction of Aliphatic Amine (Equation (16)) [190]}

Catalytic dehydrogenation of amines has been investigated extensively, and the dehydrogenation of primary amines usually gives the corresponding nitriles. Sometimes, an $N$-substituted Schiff base can be obtained by dehydrogenation followed by condensation with the amine: benzylamine is converted to $\mathrm{N}$-benzylidenebenzylamine over Mo-V-heteropoly acid in the presence of dioxygen [191]. On the other hand, catalytic dehydrogenation without oxidizing reagents is rare: molten $\mathrm{Zn}$ or $\mathrm{Ga}$ metal [192] and Ga-MFI zeolite [193] have been used as catalysts in gas-phase reactions. There are several reports on the catalytic and stoichiometric dehydrogenation of activated secondary amines, $\mathrm{Ar}-\mathrm{CH}_{2}-\mathrm{NH}-\mathrm{R}(\mathrm{Ar}=$ aryl, $\mathrm{R}=$ alkyl or aryl). In this case the dehydrogenation product is unique, and hence, selective reaction can be readily achieved as long as $\mathrm{C}-\mathrm{N}$ bond cleavage does not occur. In contrast, reports on aliphatic secondary and tertiary amines are few, particularly in the gas phase.

The powdered crystals of $\left(\mathrm{H}_{3} \mathrm{O}\right)_{2}\left[\left(\mathrm{Mo}_{6} \mathrm{Cl}_{8}\right) \mathrm{Cl}_{6}\right] \cdot 6 \mathrm{H}_{2} \mathrm{O}$ were activated in a stream of hydrogen or helium for $1 \mathrm{~h}$. The reaction was started by introducing diethylamine into the stream without changing the temperature. The effect of the reaction temperature is presented in Figure 27. Under hydrogen, the reactivity increased with increasing temperature. At lower temperatures below $300{ }^{\circ} \mathrm{C}$, disproportionation yielding ethylamine and triethylamine was predominant; at higher temperatures at $400-450{ }^{\circ} \mathrm{C}$ dehydrogenation providing $N$-ethylideneethylamine was the main reaction $\left(72 \%\right.$ selectivity at $400{ }^{\circ} \mathrm{C}$ ). Under helium the catalytic activity was about half that under hydrogen. Hydrogen would prevent dealkylation and the deposition of coke on the active sites $[15,16]$. Under helium, dealkylation yielding ethylamine was noticeable at lower temperatures below $300{ }^{\circ} \mathrm{C}$, and at higher temperatures above 
$350{ }^{\circ} \mathrm{C}$, dehydrogenation yielding $N$-ethylideneethylamine was predominant with a maximum $69 \%$ selectivity at $425{ }^{\circ} \mathrm{C}$. Tungsten cluster similarly dehydrogenated to produce $N$-ethylideneethylamine with $62 \%$ selectivity at $400{ }^{\circ} \mathrm{C}$ under hydrogen.

Figure 27. Effect of temperature on reactivity and product selectivity of diethylamine over $\left(\mathrm{H}_{3} \mathrm{O}\right)_{2}\left[\left(\mathrm{Mo}_{6} \mathrm{Cl}_{8}\right) \mathrm{Cl}_{6}\right] \cdot 6 \mathrm{H}_{2} \mathrm{O}$ in a (a) hydrogen; and (b) helium stream. Following activation of the cluster $(30 \mathrm{mg}, 25 \mu \mathrm{mol})$ in the gas stream $(600 \mathrm{~mL} / \mathrm{h})$ for $1 \mathrm{~h}$, reaction was started by introduction of diethylamine $(0.20 \mathrm{~mL} / \mathrm{h}, 1.9 \mathrm{mmol} / \mathrm{h})$ to the stream without changing the temperature. Conversion and selectivities are based on diethylamine at $3 \mathrm{~h}$ after reaction started.
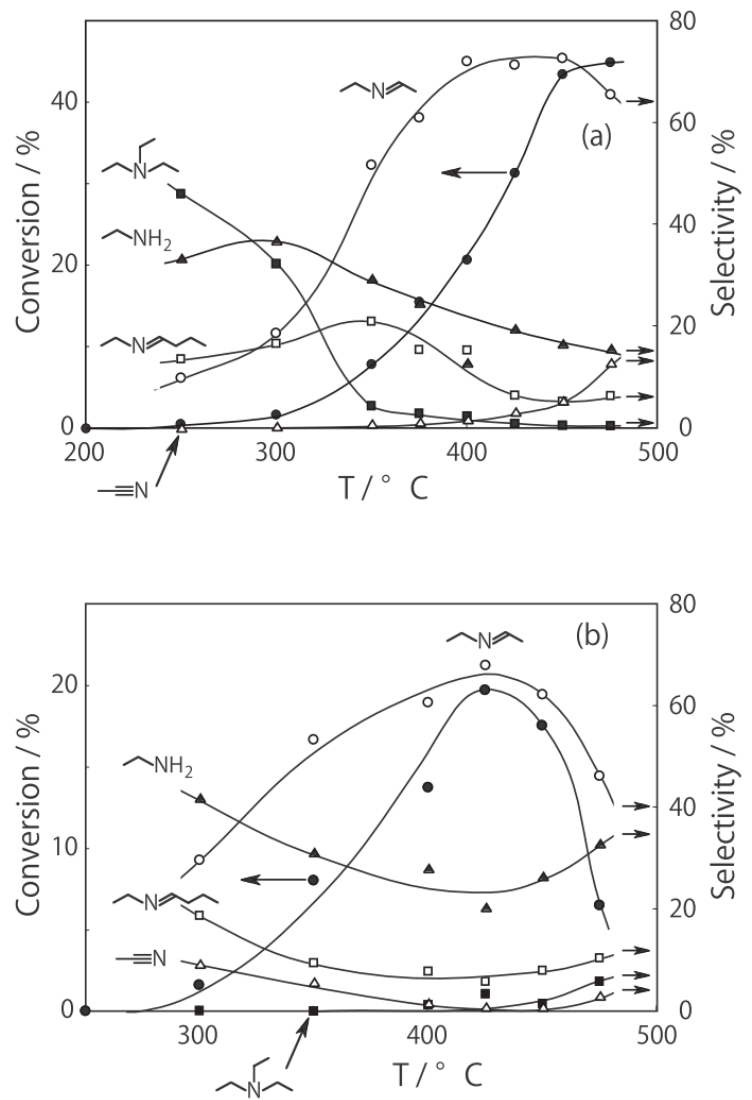

The Group 5 metal clusters preferentially dealkylated diethylamine to yield ethylamine and its dehydrogenation product acetonitrile (44\%-59\% selectivity under both hydrogen and helium) in conjunction with the transalkylation product triethylamine with more than $12 \%$ selectivity. Aliphatic amines usually afford diverse products in catalysis; hence, there are few reports on selective reactions.

The catalytic activity of $\left(\mathrm{H}_{3} \mathrm{O}\right)_{2}\left[\left(\mathrm{Mo}_{6} \mathrm{Cl}_{8}\right) \mathrm{Cl}_{6}\right] \cdot 6 \mathrm{H}_{2} \mathrm{O}$ for some primary amines was examined at $400{ }^{\circ} \mathrm{C}$. Ethylamine was exclusively dehydrogenated to acetonitrile and $N$-ethylideneethylamine. The latter, a Schiff base, would be produced by condensation of ethylamine with ethylideneamine, which is a dehydrogenation intermediate to acetonitrile (Equation (36)) [194].

$$
\mathrm{EtNH}_{2}+\mathrm{MeCH}=\mathrm{NH} \rightarrow \mathrm{MeCH}=\mathrm{NEt}+\mathrm{NH}_{3}
$$

Butylamine gave the dehydrogenation product butyronitrile with more than $80 \%$ selectivity and with a small amount of the condensation product $N$-butylidenebutylamine. Thus, the cluster 
selectively catalyzed dehydrogenation of primary amines to give the corresponding nitriles with their condensation products, Schiff bases. Many catalysts have been applied to aliphatic primary amines. Basic metal oxides, $\mathrm{ZrO}_{2}$ and $\mathrm{MgO}$, selectively dehydrogenate primary amines to yield the corresponding nitriles [195]. Solid acids exhibit various activities: $\mathrm{Al}_{2} \mathrm{O}_{3}$ catalyzes transalkylation, dehydrogenation, condensation, and deamination nonselectively [196,197]. Another report states that $\mathrm{Al}_{2} \mathrm{O}_{3}$ deaminates ethylamine [198] and various aliphatic primary amines [194] to give olefins with ammonia. H-MFI and Ga-MFI zeolites catalyze transalkylation of propylamine to provide dipropylamine. In-MFI further catalyzes dehydrogenation to give dipropylamine and $N$-propylidenepropylamine. $\mathrm{Cu}-\mathrm{MFI}$ catalyzes $\mathrm{C}-\mathrm{C}$ coupling of the alkyl substituents of propylamine and dehydrogenation to yield 2-methylpentanenitrile and propiononitrile as the major products [193,199].

The secondary amines, diethylamine and dibutylamine, selectively gave dehydrogenation products (imines) in a hydrogen stream over $\left(\mathrm{H}_{3} \mathrm{O}\right)_{2}\left[\left(\mathrm{Mo}_{6} \mathrm{Cl}_{8}\right) \mathrm{Cl}_{6}\right] \cdot 6 \mathrm{H}_{2} \mathrm{O}$, although dealkylation proceeded in a helium stream at $400{ }^{\circ} \mathrm{C}$. Several catalytic reactions of aliphatic secondary amines have been reported. Diethylamine is dehydrogenated to $\mathrm{N}$-ethylideneethylamine at $350{ }^{\circ} \mathrm{C}$ over Mo-heteropoly acid [197]. Solid acid $\mathrm{Al}_{2} \mathrm{O}_{3}$ [196] and W-heteropoly acid [200] nonselectively catalyzes dealkylation, dehydrogenation, and disproportionation. Another report mentions that $\mathrm{SiO}_{2}-\mathrm{Al}_{2} \mathrm{O}_{3}$ dealkylates and that acid-base bifunctional catalysts, such as $\mathrm{SiO}_{2}-\mathrm{Al}_{2} \mathrm{O}_{3} / \mathrm{MgO}$ and $\mathrm{ZrO}_{2}$, selectively transform diethylamine into acetonitrile [195]. To the best of our knowledge, the successful application of the platinum metal catalysts to give normal alkylimines has not been reported. Thus, dehydrogenation selectivity of the cluster catalyst for secondary aliphatic amines differs from that of conventional acid or base catalysts but is similar to that of the Mo-heteropoly acid, which is characterized by very weak basicity, great softness, and a large polyhedral anion structure [201].

Tertiary amines were allowed to react over $\left(\mathrm{H}_{3} \mathrm{O}\right)_{2}\left[\left(\mathrm{Mo}_{6} \mathrm{Cl}_{8}\right) \mathrm{Cl}_{6}\right] \cdot 6 \mathrm{H}_{2} \mathrm{O}$ at $400{ }^{\circ} \mathrm{C}$. In the case of triethylamine, dealkylation and successive dehydrogenation yielded diethylamine and $N$-ethylideneethylamine as the major products. The combined selectivity for the monodealkylation and the following dehydrogenation amount to $68 \%$ in a hydrogen stream and $55 \%$ in a helium stream. Dehydrogenation of trietylamine occurred also in the alkyl chain, yielding $N$-vinyldiethylamine with $21 \%-26 \%$ selectivity. Furthermore, tripropylamine and tributylamine gave the corresponding $N$-vinylamines as the main products in a hydrogen stream with 52 and $45 \%$ selectivity, respectively. There are only a few examples of the catalytic dealkylation or dehydrogenation of tertiary amines. When the acid catalyst $\mathrm{SiO}_{2}-\mathrm{Al}_{2} \mathrm{O}_{3}$ is applied to triethylamine, dealkylation proceeds nonselectively [195]. The base catalyst $\mathrm{MgO}$ dealkylates and dehydrogenates triethylamine to nonselectively give diethylamine, ethylamine, and acetonitrile, whereas the acid-base bifunctional catalyst $\mathrm{SiO}_{2}-\mathrm{Al}_{2} \mathrm{O}_{3} / \mathrm{MgO}$ selectively converts triethylamine to acetonitrile [195]. Consequently, selective dealkylation of trialkylamine to dialkylamine has not yet been achieved. Furthermore, the formation of even a trace amount of $N$-vinyldialkylamine over solid catalysts has not been reported.

One of the active sites on the molybdenum and tungsten clusters is coordinatively unsaturated or, more likely, hydrido ligand coordinated Mo and $\mathrm{W}$ atoms, which behave like the platinum group metals [1]. There are many reports on Group 8-10 transition metals for the exhaustive dehydrogenation of alicyclic amines. However, no reports of success with $n$-alkyl amines have been published, presumably because of their high activity, leading to polyunsaturated alkyl chains or their random 
cleavage. Hence, the characteristic features of the halide clusters to amines cannot be attributed to their similarity to the platinum group metals.

There are fewer cases of dehydrogenation of amines over heteropoly acid, one of which, 12-molybdophosphoric acid, catalyzed the selective dehydrogenation to yield $N$-ethylideneethylamine [200]. The selectivity is similar to that of the halide cluster catalysts. A heteropoly acid has several types of protons, one of which originates from coordinated water [202,203]. It has a Brønsted acid site, but no Lewis acid site [204]. The heteropoly anions are large and hence, have very low charge densities on their surface [205], as in the case of the large halide cluster anion.

The large anions would not participate in the reaction in either case. Consequently, the reaction proceeded by way of the protonated amines without interaction with the large counter-anions. On the other hand, alumina has been classified as a solid acid. However, it has both acidic and basic sites: incompletely coordinated aluminum ions (strong Lewis acids) and oxide ions (weak Lewis bases) [49-53]. Similarly, solid bases such as $\mathrm{MgO}$ [206] and hematite $\left(\alpha-\mathrm{Fe}_{2} \mathrm{O}_{3}\right)$ [207] have both basic sites as oxide ions and acidic surface sites as $\mathrm{Mg}^{2+}, \mathrm{Fe}^{3+}$, and $\mathrm{Fe}-\mathrm{OH}$. All of these sites are small and have high charge densities with participation in the reactions.

In summary, when the halide clusters were treated above $300{ }^{\circ} \mathrm{C}$, the catalytic activity for dehydrogenation of aliphatic amines developed. Primary amines were dehydrogenated to the corresponding nitriles, some of which condensed to the alkylidenealkylamines. Secondary aliphatic amines were dehydrogenated to the corresponding imines. Tertiary amines were dealkylated to dialkylamines, which was followed by dehydrogenation to $\mathrm{N}$-alkylidenealkylamines, or directly dehydrogenated to $N$-vinyldialkylamines. These selectivities were different from conventional catalysts, such as solid acid-base catalysts or the Group 8-10 transition metals. Spontaneous degradation of the protonated amine at high temperature without interaction with the large cluster counter-anion would be the driving force for these reactions. The initial step of the reactions is simple: from protonated amine, nitrogen-bonded hydrogens are removed completely to yield nitrile or imine; when there is no such hydrogen, either a neighboring hydrogen or the nitrogen-bonded alkyl group is removed to yield vinylamine or alkylideneamine.

\subsection{Beckmann Rearrangement (Equation (17)) [208]}

The Beckmann rearrangement is used for the industrial synthesis of azepan-2-one ( $\varepsilon$-caprolactam), which is the starting material for nylon 6 . The rearrangement is performed in the liquid phase by using an excess amount of fuming sulfuric acid as a promoter, followed by neutralization of the acid with ammonia [209]. This process has serious disadvantages such as corrosion of equipment by the strong acid and by-production of a large amount of ammonium sulfate. To circumvent these issues, alternative catalytic vapor-phase Beckmann rearrangements have been developed by using solid acids such as silica-alumina [210], boria [211], and $\mathrm{Ta}_{2} \mathrm{O}_{5} / \mathrm{SiO}_{2}$ [212]. Various zeolites such as $\mathrm{HNaY}$ [213], H-USY [214], H-beta [215], H-MCM-41, H-FSM-16 [216], and MFI [214,215] have also been applied to the reaction, and the weak acidity of these catalysts is reported to be favorable for the reaction [215,216]. Then, application of halide cluster catalysts to the Beckmann rearrangement was made. 
The supported tungsten cluster, $\left(\mathrm{H}_{3} \mathrm{O}\right)_{2}\left[\left(\mathrm{~W}_{6} \mathrm{Cl}_{8}\right) \mathrm{Cl}_{6}\right] \cdot 6 \mathrm{H}_{2} \mathrm{O} / \mathrm{SiO}_{2}$, was activated at an elevated temperature in a helium stream for $1 \mathrm{~h}$. The reaction was initiated by introduction of a methanol solution of cyclohexanone oxime into the helium stream without changing the temperature. The effect of the reaction temperature on activity and selectivity is shown in Figure 28. The catalytic activity significantly developed above $250{ }^{\circ} \mathrm{C}$. At $300{ }^{\circ} \mathrm{C}$, the conversion was $91 \%$ and the selectivity for $\varepsilon$-caprolactam was as high as $93 \%$. Cyclohexanone, 2-cyclohexen-1-one, hexanenitrile, and hex-5-enenitrile were formed as by-products, and these by-products are also formed in the Beckmann rearrangement over acidic zeolites [214-219]. Assuming that all the cluster molecules were active, the turnover frequency per cluster unit at $300{ }^{\circ} \mathrm{C}$ during a period of $2-4 \mathrm{~h}$ was $0.85 \mathrm{~s}^{-1}$, which is a very large value for a molecular catalyst. Above $400{ }^{\circ} \mathrm{C}$, selectivity for $\varepsilon$-caprolactam decreased $(<22 \%)$, and decomposition products such as the nitriles were increased $(>60 \%)$. A similar increase in the decomposition above $400{ }^{\circ} \mathrm{C}$ has been observed in the rearrangement over HY [220] and B-MFI [218]. When the supported cluster was activated at $400{ }^{\circ} \mathrm{C}$ and the reaction was performed at $300{ }^{\circ} \mathrm{C}$, the selectivity for $\varepsilon$-caprolactam was $93 \%$, indicating the dependence of the reaction temperature.

Figure 28. Effect of temperature on the reaction of cyclohexanone oxime over $\left(\mathrm{H}_{3} \mathrm{O}\right)_{2}\left[\left(\mathrm{~W}_{6} \mathrm{Cl}_{8}\right) \mathrm{Cl}_{6}\right] \cdot 6 \mathrm{H}_{2} \mathrm{O} / \mathrm{SiO}_{2}$ in a helium stream. Supported cluster $(10 \mathrm{mg}, 0.29 \mu \mathrm{mol})$ were activated in a helium stream $(1.2 \mathrm{~L} / \mathrm{h})$ for $1 \mathrm{~h}$, and a methanol solution of cyclohexanone oxime $(17 \mathrm{~mol} \%, 200 \mu \mathrm{L} / \mathrm{h}, 0.65 \mathrm{mmol} / \mathrm{h})$ was introduced into the helium stream without changing the temperature. Conversion of cyclohexanone oxime $(\bullet)$; selectivity for $\varepsilon$-caprolactam $(\circ)$; selectivity for cyclohexanone and 2-cyclohexen-1-one $(\Delta)$; and selectivity for decomposition products including hexanenitrile and hex-5-enenitrile $(\square)$; at $3 \mathrm{~h}$ after the start of the reaction.

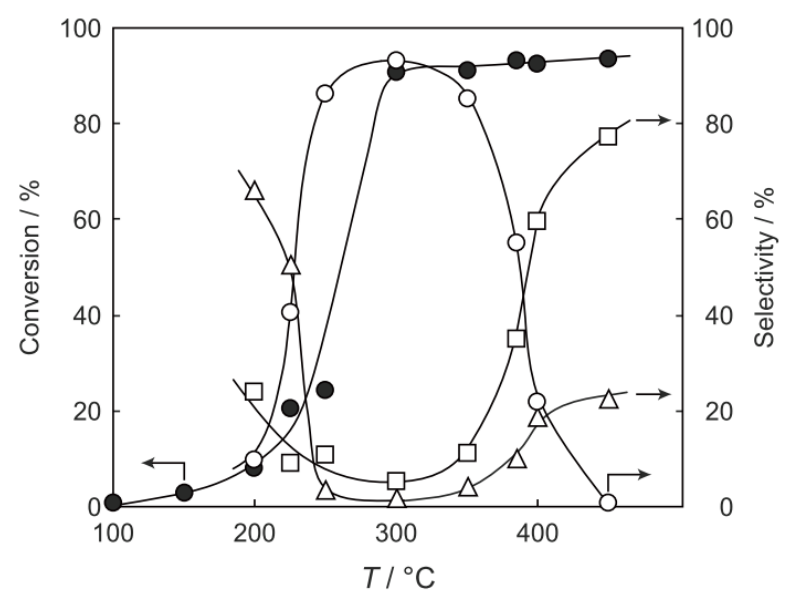

Supported clusters of niobium and tantalum were also active catalysts for the reaction. When acetone oxime was allowed to react over $\left(\mathrm{H}_{3} \mathrm{O}\right)_{2}\left[\left(\mathrm{~W}_{6} \mathrm{Cl}_{8}\right) \mathrm{Cl}_{6}\right] \cdot 6 \mathrm{H}_{2} \mathrm{O} / \mathrm{SiO}_{2}$ at $300{ }^{\circ} \mathrm{C}, N$-methylacetamide was obtained with $76 \%$ selectivity. Cyclopentanone oxime was also converted to piperidin-2-one ( $\delta$-valerolactam) with $81 \%$ selectivity. Thus, the halide clusters were effective catalysts for the Beckmann rearrangement of various oximes.

The acid strength of $\left(\mathrm{H}_{3} \mathrm{O}\right)_{2}\left[\left(\mathrm{~W}_{6} \mathrm{Cl}_{8}\right) \mathrm{Cl}_{6}\right] \cdot 6 \mathrm{H}_{2} \mathrm{O} / \mathrm{SiO}_{2}$ that was activated at $300{ }^{\circ} \mathrm{C}$ for $1 \mathrm{~h}$ was determined using the butylamine titration method with various Hammett indicators. The cluster exhibited an equimolar amount of acid sites at $H_{0} \approx 1.3$ with an additional equimolar amount of acid 
sites at $H_{0} \approx 4.0-2.0$. The weak Brønsted acidity $\left(H_{0} \approx+1.3\right)$ of the hydroxo ligand, which is developed on the activated cluster [1], would be favorable for the rearrangement, since weak acids such as H-beta [215], H-MCM-41, and H-FSM-16 are reported to be effective catalysts for the Beckmann rearrangement [216]. On the other hand, HY and H-mordenite, having strong acid sites, exhibit low activity and low selectivity for the reaction [221]. Weak acid sites on $\mathrm{Ta}_{2} \mathrm{O}_{5} / \mathrm{SiO}_{2}$ and H-USY effectively catalyze the rearrangement, whereas strong acid sites on the catalysts accelerate formation of by-products [212,214]. The rearrangement over $\mathrm{HNaY}$ is catalyzed by weak acid sites with a $\mathrm{p} K_{\mathrm{a}}$ less than 1.5 , whereas the strong acid sites with a $\mathrm{p} K_{\mathrm{a}}$ less than -3.0 are not active for the reaction [213]. Over high-silica MFI, the catalytically active sites are ascribed to nest silanols with very weak acidity, which is undetectable by the temperature-programmed desorption of ammonia $\left(\mathrm{NH}_{3}\right.$-TPD) [217]. Thus, the weak acid sites of the hydroxo ligand on the halide clusters are favorable for the selective vapor-phase Beckmann rearrangement.

\subsection{Acylation of Thiol (Equation (18)) [222]}

Acylation of alcohols, phenols, amines, and thiols is a frequently used transformation in organic synthesis, and it provides an efficient and inexpensive means of protecting the groups in a multistep synthetic process. Acylation is mostly carried out by use of acid anhydrides or acyl chlorides in the presence of acid catalysts or basic reagents such as 4-(dimethylamino)pyridine, 4-pyrrolidinopyridine, pyridine, or tertiary amines [223]. Direct acylation with carboxylic acids in the absence of any reagents is the best method for performing the acylation reaction, as the atomic economy is high and only water is produced as a by-product. Another advantage is the relatively cheaper route for industrial purposes when compared with the use of acid anhydrides or acid chlorides. Although many catalytic acylations of alcohols, phenols, and amines with carboxylic acids have been reported, acylation of thiols with carboxylic acids is quite rare. The reactivity of thiol is very much lower than that of an alcohol or amine [224]. Although, acetyl chloride or acetic anhydride spontaneously reacts with benzenethiol to afford $S$-acetylation product at room temperature, acetic acid and methyl acetate did not afford even a trace amount of the thioacetate even in the presence of any catalyst. The single example reported is $S$-acetylation of benzenethiol with acetic acid: in a batch reaction system a mixture of benzenethiol and acetic acid at $110{ }^{\circ} \mathrm{C}$ for $8 \mathrm{~h}$ under neat conditions in the presence of $20 \mathrm{wt} \%$ of yttria-zirconia-based Lewis acid catalyst to yield $S$-phenyl thioacetate in $94 \%$ yield [225]. $S$-Acylation with carboxylic ester has not been reported.

As mentioned in Section 4.5, when alkyl acetates were applied to benzenethiol, selective $S$-alkylation or $S$-acetylation proceeded depending on the kind of the cluster catalyst (Equation (37)). Further investigation revealed a universally applicable simple and practical method for the acylation of both aliphatic and aromatic thiols with carboxylic acids or their esters over various solid acid catalysts that are stable above $200{ }^{\circ} \mathrm{C}$ (Equation (38)).

$$
\begin{gathered}
\mathrm{C}_{6} \mathrm{H}_{5} \mathrm{SH}+\mathrm{CH}_{3} \mathrm{COOR} \rightarrow \mathrm{C}_{6} \mathrm{H}_{5} \mathrm{SR}+\mathrm{C}_{6} \mathrm{H}_{5} \mathrm{SCOCH}_{3}\left(\mathrm{R}=\mathrm{CH}_{3}, \mathrm{C}_{2} \mathrm{H}_{5}, \mathrm{C}_{3} \mathrm{H}_{7}\right) \\
\mathrm{R}_{1} \mathrm{SH}+\mathrm{R}_{2} \mathrm{COOR}_{3} \rightarrow \mathrm{R}_{1} \mathrm{SCOR}_{2}+\mathrm{HOR}_{3} \\
\left(\mathrm{R}_{1}=\mathrm{C}_{5}-\mathrm{C}_{8} \text { alkyl, } \mathrm{C}_{6} \mathrm{H}_{5} ; \mathrm{R}_{2}=\mathrm{C}_{1}-\mathrm{C}_{4} \text { alkyl, } \mathrm{C}_{6} \mathrm{H}_{5} ; \mathrm{R}_{3}=\mathrm{H}, \mathrm{C}_{1}-\mathrm{C}_{3} \text { alkyl }\right)
\end{gathered}
$$


After activation of $\left(\mathrm{H}_{3} \mathrm{O}\right)_{2}\left[\left(\mathrm{Mo}_{6} \mathrm{Cl}_{8}\right) \mathrm{Cl}_{6}\right] \cdot 6 \mathrm{H}_{2} \mathrm{O} / \mathrm{SiO}_{2}$ at various temperatures in a hydrogen stream for $1 \mathrm{~h}$, reactions were started by introduction of a mixture of benzenethiol with acetic acid without changing the temperature. The effect of the temperature is presented in Figure 29. Practically no catalytic activity for the $S$-acetylation was observed below $150{ }^{\circ} \mathrm{C}$, although there was considerable spontaneous oxidative coupling of benzenethiol to yield diphenyl disulfide. Catalytic activity for the $S$-acetylation of benzenethiol to yield $S$-phenyl thioacetate developed above $200{ }^{\circ} \mathrm{C}$ and increased with increasing temperature. Over the temperature range $200-450{ }^{\circ} \mathrm{C}$, selectivity for $S$-phenyl thioacetate was more than $94 \%$. Side reactions were the coupling of benzenethiol yielding diphenyl sulfide and diphenyl disulfide. The turnover frequency per $\mathrm{Mo}_{6}$ cluster unit during a period of 2-4 h was $150 \mathrm{~h}^{-1}$, assuming that all of the cluster molecules were active.

Figure 29. Effect of temperature on the $S$-acetylation of benzenethiol with acetic acid over $\left(\mathrm{H}_{3} \mathrm{O}\right)_{2}\left[\left(\mathrm{Mo}_{6} \mathrm{Cl}_{8}\right) \mathrm{Cl}_{6}\right] \cdot 6 \mathrm{H}_{2} \mathrm{O} / \mathrm{SiO}_{2}$. Following the activation of the supported cluster (30 mg, $1.23 \mu \mathrm{mol})$ in a hydrogen stream $(300 \mathrm{~mL} / \mathrm{h})$ for $1 \mathrm{~h}$, reaction was initiated by introduction of a mixture of benzenethiol $(102 \mu \mathrm{L} / \mathrm{h}, 1.0 \mathrm{mmol} / \mathrm{h})$ and acetic acid (114 $\mu \mathrm{L} / \mathrm{h}, 2.0 \mathrm{mmol} / \mathrm{h})$ to the hydrogen stream without changing the temperature. Conversion of benzenethiol $(\bullet)$; selectivity for $S$-phenyl thioacetate (०); selectivity for diphenyl sulfide $(\Delta)$; and selectivity for diphenyldisulfide $(\square)$; at $3 \mathrm{~h}$ after the start of the reaction.

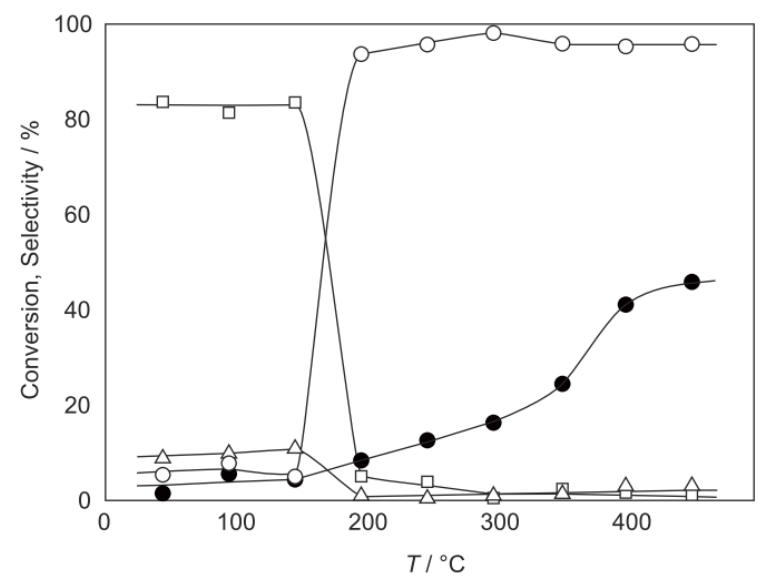

Various halide clusters were applied to $S$-acetylation of benzenethiol with acetic acid at $300{ }^{\circ} \mathrm{C}$, and the results are summarized in Table 10. The supported clusters of niobium, tantalum, and tungsten also selectively catalyzed the $S$-acetylation. Brønsted acid sites developed on the halide cluster seemed to be active sites, and hence various solid acids were applied to the reaction. Table 10 also lists the catalytic activities of silica-alumina, zeolites, and heteropoly acids; their acidity is stable above $200{ }^{\circ} \mathrm{C}$. All these acids selectively catalyzed $S$-acetylation of benzenethiol, as expected. On the other hand, alumina (a Lewis acid) exhibited essentially no catalytic activity for the acetylation. Thus, protonation of the carbonyl group of the acetic acid would facilitate nucleophilic attack of benzenethiol to yield $S$-phenyl thioacetate (Scheme 5). Stability above $200{ }^{\circ} \mathrm{C}$ is a requisite of the catalyst for the reaction. Phosphoric acid polymerizes to diphosphoric acid or polyphosphoric acid above $200{ }^{\circ} \mathrm{C}$, and Nafion-H is not stable above $200{ }^{\circ} \mathrm{C}$. 
Table 10. $S$-Acetylation of benzenethiol with acetic acid over various catalysts ${ }^{\text {a }}$.

\begin{tabular}{|c|c|c|c|c|}
\hline \multirow{2}{*}{ Catalyst } & \multirow{2}{*}{$\begin{array}{c}\text { Conversion } \\
(\%) \\
\end{array}$} & \multicolumn{3}{|c|}{ Selectivity (\%) } \\
\hline & & $S$-Phenyl thioacetate & Diphenyl sulfide & Diphenyl disulfide \\
\hline$\left[\left(\mathrm{Nb}_{6} \mathrm{Cl}_{12}\right) \mathrm{Cl}_{2}\left(\mathrm{H}_{2} \mathrm{O}\right)_{4}\right] \cdot 4 \mathrm{H}_{2} \mathrm{O} / \mathrm{SiO}_{2}$ & 18.5 & 96.9 & 0.4 & 2.7 \\
\hline$\left(\mathrm{H}_{3} \mathrm{O}\right)_{2}\left[\left(\mathrm{Mo}_{6} \mathrm{Cl}_{8}\right) \mathrm{Cl}_{6}\right] \cdot 6 \mathrm{H}_{2} \mathrm{O} / \mathrm{SiO}_{2}$ & 18.7 & 98.2 & 1.2 & 0.6 \\
\hline$\left[\left(\mathrm{Ta}_{6} \mathrm{Cl}_{12}\right) \mathrm{Cl}_{2}\left(\mathrm{H}_{2} \mathrm{O}\right)_{4}\right] \cdot 4 \mathrm{H}_{2} \mathrm{O} / \mathrm{SiO}_{2}$ & 11.9 & 96.1 & 1.7 & 2.3 \\
\hline$\left(\mathrm{H}_{3} \mathrm{O}\right)_{2}\left[\left(\mathrm{~W}_{6} \mathrm{Cl}_{8}\right) \mathrm{Cl}_{6}\right] \cdot 6 \mathrm{H}_{2} \mathrm{O} / \mathrm{SiO}_{2}$ & 17.6 & 97.8 & 0.2 & 2.0 \\
\hline $\mathrm{SiO}_{2}-\mathrm{Al}_{2} \mathrm{O}_{3}(\text { high alumina })^{\mathrm{b}}$ & 15.7 & 93.6 & 5.3 & 1.1 \\
\hline $\mathrm{H}-\mathrm{Y}$ zeolite ${ }^{\mathrm{b}}$ & 14.5 & 96.4 & 2.3 & 1.3 \\
\hline H-beta ${ }^{b}$ & 14.2 & 94.3 & 3.4 & 2.3 \\
\hline $\mathrm{H}$-mordenite ${ }^{\mathrm{b}}$ & 6.4 & 92.5 & 1.7 & 5.8 \\
\hline $\mathrm{H}_{3}\left[\mathrm{PMo}_{12} \mathrm{O}_{40}\right] \cdot 30 \mathrm{H}_{2} \mathrm{O}^{\mathrm{c}}$ & 2.5 & 88.5 & 3.7 & 7.8 \\
\hline $\mathrm{H}_{3}\left[\mathrm{PW}_{12} \mathrm{O}_{40}\right] \cdot 30 \mathrm{H}_{2} \mathrm{O}^{\mathrm{c}}$ & 23.3 & 92.0 & 5.8 & 2.2 \\
\hline $\mathrm{H}_{3}\left[\mathrm{SiW}_{12} \mathrm{O}_{40}\right] \cdot 24 \mathrm{H}_{2} \mathrm{O}^{\mathrm{c}}$ & 11.4 & 88.1 & 1.8 & 10.1 \\
\hline $\mathrm{Al}_{2} \mathrm{O}_{3}$ & 0.9 & 41.6 & 0.0 & 58.4 \\
\hline
\end{tabular}

${ }^{\text {a }}$ After activation of catalyst $(30.0 \mathrm{mg})$ in hydrogen stream $(300 \mathrm{~mL} / \mathrm{h})$ at $300{ }^{\circ} \mathrm{C}$ for $1 \mathrm{~h}$, reaction was started by introduction of benzenethiol $(102 \mu \mathrm{L} / \mathrm{h}, 1.0 \mathrm{mmol} / \mathrm{h})$ and acetic acid $(114 \mu \mathrm{L} / \mathrm{h}, 2.0 \mathrm{mmol} / \mathrm{h})$ to the stream without changing the temperature. At $3 \mathrm{~h}$ after the start of the reaction; ${ }^{\mathrm{b}}$ Reference catalyst, The Catalysis Society of Japan; ${ }^{\mathrm{c}}$ Crushed and screened (166-200 mesh) crystals (Nippon Inorganic Colour and Chemical Co., Ltd., Tokyo, Japan).

Scheme 5. S-Acetylation mechanism with acetic acid over a simple Brønsted acid site.

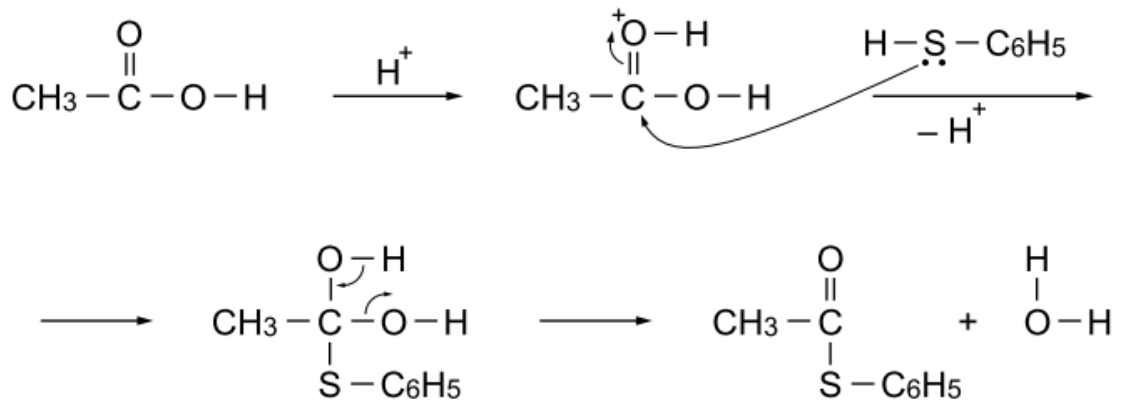

Several aliphatic and aromatic carboxylic acids were applied to the $S$-acylation of benzenethiol over $\left(\mathrm{H}_{3} \mathrm{O}\right)_{2}\left[\left(\mathrm{Mo}_{6} \mathrm{Cl}_{8}\right) \mathrm{Cl}_{6}\right] \cdot 6 \mathrm{H}_{2} \mathrm{O} / \mathrm{SiO}_{2}$ at $300{ }^{\circ} \mathrm{C}$. $S$-Acylation with all the saturated aliphatic $\mathrm{C}_{2}-\mathrm{C}_{5}$ carboxylic acids proceeded; the longer and bulkier the alkyl chain, the lower the reactivity and selectivity. The selectivities for $S$-acylation were more than $91 \%$ when carboxylic acids bearing $\alpha$-hydrogen were used. Even carboxylic acids having no $\alpha$-hydrogen, pivalic acid and benzoic acid, afforded the $S$-acylation products with selectivities of more than $77 \%$. $S$-Formylation of benzenethiol was unsuccessful under these reaction conditions, probably because of the thermolability of the product.

Esters, which have higher solubilities and lower melting points compared with the corresponding acids, are occasionally used for acylation of alcohols and amines. Catalytic $S$-acylation with esters has not been reported. Methyl acetate was applied to $S$-acetylation of benzenethiol in the presence of the $\left[\left(\mathrm{Nb}_{6} \mathrm{Cl}_{12}\right) \mathrm{Cl}_{2}\left(\mathrm{H}_{2} \mathrm{O}\right)_{4}\right] \cdot 4 \mathrm{H}_{2} \mathrm{O}$ at various temperatures, and the results are shown in Figure 30. Catalytic activity developed above $200{ }^{\circ} \mathrm{C}$ and increased with increasing temperature. Over the temperature range $300-400{ }^{\circ} \mathrm{C}$, selective $S$-methylation proceeded to yield methyl phenyl sulfide, and at around 
$450{ }^{\circ} \mathrm{C}, S$-acetylation was replaced to yield $S$-phenyl thioacetate preferentially. Then, methyl acetate was applied to the reaction at $450{ }^{\circ} \mathrm{C}$ over various catalysts, and the data are listed in Table 11 . Supported clusters of niobium and tantalum catalyzed $S$-acetylation selectively to provide $S$-phenyl thioacetate. Silica-alumina, $\mathrm{H}-\mathrm{Y}$ zeolite, $\mathrm{H}$-beta, $\mathrm{H}$-mordenite, and phosphotungstic acid were also effective catalysts for the reaction. The progress of $S$-acetylation with methyl acetate can be explained as simple Brønsted acid catalysis: the carbonyl group of the ester activated by a proton is attacked by benzenethiol to afford $S$-phenyl thioacetate (Scheme 6).

Figure 30. Effect of temperature on the reaction of benzenethiol with methyl acetate in the presence of $\left[\left(\mathrm{Nb}_{6} \mathrm{Cl}_{12}\right) \mathrm{Cl}_{2}\left(\mathrm{H}_{2} \mathrm{O}\right)_{4}\right] \cdot 4 \mathrm{H}_{2} \mathrm{O} / \mathrm{SiO}_{2}$. A mixture of benzenethiol $(102 \mu \mathrm{L} / \mathrm{h}$, $1.0 \mathrm{mmol} / \mathrm{h})$ and methyl acetate $(795 \mu \mathrm{L} / \mathrm{h}, 10.0 \mathrm{mmol} / \mathrm{h})$ was reacted. Other conditions are the same as in Figure 29. Conversion of benzenethiol $(\bullet)$; selectivity for $S$-phenyl thioacetate $(\circ)$; selectivity for methyl phenyl sulfide $(\diamond)$; selectivity for diphenyl sulfide $(\Delta)$; and selectivity for diphenyl disulfide ( $\square)$; at $3 \mathrm{~h}$ after the start of the reaction.

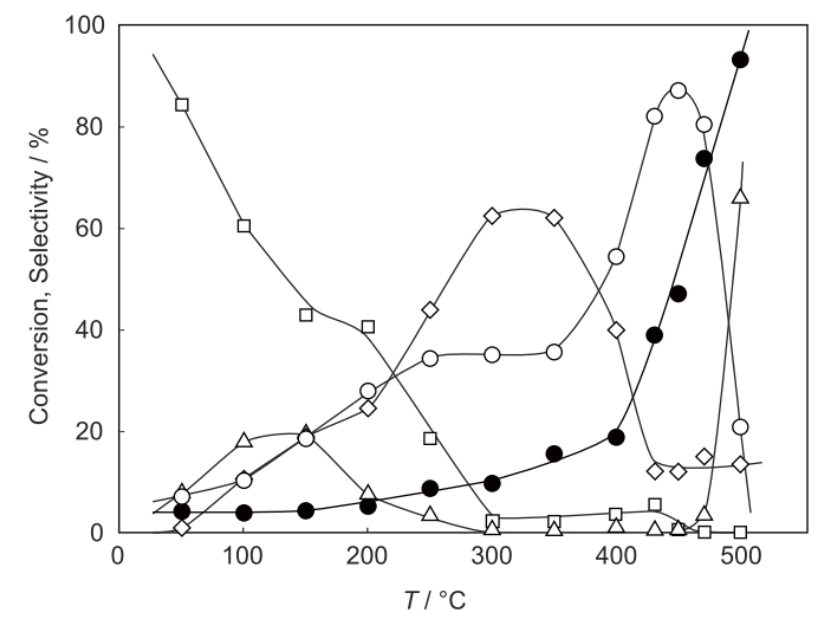

Scheme 6. $S$-Acetylation mechanism with methyl acetate over a simple Brønsted acid site.<smiles>COC(=O)CCC(C)(C)OC</smiles><smiles>[CH]O[C@H](OC)C(=O)SCC(=O)OC</smiles> 
Table 11. $S$-Acetylation and $S$-methylation of benzenethiol with methyl acetate over various catalysts a

\begin{tabular}{|c|c|c|c|c|c|}
\hline \multirow{2}{*}{ Catalyst disulfide } & \multirow{2}{*}{ Conversion (\%) } & \multicolumn{4}{|c|}{ Selectivity (\%) } \\
\hline & & $S$-Phenyl thioacetate & Methyl phenyl sulfide & Diphenyl sulfide & Diphenyl \\
\hline$\left[\left(\mathrm{Nb}_{6} \mathrm{Cl}_{12}\right) \mathrm{Cl}_{2}\left(\mathrm{H}_{2} \mathrm{O}\right)_{4}\right] \cdot 4 \mathrm{H}_{2} \mathrm{O} / \mathrm{SiO}_{2}$ & 46.8 & 86.9 & 12.0 & 0.6 & 0.5 \\
\hline$\left(\mathrm{H}_{3} \mathrm{O}\right)_{2}\left[\left(\mathrm{Mo}_{6} \mathrm{Cl}_{8}\right) \mathrm{Cl}_{6}\right] \cdot 6 \mathrm{H}_{2} \mathrm{O} / \mathrm{SiO}_{2}$ & 84.7 & 4.1 & 94.7 & 1.0 & 0.2 \\
\hline$\left[\left(\mathrm{Ta}_{6} \mathrm{Cl}_{12}\right) \mathrm{Cl}_{2}\left(\mathrm{H}_{2} \mathrm{O}\right)_{4}\right] \cdot 4 \mathrm{H}_{2} \mathrm{O} / \mathrm{SiO}_{2}$ & 35.8 & 80.6 & 14.8 & 4.1 & 0.6 \\
\hline$\left(\mathrm{H}_{3} \mathrm{O}\right)_{2}\left[\left(\mathrm{~W}_{6} \mathrm{Cl}_{8}\right) \mathrm{Cl}_{6}\right] \cdot 6 \mathrm{H}_{2} \mathrm{O} / \mathrm{SiO}_{2}$ & 44.1 & 58.1 & 39.9 & 1.1 & 0.9 \\
\hline $\mathrm{SiO}_{2}-\mathrm{Al}_{2} \mathrm{O}_{3}$ (high alumina) ${ }^{\mathrm{b}}$ & 44.5 & 68.3 & 30.2 & 0.7 & 0.8 \\
\hline H-Y zeolite ${ }^{b}$ & 44.6 & 88.3 & 9.3 & 1.6 & 0.9 \\
\hline H-beta ${ }^{b}$ & 37.7 & 70.8 & 26.9 & 0.7 & 1.6 \\
\hline $\mathrm{H}$-mordenite ${ }^{\mathrm{b}}$ & 31.1 & 82.0 & 12.9 & 4.0 & 1.1 \\
\hline $\mathrm{H}_{3}\left[\mathrm{PMo}_{12} \mathrm{O}_{40}\right] \cdot 30 \mathrm{H}_{2} \mathrm{O}^{\mathrm{c}}$ & 28.6 & 19.9 & 74.4 & 4.8 & 0.9 \\
\hline $\mathrm{H}_{3}\left[\mathrm{PMo}_{12} \mathrm{O}_{40}\right] \cdot 30 \mathrm{H}_{2} \mathrm{O}^{\mathrm{c}, \mathrm{d}}$ & 5.8 & 14.7 & 9.0 & 13.0 & 63.3 \\
\hline $\mathrm{H}_{3}\left[\mathrm{PW}_{12} \mathrm{O}_{40}\right] \cdot 30 \mathrm{H}_{2} \mathrm{O}^{\mathrm{c}}$ & 13.6 & 57.4 & 14.7 & 18.8 & 9.1 \\
\hline $\mathrm{H}_{3}\left[\mathrm{SiW}_{12} \mathrm{O}_{40}\right] \cdot 24 \mathrm{H}_{2} \mathrm{O}^{\mathrm{c}}$ & 4.5 & 28.0 & 17.1 & 31.4 & 23.5 \\
\hline
\end{tabular}

${ }^{a}$ After activation of catalyst $(30 \mathrm{mg})$ in a hydrogen stream $(300 \mathrm{~mL} / \mathrm{h})$ at $450{ }^{\circ} \mathrm{C}$ for $1 \mathrm{~h}$, reaction was started by introduction of benzenethiol $(102 \mu \mathrm{L} / \mathrm{h}, 1.0 \mathrm{mmol} / \mathrm{h})$ and methyl acetate $(795 \mu \mathrm{L} / \mathrm{h}, 10.0 \mathrm{mmol} / \mathrm{h})$ to the hydrogen stream without changing the temperature. At $3 \mathrm{~h}$ after the start of the reaction. Other conditions are the same as in Table 10; ${ }^{\mathrm{b}}$ Reference catalyst, The Catalysis Society of Japan; ${ }^{\mathrm{c}}$ Crushed and screened (166-200 mesh) crystals (Nippon Inorganic Colour and Chemical Co., Ltd., Tokyo, Japan); ${ }^{\mathrm{d}}$ In a helium stream $(300 \mathrm{~mL} / \mathrm{h})$. 
As Table 11 lists, supported cluster of molybdenum catalyzed $S$-methylation to afford methyl phenyl sulfide almost exclusively. Tungsten halide clusters also catalyzed $S$-methylation, though less selectively. With heteropoly acids, phosphomolybdic acid catalyzed $S$-methylation preferentially. Over molybdenum and tungsten halide clusters, coordinatively unsaturated sites were formed by thermal activation [1]. With niobium and tantalum clusters, formation of coordinatively unsaturated sites is difficult because of the high bond energy of $\mathrm{Nb}-\mathrm{O}\left(771.5 \mathrm{~kJ} \mathrm{~mol}^{-1}\right)$ and Ta-O $\left(799.1 \mathrm{~kJ} \mathrm{~mol}^{-1}\right)$. Under hydrogen, $\mathrm{MoO}_{3}$ is reported to be reduced to a suboxide of chemical composition between $\mathrm{Mo}_{2} \mathrm{O}$ and $\mathrm{MoO}$ at $300{ }^{\circ} \mathrm{C}$ and to molybdenum metal at $600{ }^{\circ} \mathrm{C}$ [226]. Consequently, coordinatively unsaturated sites should appear in part on phosphomolybdic acid under the reaction conditions. As Table 11 shows, $S$-methylation over phosphomolybdic acid was obviously depressed under a helium stream. S-Methylation over molybdenum cluster and phosphomolybdic acid under hydrogen can be explained on the basis of a Brønsted acid site in concert with the coordinatively unsaturated site. The carbonyl group of methyl acetate is activated by protonation, and the oxygen atom of the methoxy group coordinates to the molybdenum atom. Then, the electron-deficient methyl group is attacked by benzenethiol to afford the $S$-methyl sulfide (Scheme 7).

Scheme 7. S-Methylation mechanism with methyl acetate over a combined Brønsted acid site and coordinatively unsaturated site.

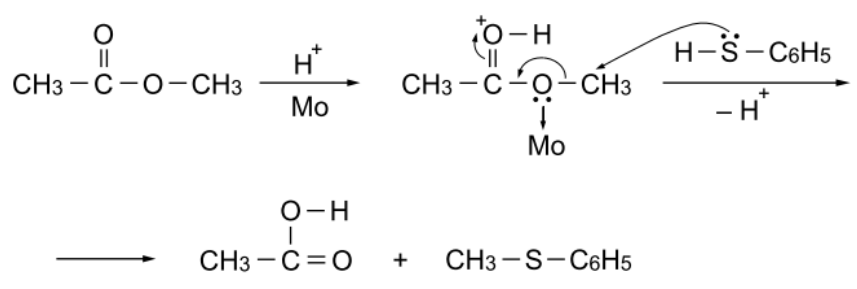

Several carboxylic esters were reacted with benzenethiol over $\left[\left(\mathrm{Nb}_{6} \mathrm{Cl}_{12}\right) \mathrm{Cl}_{2}\left(\mathrm{H}_{2} \mathrm{O}\right)_{4}\right] \cdot 4 \mathrm{H}_{2} \mathrm{O} / \mathrm{SiO}_{2}$ at $450{ }^{\circ} \mathrm{C}$, and the data are listed in Table 12 . Acetyl esters provided $S$-acetate almost exclusively. On the other hand, methyl esters of butyric, valeric, and benzoic acids afforded $S$-methyl sulfide preferentially. Methyl propionate showed an intermediate selectivity to afford both $S$-acyl and $S$-alkyl products. Accordingly, a relatively smaller acyl or alkyl moiety of the ester was incorporated into the thiol.

It is known that aliphatic thiols bearing a $\beta$-hydrogen atom are susceptible to decomposing to olefins by eliminating hydrogen sulfide at elevated temperatures, particularly in the presence of acid catalysts [227,228], as in the case of alcohols decomposing to olefins. When 1-hexanethiol was reacted alone at $300{ }^{\circ} \mathrm{C}$ over $\left[\left(\mathrm{Nb}_{6} \mathrm{Cl}_{12}\right) \mathrm{Cl}_{2}\left(\mathrm{H}_{2} \mathrm{O}\right)_{4}\right] \cdot 4 \mathrm{H}_{2} \mathrm{O} / \mathrm{SiO}_{2}$, the conversion was $36 \%$ and decomposition to 1-hexene proceeded with $74 \%$ selectivity. However, when 1-hexanethiol was reacted in the presence of acetic acid under identical conditions, the conversion increased to $43 \%$ and acetylation to $S$-hexyl thioacetate proceeded with $87 \%$ selectivity. Halide clusters except molybdenum cluster, acid catalysts such as silica-alumina, H-Y zeolite, and phosphotungstic acid were effective catalysts for the $S$-acetylation of 1-hexanethiol. Then, several $\mathrm{C}_{5}-\mathrm{C}_{8}$ aliphatic thiols were reacted with aromatic and $\mathrm{C}_{2}-\mathrm{C}_{5}$ aliphatic carboxylic acids over $\left[\left(\mathrm{Nb}_{6} \mathrm{Cl}_{12}\right) \mathrm{Cl}_{2}\left(\mathrm{H}_{2} \mathrm{O}\right)_{4}\right] \cdot 4 \mathrm{H}_{2} \mathrm{O} / \mathrm{SiO}_{2}$ at $300{ }^{\circ} \mathrm{C}$. All in all, the combination of aliphatic thiol and carboxylic acid afforded the corresponding $S$-alkyl carbothioate selectively. 
Table 12. $S$-Acylation and $S$-alkylation of benzenethiol with esters over $\left[\left(\mathrm{Nb}_{6} \mathrm{Cl}_{12}\right) \mathrm{Cl}_{2}\left(\mathrm{H}_{2} \mathrm{O}\right)_{4}\right] \cdot 4 \mathrm{H}_{2} \mathrm{O} / \mathrm{SiO}_{2}{ }^{\mathrm{a}}$.

\begin{tabular}{|c|c|c|c|c|c|}
\hline \multirow{2}{*}{ Reagent } & \multirow{2}{*}{$\begin{array}{c}\text { Conversion } \\
(\%) \\
\end{array}$} & \multicolumn{4}{|l|}{ Selectivity (\%) } \\
\hline & & $S$-Phenyl Carbothioate & Alkyl Phenyl Sulfide & Diphenyl Sulfide & Diphenyl Disulfide \\
\hline Methyl acetate & 46.8 & 86.9 & 12.0 & 0.6 & 0.5 \\
\hline Ethyl acetate & 45.0 & 88.7 & 9.7 & 0.4 & 1.2 \\
\hline$n$-Propyl acetate & 48.0 & 98.3 & 0.8 & 0.7 & 0.3 \\
\hline Methyl propionate & 36.9 & 69.0 & 30.6 & 0.0 & 0.4 \\
\hline Methyl butyrate & 40.4 & 29.5 & 62.2 & 8.0 & 0.3 \\
\hline Methyl valerate & 44.8 & 27.9 & 62.1 & 8.5 & 1.5 \\
\hline Methyl benzoate & 14.7 & 33.2 & 58.8 & 2.2 & 5.8 \\
\hline
\end{tabular}

${ }^{\text {a }}$ After activation of cluster $(30 \mathrm{mg}, 25 \mu \mathrm{mol})$ in a hydrogen stream $(300 \mathrm{~mL} / \mathrm{h})$ at $450{ }^{\circ} \mathrm{C}$ for $1 \mathrm{~h}$, reaction was started by introduction of a mixture of benzenethiol $(102 \mu \mathrm{L} / \mathrm{h}, 1.0 \mathrm{mmol} / \mathrm{h})$ and acetate $(10.0 \mathrm{mmol} / \mathrm{h})$ to the hydrogen stream without changing the temperature. At $3 \mathrm{~h}$ after the start of the reaction. Other conditions are the same as in Table 10.

Thus, $S$-acylation of thiols with carboxylic acids or their esters has been difficult even in the presence of catalysts, and there has been only one report of such an acylation by heating the neat mixture at $110{ }^{\circ} \mathrm{C}$ for $8 \mathrm{~h}$ in the presence of an acid catalyst [225]. However, halide clusters catalyze $S$-acylation of both aliphatic and aromatic thiols with aliphatic and aromatic carboxylic acids or their esters, when the reaction is conducted above $200{ }^{\circ} \mathrm{C}$. Harsh reaction conditions are required for the reaction. The Brønsted acid site developed on the clusters was the active site of the catalyst, and accordingly Brønsted acids such as silica-alumina, zeolites, or heteropoly acids that are stable above $200{ }^{\circ} \mathrm{C}$ have also been proved to catalyze the reaction.

\subsection{Isomerization and Hydrogenation of Alkyne (Equation (19)) [229]}

\subsubsection{Isomerization of Alkyne under Inert Gas}

Isomerization of alkynes to conjugated dienes and allenes has been reported over several base catalysts: $\mathrm{NaOBu}^{t}, \mathrm{KOBu}^{t}, \mathrm{KOH}$, alkaline earth metal oxides, and basic zeolites [230,231]. Base-modified $\mathrm{SiO}_{2}$, $\mathrm{Al}_{2} \mathrm{O}_{3}$ and $\mathrm{SiO}_{2}-\mathrm{Al}_{2} \mathrm{O}_{3}$ have also been used [232]. Acid catalysts, such as $\mathrm{SiO}_{2}, \mathrm{Al}_{2} \mathrm{O}_{3}$ [231], $\mathrm{SiO}_{2}-\mathrm{Al}_{2} \mathrm{O}_{3}$ [232], and $\mathrm{Cr}_{2} \mathrm{O}_{3} / \mathrm{Al}_{2} \mathrm{O}_{3}$ [233] have also been applied to the reaction. However, other types of catalyst have not been reported as being used in this reaction. Then, halide clusters were applied to the reaction of alkynes.

After the activation of crushed (150-200 mesh) crystals of $\left[\left(\mathrm{Ta}_{6} \mathrm{Cl}_{12}\right) \mathrm{Cl}_{2}\left(\mathrm{H}_{2} \mathrm{O}\right)_{4}\right] \cdot 4 \mathrm{H}_{2} \mathrm{O}$ at elevated temperatures in a nitrogen stream for $1 \mathrm{~h}$, reactions were initiated by introduction of 2-pentyne to the stream without changing the temperature. The effect of the reaction temperature is shown in Figure 31. The catalytic activity appeared above $300{ }^{\circ} \mathrm{C}$, and enhanced with increasing temperature. The tantalum cluster catalyzed the isomerization of 2-pentyne yielding 1,3-pentadiene with a selectivity of $58 \%$ at $450{ }^{\circ} \mathrm{C}$.

The catalytic activities of various halide clusters of Group 5-7 metals were examined at $400{ }^{\circ} \mathrm{C}$. When the reaction was performed under helium or argon stream over $\left[\left(\mathrm{Ta}_{6} \mathrm{Cl}_{12}\right) \mathrm{Cl}_{2}\left(\mathrm{H}_{2} \mathrm{O}\right)_{4}\right] \cdot 4 \mathrm{H}_{2} \mathrm{O}$, the selectivity was virtually the same as that under nitrogen, indicating that these gases did not participate in the reaction. The niobium and tungsten chloride clusters also catalyzed isomerization to yield 
1,3-pentadiene preferentially under nitrogen. However, the catalytic activity of the molybdenum chloride cluster was low, and no catalytic activity was observed over the rhenium chloride cluster under nitrogen.

Figure 31. Effect of temperature on the reaction of 2-pentyne over $\left[\left(\mathrm{Ta}_{6} \mathrm{Cl}_{12}\right) \mathrm{Cl}_{2}\left(\mathrm{H}_{2} \mathrm{O}\right)_{4}\right] \cdot 4 \mathrm{H}_{2} \mathrm{O}$ under flowing nitrogen. Following activation of the cluster ( $80 \mathrm{mg}, 46 \mu \mathrm{mol})$ in a nitrogen stream $(1.8 \mathrm{~L} / \mathrm{h})$ for $1 \mathrm{~h}$, the reaction was initiated by introduction of 2 -pentyne $(52 \mu \mathrm{L} / \mathrm{h}$, $0.50 \mathrm{mmol} / \mathrm{h}$ ) into the nitrogen stream without changing the temperature. Conversion of 2-pentyne $(\bullet)$; selectivity for 1,3-pentadiene $(\square)$; selectivity for 1,2- and 2,3-pentadienes $(\circ)$; and selectivity for 1 - and 2-pentenes $(\Delta)$ at $3 \mathrm{~h}$ after the start of the reaction.

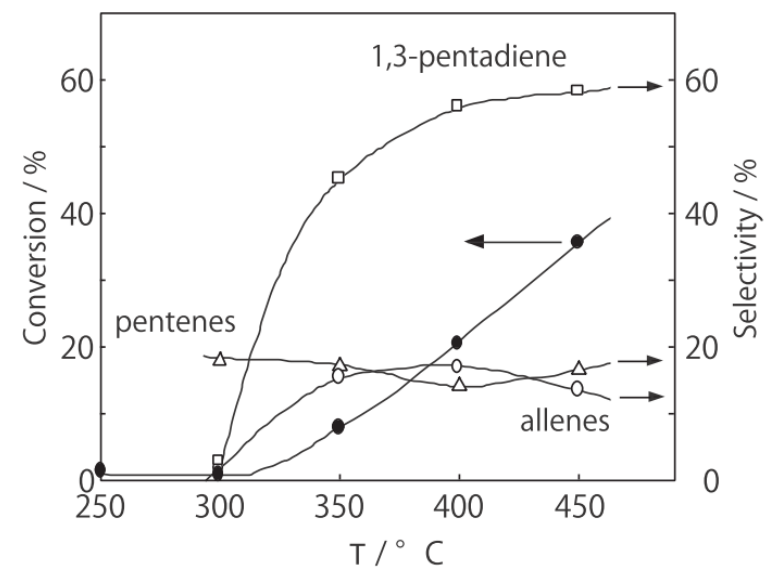

The reactivity of some alkynes were tested over $\left[\left(\mathrm{Ta}_{6} \mathrm{Cl}_{12}\right) \mathrm{Cl}_{2}\left(\mathrm{H}_{2} \mathrm{O}\right)_{4}\right] \cdot 4 \mathrm{H}_{2} \mathrm{O}$ under nitrogen. In almost cases, the main products were conjugated dienes: 1,3-pentadiene from 1- and 2-pentyne and 2,4-hexadiene from 1-, 2-, and 3-hexyne. The reactivity order of the pentynes was 2-pentyne > 1-pentyne, and that of the hexynes was 3- hexyne > 2-hexyne > 1-hexyne, indicating that the inner alkynes have a higher reactivity than the corresponding terminal alkynes. This order of reactivity is the reverse of that reported for base catalysts such as $\mathrm{NaOBu}^{t}$ and $\mathrm{KOBu}^{t}$ [234], whereas no data on the reactivity order has been reported in the case of acid catalysts. Isomerization of alkynes is initiated by protonation at the triple bond [232]. The electron density of the triple bond is higher for more substituted alkynes. Consequently, inner alkynes would be expected to have a higher reactivity for isomerization over Brønsted acid catalysts, which is the case for halide cluster.

\subsubsection{Hydrogenation of Alkyne under Hydrogen}

The hydrogenation of alkynes proceeds over the platinum group metals [27,56]. In particular, metallic palladium, such as $\mathrm{Pd} / \mathrm{CaCO}_{3}$ or $\mathrm{Pd} / \mathrm{BaSO}_{4}$, partially hydrogenates alkynes to alkenes in a selective manner owing to the strong adsorption of the alkyne on the catalyst. Then, halide clusters were applied to the reaction of alkynes.

In a hydrogen stream, 2-pentyne was allowed to react over the tantalum halide cluster at $400{ }^{\circ} \mathrm{C}$. The activity and product selectivity over $\left[\left(\mathrm{Ta}_{6} \mathrm{Cl}_{12}\right) \mathrm{Cl}_{2}\left(\mathrm{H}_{2} \mathrm{O}\right)_{4}\right] \cdot 4 \mathrm{H}_{2} \mathrm{O}$ under hydrogen was virtually the same as that under nitrogen, and the selectivity was similar to those under helium and argon. The Raman spectrum and XRD pattern of $\left[\left(\mathrm{Ta}_{6} \mathrm{Cl}_{12}\right) \mathrm{Cl}_{2}\left(\mathrm{H}_{2} \mathrm{O}\right)_{4}\right] \cdot 4 \mathrm{H}_{2} \mathrm{O}$ activated under hydrogen 
at each temperature were identical to those under nitrogen, and hence atmospheric hydrogen participated in neither the activation of $\left[\left(\mathrm{Ta}_{6} \mathrm{Cl}_{12}\right) \mathrm{Cl}_{2}\left(\mathrm{H}_{2} \mathrm{O}\right)_{4}\right] \cdot 4 \mathrm{H}_{2} \mathrm{O}$ nor the reaction with 2-pentyne.

In the case of the niobium, molybdenum, and tungsten clusters, the catalytic activity increased noticeably under hydrogen, and the main reaction changed to hydrogenation, yielding 2-pentene with a selectivity of $42 \%-69 \%$ at $400{ }^{\circ} \mathrm{C}$. When pyridine equimolar to 2-pentyne was added to the hydrogen stream over the niobium cluster, conversion for isomerization was reduced to about one-third, but that for hydrogenation was virtually unchanged, indicating that the active site for hydrogenation was independent of the Brønsted acid site.

When 1-pentene was allowed to react over the niobium cluster in hydrogen under identical conditions, the conversion of the olefinic bond was 67\%, and the selectivity for isomerization to 2-pentene was as high as $87 \%$, resulting in an approximate equilibrium composition of 1 - and 2 -pentenes. In contrast, the selectivity for hydrogenation to pentane was as low as $2 \%$. Consequently, the halide clusters catalyzed partial hydrogenation of alkynes to alkenes selectively. Hydrogenation of alkynes is exclusively catalyzed by the platinum group metals [27,56]. Metallic palladium catalyzes partial hydrogenation of alkynes to alkenes selectively, as long as the alkynes are present, and it catalyzes alkene isomerization at a faster rate than alkene hydrogenation under ambient hydrogen pressure $[27,55,56]$. Thus, the halide clusters exhibited a similar catalytic behavior to that of metallic palladium, which is ascribed to the metal atom that accepts electrons from the halogen ligands leading to isoelectronic with the platinum group metals [1].

Under hydrogen, the rhenium cluster catalyzed the partial hydrogenation of 2-pentyne to yield 2-pentene with a selectivity of $58 \%$ under hydrogen along with hydrogenolyses to methane, ethane, and ethylene, etc. with $19 \%$ selectivity. This cluster has been reported to change to metallic rhenium on treatment with hydrogen at temperatures above $250{ }^{\circ} \mathrm{C}$, and this was confirmed in our reaction system [1]. The catalytic species for hydrogenation is ascribed to metallic rhenium, since $\mathrm{Re} / \mathrm{MgO}$ has also been reported to catalyze the reaction [235].

\subsection{Addition of Water to Alkyne (Equation (20)) [236]}

Hydration of alkynes is one of the simplest and convenient ways to obtain carbonyl compounds. This reaction has long been catalyzed by mercury(II) sulfate in aqueous sulfuric acid solution, in which the mercury(II) ion acts as a Lewis acid [237]. To avoid use of toxicity of mercury ion and strong acidic conditions, various alternative Lewis acids have been applied to the reaction [238,239]. Chlorides of iron, ruthenium, rhodium, platinum, and gold are reported to catalyze the reaction. $\mathrm{CdO}-\mathrm{CaO}-\mathrm{P}_{2} \mathrm{O}_{5}$ [240] and zeolites such as $\mathrm{CuX}, \mathrm{ZnX}$, and $\mathrm{CdX}$ [241] are used in the vapor phase reaction. Several Brønsted acids have also been applied to the reaction: HY zeolite [242], heteropoly acids [243], p-toluenesulfonic acid [244], trifluoromethanesulfonic acid, and trifluoromethanesulfonimide [245]. Halide cluster was applied to this reaction.

The supported tungsten cluster, $\left(\mathrm{H}_{3} \mathrm{O}\right)_{2}\left[\left(\mathrm{~W}_{6} \mathrm{Cl}_{8}\right) \mathrm{Cl}_{6}\right] \cdot 6 \mathrm{H}_{2} \mathrm{O} / \mathrm{SiO}_{2}$, was initially activated at an elevated temperature for $1 \mathrm{~h}$ in a nitrogen stream, and then reaction was initiated by introduction of an equimolar amount of 1-hexyne and water without changing the temperature. The effect of the reaction temperature on activity and selectivity is presented in Figure 32. Catalytic activity developed above $200{ }^{\circ} \mathrm{C}$. The selectivity for the hydration yielding 2-hexanone was as high as $70 \%$ 
at temperatures ranging from 200 to $400{ }^{\circ} \mathrm{C}$ along with 1,2-hexadiene (allene) with about $20 \%$ selectivity. Above $450{ }^{\circ} \mathrm{C}$, decomposition to gaseous products increased. Increase in water ratio to alkyne increased the selectivity for the hydration. The hydration similarly proceeded under hydrogen and helium streams.

The catalytic activity of clusters of Group 5 and 6 metals was examined at $400{ }^{\circ} \mathrm{C}$. The catalytic activity for hydration of the niobium, molybdenum, and tantalum clusters (3\%-14\% conversion) was lower than that of the tungsten cluster. The selectivity for hydration over those clusters was lower (24\%-28\% selectivity) than over tungsten cluster. On those clusters, isomerization to 1,2-hexadiene proceeded with moderate selectivities $(28 \%-45 \%)$. The isomerization does not involve participation of water molecule. Increase in the electronegativity of a metal atom bound to a hydroxo ligand increases its Brønsted acid strength by reducing electron density of the oxygen, and hence facilitating the release of the hydrogen as a proton [246]. The higher catalytic activity of the tungsten cluster is attributable to the higher electronegativity of tungsten atom than the other metal atoms.

Figure 32. Effect of temperature on the reaction of 1-hexyne with water over $\left(\mathrm{H}_{3} \mathrm{O}\right)_{2}\left[\left(\mathrm{~W}_{6} \mathrm{Cl}_{8}\right) \mathrm{Cl}_{6}\right] \cdot 6 \mathrm{H}_{2} \mathrm{O} / \mathrm{SiO}_{2}$ in a nitrogen stream. Following activation of the supported cluster $(40 \mathrm{mg}, 23 \mu \mathrm{mol})$ in a nitrogen stream $(600 \mathrm{~mL} / \mathrm{h})$ for $1 \mathrm{~h}$, reaction was initiated by introduction of 1 -hexyne $(115 \mu \mathrm{L} / \mathrm{h}, 1.0 \mathrm{mmol} / \mathrm{h})$ and water $(18 \mu \mathrm{L} / \mathrm{h}, 1.0 \mathrm{mmol} / \mathrm{h})$ to the nitrogen stream. Conversion of 1-hexyne $(\bullet)$; selectivity for 2-hexanone $(\circ)$; selectivity for 1,2-hexadiene $(\Delta)$; selectivity for 2-hexyne $(\square)$; and selectivity for decomposition products such as ethylene, propene, 1-butene, and 1-pentyne $(\diamond)$; at $3 \mathrm{~h}$ after the start of the reaction.

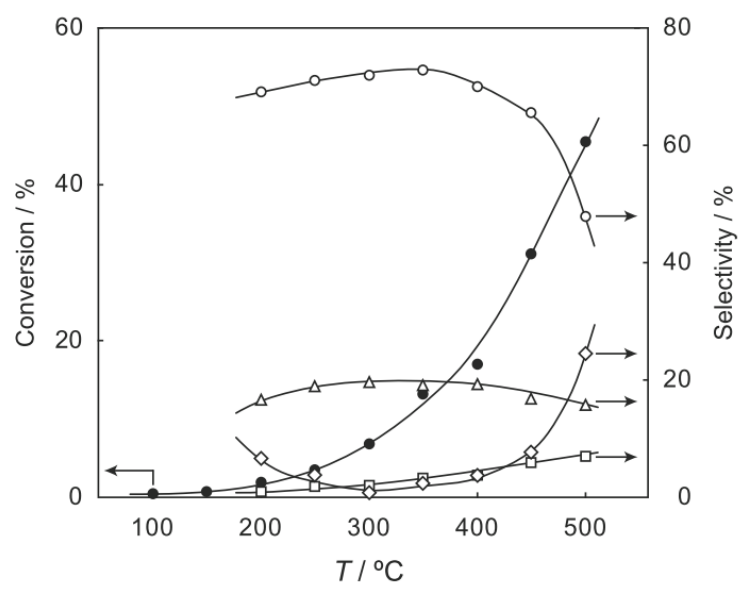

Some alkynes (1-, 2- and 3- hexyne, 1-heptyne, 1-octyne, 1-nonyne, phenylacetylene) were subjected to the reaction over $\left(\mathrm{H}_{3} \mathrm{O}\right)_{2}\left[\left(\mathrm{~W}_{6} \mathrm{Cl}_{8}\right) \mathrm{Cl}_{6}\right] \cdot 6 \mathrm{H}_{2} \mathrm{O} / \mathrm{SiO}_{2}$. Both aliphatic and aromatic terminal alkynes were efficiently hydrated to the corresponding 2-ketones (61\%-99\% selectivity). 2-Hexyne produced 2- and 3-hexanones in equal amounts.

\subsection{Dehydrohalogenation of Alkyl Halide (Equation (21)) [247]}

Various types of compounds have been reported as catalysts for the dehydrohalogenation of halogenated hydrocarbons. In most cases, a gas-phase reaction system is used for the reaction on 
solid catalysts. Metal (Ni) [248,249], metal oxide (MgO), metal oxychloride, metal sulfate, aluminosilicates [250], and solid acid and base [251] have been employed as the catalyst. Metal halides such as $\mathrm{MgCl}_{2}, \mathrm{KBr}, \mathrm{NaCl}$, and $\mathrm{ZnCl}_{2}$ are also the catalysts, and the last one is used as a molten salt. Metal halides used are normal salts that comprise ionic metals and ionic halogens. Halide cluster, in which metal atoms are not ionic but are coordinated with non-ionic halogen ligands, was applied to this reaction.

Powdered crystals of $\left[\left(\mathrm{Nb}_{6} \mathrm{Cl}_{12}\right) \mathrm{Cl}_{2}\left(\mathrm{H}_{2} \mathrm{O}\right)_{4}\right] \cdot 4 \mathrm{H}_{2} \mathrm{O}$ were activated in a stream of helium for $1 \mathrm{~h}$, and the reaction was commenced by introduction of 1-chloropentane into the stream without changing the temperature. As Figure 33 shows, activation above $200{ }^{\circ} \mathrm{C}$ brought about the catalytic activity, and the activity increased with increasing temperature up to $300{ }^{\circ} \mathrm{C}$. Blank experiment showed that 1-chloropentane spontaneously decomposed above $325{ }^{\circ} \mathrm{C}$, yielding a variety of products including pentenes as minor products. The selectivity for dehydrohalogenation to yield 1-pentene and cis- and trans-2-pentenes was $99 \%$ at $300{ }^{\circ} \mathrm{C}$. Hydrodehalogenation (dehalogenation or hydrogenolysis) to yield pentane was not observed at all temperatures tested. As mentioned in Section 3.2, the halide clusters catalyze isomerization of olefins. Then isomerization in the presence of halogenated hydrocarbon was examined. When 1-hexene in the presence of an equimolar amount of 1-chloropentane was subjected to the reaction over the niobium cluster at $300{ }^{\circ} \mathrm{C}$, no isomerization of 1-hexene to 2-hexenes was observed and only dehydrohalogenation yielding pentenes occurred. Consequently, successive isomerization of the olefin produced by dehydrohalogenation can be ruled out under these reaction conditions.

Figure 33. Effect of temperature on reactivity and selectivity for dehydrohalogenation of 1-chloropentane over $\left[\left(\mathrm{Nb}_{6} \mathrm{Cl}_{12}\right) \mathrm{Cl}_{2}\left(\mathrm{H}_{2} \mathrm{O}\right)_{4}\right] \cdot 4 \mathrm{H}_{2} \mathrm{O}$ at $5 \mathrm{~h}$ after the start of the reaction. After activation of the cluster $(30 \mathrm{mg}, 17 \mu \mathrm{mol})$ under helium $(1.2 \mathrm{~L} / \mathrm{h})$ for $1 \mathrm{~h}$, reaction was commenced by introduction of 1-chloropentane $(0.20 \mathrm{~mL} / \mathrm{h}, 1.66 \mathrm{mmol})$ without changing the temperature.

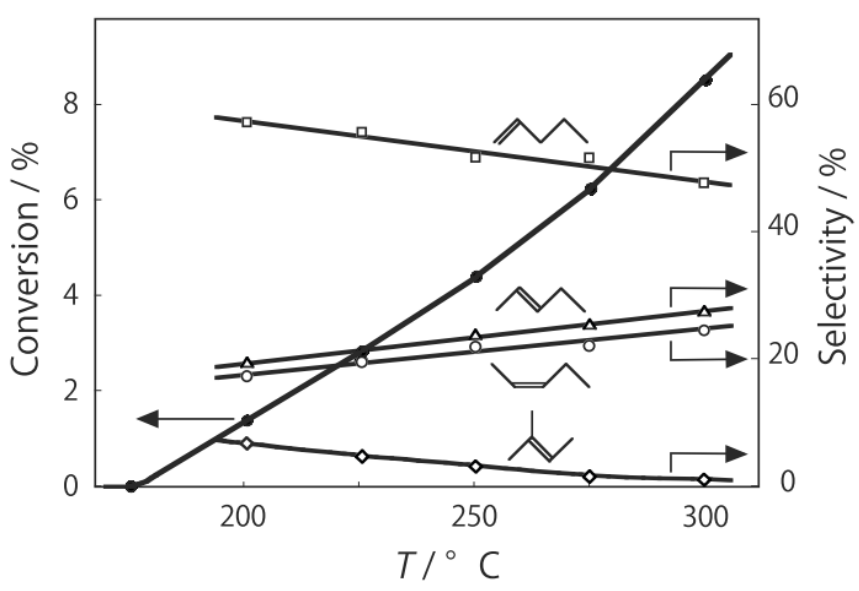


Catalytic activities of bromide cluster of niobium, [ $\left.\left(\mathrm{Nb}_{6} \mathrm{Br}_{12}\right) \mathrm{Br}_{2}\left(\mathrm{H}_{2} \mathrm{O}\right)_{4}\right] \cdot 4 \mathrm{H}_{2} \mathrm{O}$, and chloride clusters of molybdenum, tantalum, and tungsten were tested for the reaction of 1-chloropentane. All clusters, except tungsten chloride cluster under hydrogen, developed catalytic activity for dehydrohalogenation both under helium and hydrogen streams. Group 5 metal clusters exhibited practically the same catalytic activity and selectivity under helium and hydrogen streams. The selectivities of molybdenum and tungsten of Group 6 metal clusters under helium were similar.

The catalytic activity and selectivity of $\left[\left(\mathrm{Nb}_{6} \mathrm{Cl}_{12}\right) \mathrm{Cl}_{2}\left(\mathrm{H}_{2} \mathrm{O}\right)_{4}\right] \cdot 4 \mathrm{H}_{2} \mathrm{O}$ for 1-fluoro, 1-chloro-, 1-bromo-, and 1-iodopentanes were investigated in helium and hydrogen streams at $300{ }^{\circ} \mathrm{C}$. The niobium cluster dehydrohalogenated all the halogen compounds to 1-pentene, cis- and trans-2-pentenes exclusively irrespective of the gas stream. The reactivity order of the halogen substituents was $\mathrm{F}>>\mathrm{Cl}>\mathrm{Br}>\mathrm{I}$, which is the reverse of that observed in catalytic hydrogenolysis over platinum group metals $[27,56]$. Only partial data can be seen: $\mathrm{Br}_{-} \mathrm{C}_{2} \mathrm{H}_{5}>\mathrm{I}-\mathrm{C}_{2} \mathrm{H}_{5}$ over rare-earth-exchanged $13 \times$ zeolite to yield ethylene [250], and generally $\mathrm{Cl} \approx \mathrm{Br}$ over solid acids, and $\mathrm{Cl}<\mathrm{Br}$ over solid bases [252]. Over $\left[\left(\mathrm{Nb}_{6} \mathrm{Cl}_{12}\right) \mathrm{Cl}_{2}\left(\mathrm{H}_{2} \mathrm{O}\right)_{4}\right] \cdot 4 \mathrm{H}_{2} \mathrm{O}$, 2-chloropentane was dehydrogenated to yield cis- and trans-2-pentenes selectively, and the higher reactivity of 2-chloropentane compared with 1-chloropentane matches the well-known increasing activity order of primary, secondary, and tertiary carbon atoms in dehydrohalogenation [253].

The reactivity of 1-chloropentane was examined using the rhenium cluster, $\mathrm{Re}_{3} \mathrm{Cl}_{9}$, in a stream of helium at different temperatures; the results are shown in Figure 34. The activity appeared by activation at $175{ }^{\circ} \mathrm{C}$, which is a little lower than the corresponding temperature for the niobium cluster. The selectivities remained almost unchanged. The cis/trans (0.62) and 1-pentene/2-pentene rations (0.28) are roughly in accord with those of thermal equilibrium $\left(0.61\right.$ and 0.13 at $300{ }^{\circ} \mathrm{C}$, respectively), which suggests that the precursors of the products are in equilibrium.

Figure 34. Effect of temperature on reactivity and selectivity for dehydrohalogenation of 1-chloropentane $(0.20 \mathrm{~mL} / \mathrm{h}, 1.66 \mathrm{mmol})$ over $\mathrm{Re}_{3} \mathrm{Cl}_{9}(30 \mathrm{mg}, 34 \mu \mathrm{mol})$ in helium at $5 \mathrm{~h}$ after the start of the reaction. Other conditions are the same as in Figure 33.

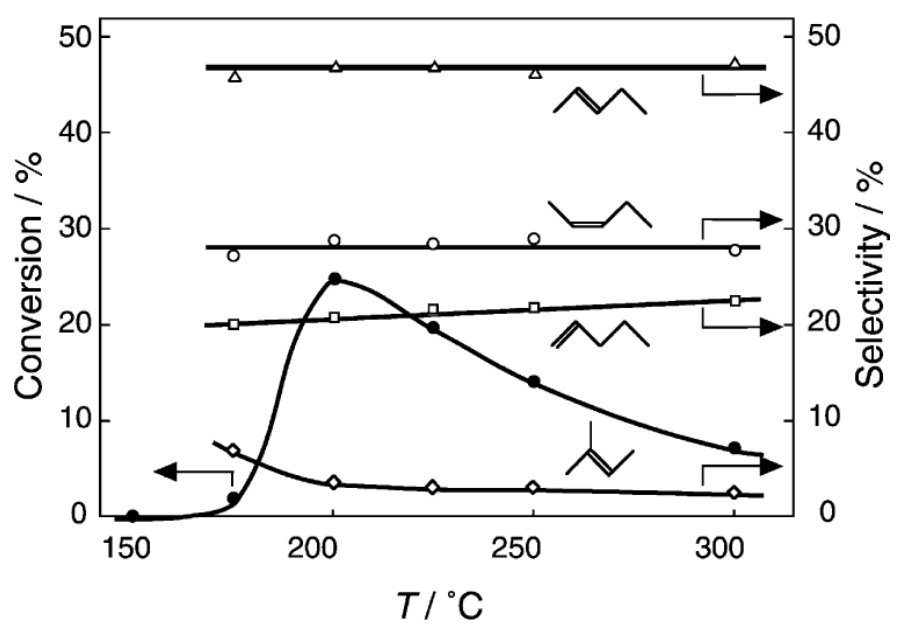

The effects of the carrier gases, helium and hydrogen, on $\mathrm{Re}_{3} \mathrm{Cl}_{9}$ at $300{ }^{\circ} \mathrm{C}$ are shown in Figure $35 \mathrm{a}$,b. The activities decreased with time but the selectivities remained substantially constant from the initial stage of the reactions. A remarkable feature of $\mathrm{Re}_{3} \mathrm{Cl}_{9}$ is that hydrogenolysis also occurred in the 
hydrogen stream to yield pentane in $38 \%$ selectivity, in contrast to the reaction in the stream of helium in which only dehydrohalogenation to yield pentenes occurred. Complex $\mathrm{Re}_{3} \mathrm{Cl}_{9}$ changed to metallic rhenium by treatment with hydrogen [1]. In this case, hydrogen participated chemically both as a reagent for the reduction of $\mathrm{Re}^{\mathrm{III}}{ }_{3} \mathrm{Cl}_{9}$ and as a reagent for hydrogenolysis of 1-chloropentane to pentane. Rhenium is located in a neighboring position to the platinum group metals in the periodic table, and is similar to them in some properties. Rhenium metal, as well as its oxide, sulfide, and selenide, is a catalyst for hydrogenation of organic compounds [90,254]; however, it has not been reported to catalyze the hydrogenolysis [255].

Figure 35. Catalytic activity and selectivity of $\mathrm{Re}_{3} \mathrm{Cl}_{9}(30 \mathrm{mg}, 34 \mu \mathrm{mol})$ in dehydrohalogenation and hydrogenolysis of 1-chloropentane $(0.20 \mathrm{~mL} / \mathrm{h}, 1.66 \mathrm{mmol})$ in a stream of (a) helium; and (b) hydrogen at $300{ }^{\circ} \mathrm{C}$. Other conditions are the same as in Figure 33.

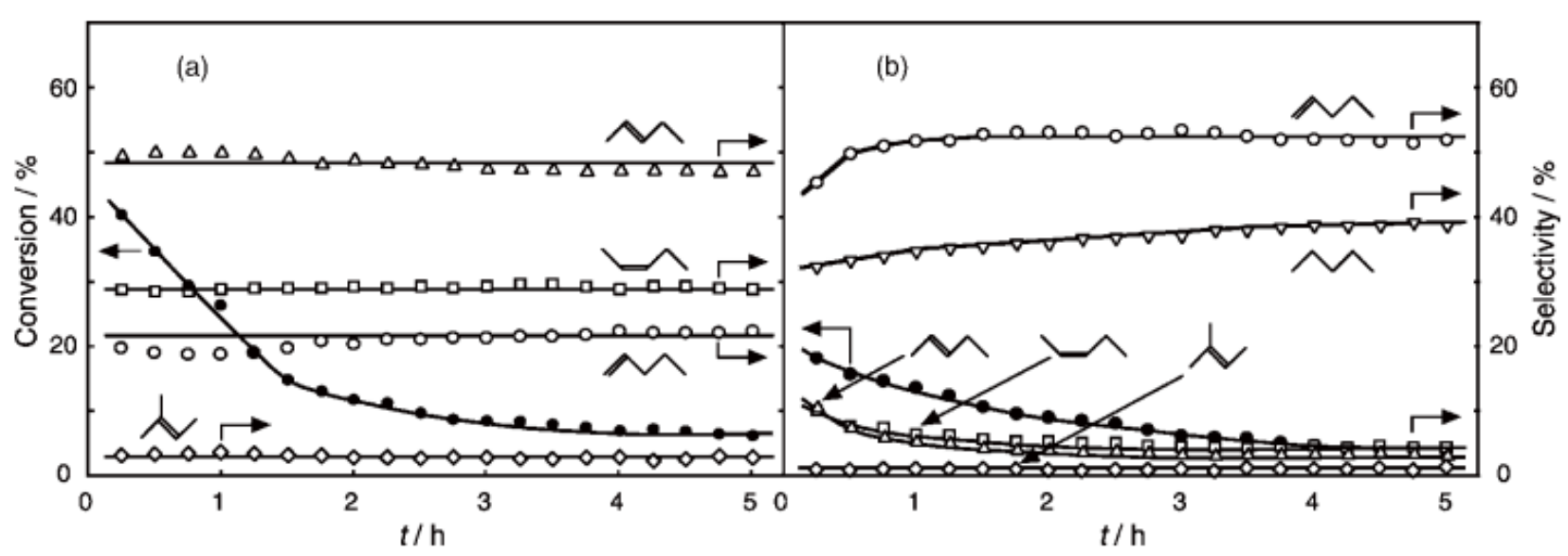

Various types of halogenated pentanes were allowed to react over $\mathrm{Re}_{3} \mathrm{Cl}_{9}$ in helium and hydrogen streams at $300{ }^{\circ} \mathrm{C}$, and the results are summarized in Table 13. Under helium, in which the cluster framework was retained, dehydrohalogenation to yield pentenes proceeded except for iodide, and the reactivity order was $\mathrm{F}>\mathrm{Cl}>\mathrm{Br}$ as in the case of niobium cluster. Under hydrogen, in which the cluster was reduced to metallic rhenium, both dehydrohalogenation to pentenes and hydrogenolysis to pentane for all 1-halogenated pentanes proceeded with almost equal reactivity. Even the $\mathrm{C}-\mathrm{F}$ bond was hydrogenolyzed by this catalyst. It has been reported in the hydrogenolysis of halogen substituents, $\mathrm{RX}$ to $\mathrm{RH}$, that the reactivity order is $\mathrm{RI}>\mathrm{RBr}>\mathrm{RCl}$ and that $\mathrm{RF}$ cannot be converted to $\mathrm{RH}$ by catalytic means $[27,56]$. However, rhenium metal obtained from reduction of cluster $\mathrm{Re}_{3} \mathrm{Cl}_{9}$ has caused the hydrogenolysis of the $\mathrm{C}-\mathrm{F}$ bond. 
Table 13. Dehydrohalogenation and hydrodehalogenation of halogenated pentanes over $\mathrm{Re}_{3} \mathrm{Cl}_{9}{ }^{\text {a }}$.

\begin{tabular}{cccccccc}
\hline $\mathbf{X}_{-} \mathbf{C}_{\mathbf{5}} \mathbf{H}_{\mathbf{1 1}}$ & Carrier & \multirow{2}{*}{ Conversion/\% } & \multicolumn{5}{c}{ Selectivity/\% } \\
\cline { 4 - 8 } $\mathbf{X}=$ & gas & & Pentane & 1-Pentene & cis-2-Pentene & trans-2-Pentene & 2-Methyl-2-butene \\
\hline $\mathrm{F}$ & $\mathrm{He}$ & 14.3 & 0.0 & 30.1 & 30.1 & 39.8 & 0.0 \\
$1-\mathrm{Cl}$ & $\mathrm{He}$ & 7.1 & 0.0 & 21.6 & 29.0 & 46.8 & 2.6 \\
$2-\mathrm{Cl}$ & $\mathrm{He}$ & 29.7 & 0.0 & 17.6 & 35.1 & 47.3 & 0.0 \\
$1-\mathrm{Br}$ & $\mathrm{He}$ & 5.7 & 0.0 & 22.9 & 28.2 & 45.0 & 3.9 \\
$1-\mathrm{I}$ & $\mathrm{He}$ & 0.0 & & & & & \\
$1-\mathrm{F}$ & $\mathrm{H}_{2}$ & 5.6 & 14.0 & 14.1 & 24.0 & 47.9 & 0.0 \\
$1-\mathrm{Cl}$ & $\mathrm{H}_{2}$ & 5.1 & 38.4 & 52.3 & 4.7 & 3.4 & 1.2 \\
$2-\mathrm{Cl}$ & $\mathrm{H}_{2}$ & 91.6 & 2.2 & 20.2 & 34.3 & 43.3 & 0.0 \\
$1-\mathrm{Br}$ & $\mathrm{H}_{2}$ & 4.7 & 40.9 & 37.2 & 7.6 & 12.7 & 1.6 \\
$1-\mathrm{I}$ & $\mathrm{H}_{2}$ & 4.9 & 37.9 & 43.5 & 9.9 & 8.7 & 0.0 \\
\hline
\end{tabular}

${ }^{\mathrm{a}}$ After activation of cluster $(30 \mathrm{mg}, 34 \mu \mathrm{mol})$ in the stream of carrier gas $(1.2 \mathrm{~L} / \mathrm{h})$ at $300{ }^{\circ} \mathrm{C}$ for $1 \mathrm{~h}$, reaction was started by introduction of halogenated pentane $(1.66 \mathrm{mmol} / \mathrm{h})$ to the stream without changing the temperature. At $5 \mathrm{~h}$ after the start of the reaction. Other conditions are the same as in Figure 33.

\section{Conclusions}

Halide clusters of Group 5-7 metals developed catalytic activity above $150-250{ }^{\circ} \mathrm{C}$, and the activity was retained up to $350-450{ }^{\circ} \mathrm{C}$ by taking advantage of their thermal stability and low vapor pressure, as well as their high melting point. Now, two types of active site have been established: the solid Brønsted acid site and a coordinatively unsaturated site that catalyzes like the platinum metals do. Various types of catalytic reactions including new reactions and concerted catalyses were observed over the cluster catalysts. Reactions catalyzed by halide cluster are shown in Figure 36.

Figure 36. Reactions catalyzed by halide clusters.

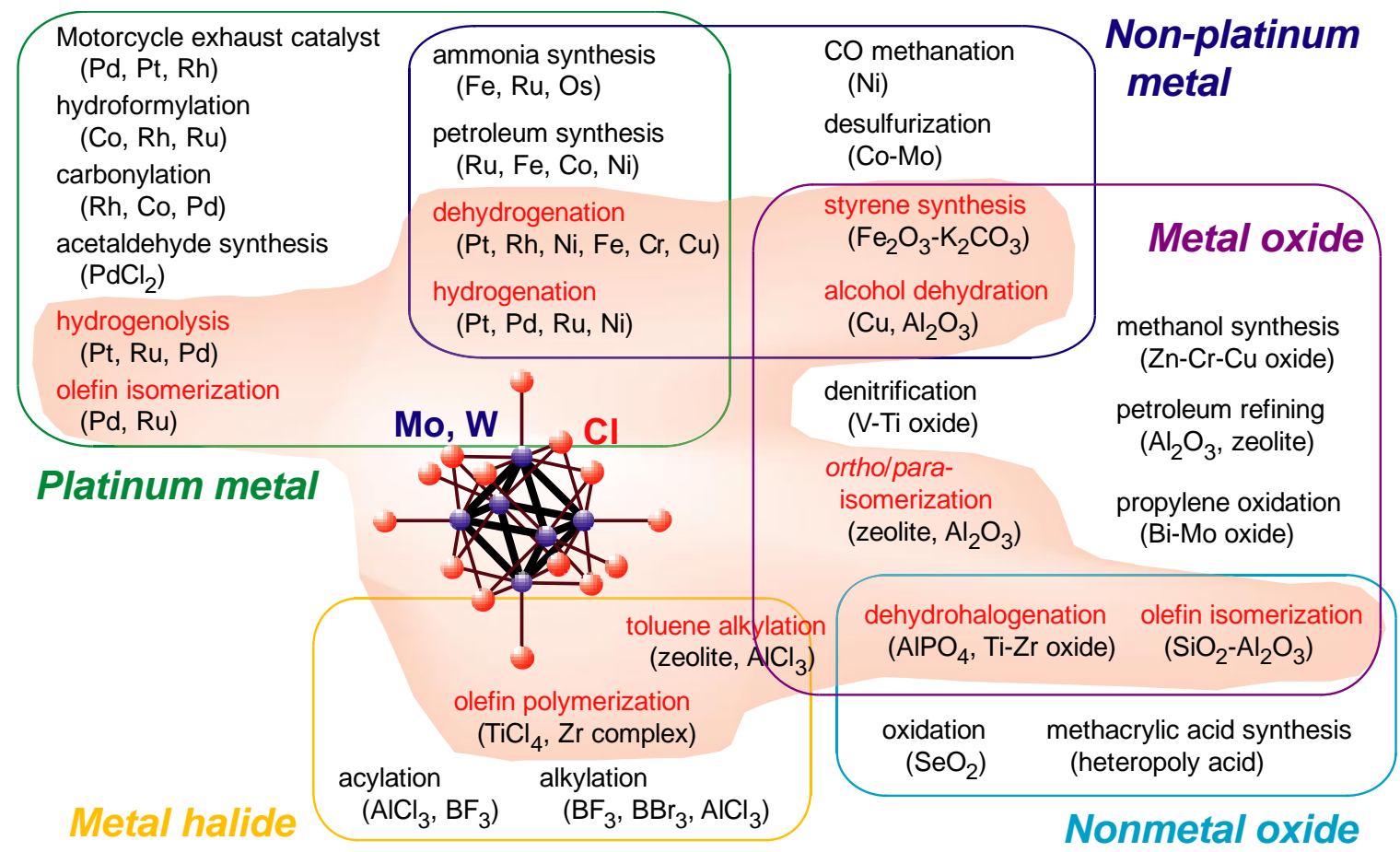


Although the majority of the reactions proceed over conventional acid catalysts or platinum-type metal catalysts, closer inspection showed some conspicuous features, particularly in terms of selectivity. Halide cluster catalysts are characterized by some aspects. Cluster counter anion is too large to abstract a counter cation from the protonated reactant. The cluster catalyst is not poisoned by halogen or sulfur atoms. Among other things, cluster catalysts are stable at high temperatures up to $350-450{ }^{\circ} \mathrm{C}$. At high temperatures, apparent activation energy decreases, and hence weak acid can be a catalyst without decomposing reactants, including basic compounds such as amine. Strong acid is less favorable as it sometimes decomposes a reactant at high temperatures. A comparison with other types of Brønsted acids that are stable at high temperatures is illustrated in Figure 37.

Figure 37. Thermally stable solid Brønsted acid catalysts. Solid acid is the mainstream of an industrial catalyst compared with liquid acid such as sulfuric acid or hydrochloric acid, since the separation of the solid acid is easy and solid acid does not corrode a container. A halide cluster has hydrogenation and dehydrogenation activity like the platinum group metals, zeolite has shape selectivity, and heteropoly acid has oxidizing power. They are stable up to $400{ }^{\circ} \mathrm{C}$ or more. Nafion- $\mathrm{H}$, a resin containing the $-\mathrm{CF}_{2} \mathrm{CF}_{2} \mathrm{SO}_{3} \mathrm{H}$ group, is stable up to about $200^{\circ} \mathrm{C}$.

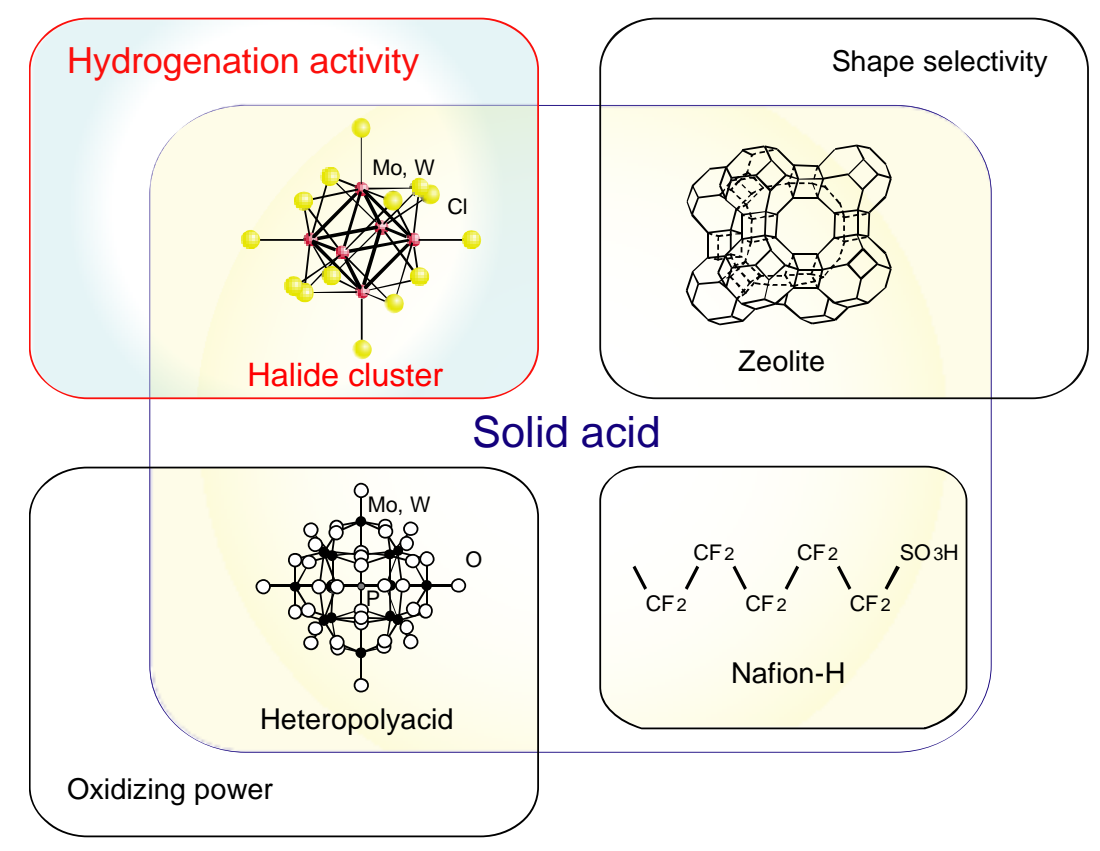

The catalytic nature of niobium and tantalum of Group 5 metal clusters were similar, and those of molybdenum and tungsten of Group 6 metal clusters were similar. Replacement of the chlorido ligands to bromido ligands had little effect on the catalytic behavior. However, the fundamental differences between the niobium cluster and tantalum cluster are not clear, and neither are those of the molybdenum cluster and tungsten cluster. The cluster framework of the rhenium cluster $\mathrm{Re}_{3} \mathrm{Cl}_{9}$ $\left(\left[\operatorname{Re}_{3} \mathrm{Cl}_{3}^{i}\right] \mathrm{Cl}_{3}^{a} \mathrm{Cl}^{a-a}{ }_{6 / 2}\right.$ ) was thermally less stable and was retained up to $300{ }^{\circ} \mathrm{C}$ under inert gas. Substitution of the weak halide bridges $\mathrm{Cl}^{a-a}{ }_{6 / 2}$ could induce new catalytic activities. A zirconium chloride cluster, $\mathrm{K}\left[\mathrm{Zr}_{6} \mathrm{Cl}_{12}^{i}\right] \mathrm{Cl}^{a-a}{ }_{6 / 2}$, has a $\mathrm{ZrCl}_{2}$ moiety, and hence it catalyzed Ziegler-Natta type polymerization of olefins combined with triethylaluminum [256]. Molybdenum [257] and rhenium sulfide clusters [258-260] also exhibited catalytic activities when activated at high temperatures. 
Although these reports are not reviewed, inorganic cluster catalysis will open a new area of high-temperature catalysis.

\section{Conflicts of Interest}

The authors declare no conflict of interest.

\section{References}

1. Kamiguchi, S.; Nagashima, S.; Chihara, T. Characterization of Catalytically Active Octahedral Metal Halide Cluster Complexes. Metals 2014, 4, 84-107.

2. Kamiguchi, S.; Iketani, S.; Kodomari, M.; Chihara, T. Catalytic Dehydrogenation of Ethylbenzene in Helium and Reductive Dealkylation in Hydrogen on $\mathrm{Nb}, \mathrm{Mo}, \mathrm{Ta}, \mathrm{W}$, and Re Halide Clusters. J. Clust. Sci. 2004, 15, 19-31.

3. Meima, G.R.; Menon, P.G. Catalyst deactivation phenomena in styrene production. Appl. Catal. A 2001, 212, 239-245.

4. Bautista, F.M.; Campelo, J.M.; Garcia, A.; Luna, D.; Marinas, J.M. Kinetics and mechanism of catalytic oxydehydrogenation of alkylbenzenes. J. Catal. 1989, 116, 338-349.

5. Bautista, F.M.; Campelo, J.M.; Garcia, A.; Luna, D.; Marinas, J.M. AlPO ${ }_{4}$-supported nickel catalysts: VIII. Support effects on the gas-phase dehydrogenation of alkylbenzenes. J. Catal. 1987, 107, 181-194.

6. Fujimoto, K.; Yamada, J.; Kunugi, T. Oxidative Dehydrogenation of Alkylbenzenes over Supported Palladium Catalysts Modified by Halide Ions. Nippon Kagaku Kaishi 1977, 1977, 523-528.

7. Bautista, F.M.; Campelo, J.M.; García, A.; Luna, D.; Marinas, J.M. Gas-Phase Dehydrogenation of Alkylbenzenes on Rh/AlPO ${ }_{4}$ Catalysts. Bull. Chem. Soc. Jpn. 1989, 62, 3670-3674.

8. Duprez, D.; Miloudi, A.; Delahay, G.; Maurel, R. Selective steam reforming of aromatic hydrocarbons: V. Steam conversion and hydroconversion of selected monoalkyl- and dialkylbenzenes on Pt and Ni catalysts. J. Catal. 1986, 101, 56-66.

9. Duprez, D.; Miloudi, A.; Delahay, G.; Maurel, R. Selective steam reforming of aromatic hydrocarbons: IV. Steam conversion and hydroconversion of selected monoalkyl- and dialkyl-benzenes on Rh catalysts. J. Catal. 1984, 90, 292-304.

10. Karge, H.G.; Ladebeck, J.; Sarbak, Z.; Hatada, K. Conversion of alkylbenzenes over zeolite catalysts. I. Dealkylation and disproportionation of ethylbenzene over mordenites. Zeolites 1982, 2, 94-102.

11. Karge, H.G.; Boldingh, E.P. In-situ IR investigation of coke formation on dealuminated mordenite catalysts. Catal. Today 1988, 3, 53-63.

12. Rudham, R.; Winstanely, A.W. Effects of dry-air calcination on the physico-chemical and catalytic properties of HZSM-5 zeolite. J. Chem. Soc. Faraday Trans. 1994, 90, 3191-3199.

13. Silva, J.M.; Ribeiro, M.F.; Ribeiro, F.R.; Benazzi, E.; Guisnet, M. Transformation of an ethylbenzene- $O$-xylene mixture on HMOR and Pt-HMOR catalysts. Comparison with ZSM-5 catalysts. Appl. Catal. A 1995, 125, 15-27. 
14. Chu, C.T-W.; Kuehl, G.H.; Lago, R.M.; Chang, C.D. Isomorphous substitution in zeolite frameworks: II. Catalytic properties of [B]ZSM-5. J. Catal. 1985, 93, 451-458.

15. Nishi, H.; Moffat, J.B. Catalysis by microporous heteropoly oxometalates: The conversion of 1-methyl-2-ethylbenzene. J. Mol. Catal. 1989, 51, 193-207.

16. Lisovskii, A.E.; Aharoni, C. Carbonaceous deposits as catalysts for oxydehydrogenation of alkylbenzenes. Catal. Rev. Sci. Eng. 1994, 36, 25-74.

17. Froment, G.F. Kinetic modeling of hydrocarbon processing and the effect of catalyst deactivation by coke formation. Catal. Rev. 2008, 50, 1-18.

18. Ganguly, P. Reactions of ketone on oxide surface II. Nature of the active sites of alumina. Proc. Indian Acad. Sci. A 1977, 86A, 283-297.

19. Kamiguchi, S.; Nishida, S.; Kodomari, M.; Chihara, T. Catalytic Hydrodehydration of Cyclohexanone, Hydrogenation of 2-Cyclohexen-1-one, and Dehydrogenation of Cyclohexene over a Mo Chloride Cluster with an Octahedral Metal Framework. J. Clust. Sci. 2005, 16, 77-91.

20. Ganguly, P. Reactions of ketones on oxide surfaces, I. Reaction sequence of cyclohexanone on alumina. Proc. Indian Acad. Sci. A 1977, 86A, 65-79.

21. Adkins, H.; Watkins, S.H. Investigation of the Properties of Alumina ex-Aluminum Isopropoxide as a Catalyst for Dehydrations. J. Am. Chem. Soc. 1951, 73, 2184-2188.

22. Spangler, C.W.; Maier, P.K.; Bennet, K.E. Alumina-catalyzed dehydration of substituted cyclohexanones. Mechanism of hydrocarbon formation. J. Org. Chem. 1972, 37, 3347-3350.

23. Jayamani, M.; Pillai, C.N. Hydrogen transfer reactions. Part X. Disproportionation of ketones. Indian J. Chem. B 1985, 24B, 1172-1174.

24. Paal, Z.; Peter, A.; Tetenyi, P. Radiotracer investigation of transformations of cyclohexanol in the presence of a nickel powder catalyst. Z. Phys. Chem. (München) 1974, 91, 54-66.

25. Dobrovolszky, M.; Tétényi, P.; Paár, Z. Catalytic transformations of cyclohexanol on Group VIII metal catalysts. J. Catal. 1982, 74, 31-43.

26. Paál, Z.; Péter, A.; Tétényi, P. Dehydrogenation of cyclohexanol in the presence of different metal catalysts. React. Kinet. Catal. Lett. 1974, 1, 121-124.

27. Rylander, P. Catalytic Hydrogenation in Organic Synthesis; Academic Press: New York, NY, USA, 1979.

28. Vít, Z.; Nondek, L.; Málek, J. Liquid-phase aldol condensation of cyclohexanone on aluminium and iron oxides. Collect. Czech. Chem. Commun. 1982, 47, 2235-2245.

29. Kousková, A.; Adámek, J.; Ponec, V. Hydrogenation of ethylene on vapour-deposited metal films. Collect. Czech. Chem. Commun. 1970, 35, 2538-2547.

30. Beeck, O. Hydrogenation catalysts. Discuss. Faraday Soc. 1950, 8, 118-128.

31. Chung, J.-S.; Zhang, J.P.; Burwell, R.L., Jr. Highly reduced $\mathrm{MoO}_{3} \mathrm{Al}_{2} \mathrm{O}_{3}$ catalysts: I. Characterization. J. Catal. 1989, 116, 506-518.

32. Yasumaru, J.; Yamada, M.; Houalla, M.; Hercules, D.M. Distribution of Mo Oxidation States in Reduced $\mathrm{Mo} / \mathrm{Al}_{2} \mathrm{O}_{3}$ Catalysts. Correlation with Catalytic Activity. Stud. Surf. Sci. Catal. 1993, 75, 1867-1870.

33. Ali, L.I.; Ali, A.-G.A.; Aboul-Fotouh, S.M.; Aboul-Gheit, A.K. Dehydrogenation of cyclohexane on catalysts containing noble metals and their combinations with platinum on alumina support. Appl. Catal. A 1999, 177, 99-110. 
34. Yamanaka, T. Catalysis by platinum metals. V. Dehydrogenation. III. Kagaku Kogyo 1979, 30, 843-847.

35. Belyi, A.S.; Smolikov, M.D.; Ostrovskii, N.M.; Kolomytsev, Y.N.; Duplyakin, V.K. Catalytic properties of metallic and electron-deficient platinum in reforming over $\mathrm{Pt} / \mathrm{Al}_{2} \mathrm{O}_{3}$ catalysts. React. Kinet. Catal. Lett. 1988, 37, 457-462.

36. Engels, S.; Specht, H.; Hille, J. Untersuchungen an Metallkatalysatoren; Zur Wirkungsweise von Pt- $\mathrm{Al}_{2} \mathrm{O}_{3}$-Katalysatoren. Z. Chem. 1974, 14, 202-203.

37. Kamiguchi, S.; Mori, T.; Watanabe, M.; Suzuki, A.; Kodomari, M.; Nomura, M.; Iwasawa, Y.; Chihara, $\mathrm{T}$. Retention of the octahedral metal framework of $\mathrm{Nb}$ and Mo halide clusters in catalytic decomposition of phenyl acetate to phenol and ketene. J. Mol. Catal. A 2006, 253, 176-186.

38. Blatt, A.H. The Fries Reaction. Org. React. 1942, 1, 342-369.

39. Koningsveld, H.; Scheele, J.J.; Jansen, J.C. Structure of 4-tert-butyl-2,6-dimethylacetophenone and comparison with its $\mathrm{FeCl}_{3}$ complex. Acta. Cryst. 1987, C43, 294-296.

40. Vogt, A.H.G.; Kouwenhoven, H.W. Fries Rearrangement of Phenyl Acetate over ZSM-5 Based Catalysts. Collect. Czech. Chem. Commun. 1992, 57, 853-861.

41. Vogt, A.; Kouwenhoven, H.W.; Prins, R. Fries rearrangement over zeolitic catalysts. Appl. Catal. A 1995, 123, 37-49.

42. Freese, U.; Heinrich, F.; Roessner, F. Acylation of aromatic compounds on H-Beta zeolites. Catal. Today 1999, 49, 237-244.

43. Van Bekkum, H.; Hoefnagel, A.J.; van Koten, M.A.; Gunnewegh, E.A.; Vogt, A.H.G.; Kouwenhoven, H.W. Zeolite Catalyzed Aromatic Acylation and Related Reaches. Stud. Surf. Sci. Catal. 1994, 83, 379-390.

44. Pouilloux, Y.; Gnep, N.S.; Magnoux, P.; Perot, G. Zeolite-catalyzed rearrangement of phenyl acetate. J. Mol. Catal. 1987, 40, 231-233.

45. Pouilloux, Y.; Bodibo, J.-P.; Neves, I.; Gubelmann, M.; Perot, G.; Guisnet, M. Mechanism of Phenylacetate Transformation on Zeolites. Stud. Surf. Sci. Catal. 1991, 59, 513-522.

46. Cundy, C.S.; Higgins, R.; Kibby, S.A.M.; Lowe, B.M.; Paton, R.M. Para-selective Fries rearrangement of phenyl acetate in the presence of zeolite molecular sieves. Tetrahedron Lett. 1989, 30, 2281-2284.

47. Borzatta, V.; Busca, G.; Poluzzi, E.; Rossetti, V.; Trombetta, M.; Vaccari, A. As to the reasons of the high activity of a commercial pentasil-type zeolite in the vapor-phase Fries rearrangement. Appl. Catal. A 2004, 257, 85-95.

48. Heidekum, A.; Harmer, M.A.; Hoelderich, W.F. Highly Selective Fries Rearrangement over Zeolites and Nafion in Silica Composite Catalysts: A Comparison. J. Catal. 1998, 176, 260-263.

49. Neves, I.; Jayat, F.; Magnoux, P.; Pérot, G.; Ribeiro, F.R.; Gubelmann, M.; Guisnet, M. Acylation of phenol with acetic acid over a HZSM5 zeolite, reaction scheme. J. Mol. Catal. 1994, 93, 169-179.

50. Peri, J.B. A Model for the Surface of $\gamma$-Alumina. J. Phys. Chem. 1965, 69, 220-230.

51. Koubek, J.; Volf, J.; Pašek, J. Adsorption of amines on alumina. J. Catal. 1975, 38, 385-393.

52. Hogan, P.; Pašek, J. Reaction of amines and acid catalysts. IV. Kinetics and mechanism of olefin formation from triethylamine and diisopropylamine on $\gamma$-alumina. Collect. Czech. Chem. Commun. 1973, 38, 1513-1521. 
53. Rajagopal, S.; Grimm, T.L.; Collins, D.J.; Miranda, R. Denitrogenation of piperidine on alumina, silica, and silica-aluminas: The effect of surface acidity. J. Catal. 1992, 137, 453-461.

54. Kamiguchi, S.; Noda, M.; Miyagishi, Y.; Nishida, S.; Kodomari, M.; Chihara, T. Catalytic isomerization of 1-hexene to 2-hexene by halide clusters of $\mathrm{Nb}$, Mo, Ta and $\mathrm{W}$ possessing an octahedral metal core. J. Mol. Catal. A 2003, 195, 159-171.

55. Freifelder, M. Catalytic Hydrogenation in Organic Synthesis, Procedures and Commentary; Wiley: New York, NY, USA, 1978.

56. Freifelder, M. Practical Catalytic Hydrogenation; Wiley: New York, NY, USA, 1971.

57. Edgecombe, F.H.C. The isomerization of 1-butene on $\mathrm{TiCl}_{3}$ an example of kinetically controlled isomerization. Tetraherdon. Lett. 1962, 24, 1161-1163.

58. Broadbent, H.S.; Campbell, G.C.; Bartley, W.J.; Johnson, J.H. Rhenium and Its Compounds as Hydrogenation Catalysts. III. Rhenium Heptoxide. J. Org. Chem. 1959, 24, 1847-1854.

59. Broadbent, H.S.; Slaugh, L.H.; Jarvis, N.L. Rhenium Sulfides as Liquid-Phase Hydrogenation Catalysts. A Comparison with Molybdenum Sulfide and Cobalt Polysulfide. J. Am. Chem. Soc. 1954, 76, 1519-1523.

60. Hattori, H. Heterogeneous Basic Catalysis. Chem. Rev. 1995, 95, 537-558.

61. Iizuka, T.; Ogasawara, K.; Tanabe, K. Acidic and Catalytic Properties of Niobium Pentaoxide. Bull. Chem. Soc. Jpn. 1983, 56, 2927-2931.

62. Hattori, H.; Asada, N.; Tanabe, K. Acidic Property and Catalytic Activity of Tungsten Oxide. Bull. Chem. Soc. Jpn. 1978, 51, 1704-1707.

63. Abbot, J.; Wojciechowski, B.W. The nature of active sites in the isomerization of 1-hexene on cracking catalysts. J. Catal. 1984, 90, 270-278.

64. Abbot, J.; Corma, A.; Wojciechowski, B.W. The catalytic isomerization of 1-hexene on H-ZSM-5 zeolite: The effects of a shape-selective catalyst. J. Catal. 1985, 92, 398-408.

65. Kamiguchi, S.; Nagashima, S.; Komori, K.; Kodomari, M.; Chihara, T. Thermal Activation of Molecular Tungsten Halide Clusters with the Retention of an Octahedral Metal Framework and the Catalytic Dehydration of Alcohols to Olefins as a Solid Acid Catalyst. J. Clust. Sci. 2007, 18, 414-430.

66. Winfield, M.E. Catalytic dehydration and hydration. In Catalysis; Emmett, P.H., Ed.; Reinhold: New York, NY, USA, 1960; Volume 7, pp. 93-182.

67. Pines, H.; Manassen, J. The Mechanism of Dehydration of Alcohols over Alumina Catalysts. Adv. Catal. 1966, 16, 49-93.

68. Park, C.; Keane, M.A. Gas phase dehydration of $\mathrm{C}_{6}$ alcohols promoted by $\mathrm{Y}$ zeolite and supported nafion catalysts. J. Mol. Catal. A 2001, 166, 303-322.

69. Okuhara, T.; Kasai, A.; Hayakawa, N.; Misono, M.; Yoneda, Y. The important role of the bulk of 12-tungstophosphoric acid in the catalytic dehydration of alcohols to olefins. Chem. Lett. 1981, 391-394.

70. Haber, J.; Pamin, K.; Matachowski, L.; Napruszewska, B.; Połtowicz, J. Potassium and Silver Salts of Tungstophosphoric Acid as Catalysts in Dehydration of Ethanol and Hydration of Ethylene. J. Catal. 2002, 207, 296-306.

71. Saito, Y.; Cook, P.N.; Niiyama, H.; Echigoya, E. Dehydration of alcohols on/in heteropoly compounds. J. Catal. 1985, 95, 49-56. 
72. Saito, Y.; Niiyama, H.; Echigoya, E. Ether Formation from Alcohols on Heteropolyacid. Nippon Kagaku Kaishi 1984, 1984, 391-396.

73. Nishiguchi, T.; Kamio, C. Dehydration of alcohols catalysed by metallic sulphates supported on silica gel. J. Chem. Soc. Perkin Trans. 1 1989, 707-710.

74. Halász, I.; Vinek, H.; Thomke, K.; Noller, H. Rate Determining Step in Alcohol Dehydration on $\mathrm{La}_{2} \mathrm{O}_{3}, \mathrm{ThO}_{2}$ and $\mathrm{MoO}_{3}$, and Relations to Double Bond Shift in Olefins. Z. Phys. Chem. (München) 1985, 144, 157-163.

75. Yamaguchi, T.; Tanabe, K. Dehydration of Secondary Alcohols Catalyzed by Solid Acids. Bull. Chem. Soc. Jpn. 1974, 47, 424-429.

76. Lundeen, A.J.; van Hoozer, R. Selective catalytic dehydration. Thoria-catalyzed dehydration of alcohols. J. Org. Chem. 1967, 32, 3386-3389.

77. Kamiguchi, S.; Nishida, S.; Kurokawa, H.; Miura, H.; Chihara, T. Formation of Brønsted acid site on halide clusters of group 5 and 6 transition metals Catalytic methylation and demethylation of methylbenzenes with methanol. J. Mol. Catal. A 2005, 226, 1-9.

78. Roberts, R.M.; Lin, Y.-T.; Anderson, G.P., Jr. New Friedel-Crafts chemistry-XX: Reported lack of rearrangement in alkylations with primary alcohols and aluminum chloride. Tetrahedron 1969, 25, 4173-4182.

79. Streitwieser, A., Jr.; Stang, P.J. Boron Fluoride-Alcohol Alkylations. III. Stereochemistry of alkylation of benzene with 2-propanol-1-d 3 . J. Am. Chem. Soc. 1965, 87, 4953.

80. Benito, I.; del Riego, A.; Martinez, M.; Blanco, C.; Pesquera, C.; González, F. Toluene methylation on $\mathrm{Al}_{13^{-}}$and $\mathrm{GaAl}_{12}$-pillared clay catalysts. Appl. Catal. A 1999, 180, 175-182.

81. Bautista, F.M.; Blanco, A.; Campelo, J.M.; Garcia, A.; Luna, D.; Marinas, J.M.; Romero, A.A. Continuous flow toluene methylation over $\mathrm{AlPO}_{4}$ and $\mathrm{AlPO}_{4}-\mathrm{Al}_{2} \mathrm{O}_{3}$ catalysts. Catal. Lett. 1994, 26, 159-167.

82. Bautista, F.M.; Campelo, J.M.; Garcia, A.; Luna, D.; Marinas, J.M.; Romero, A.A. Toluene methylation on $\mathrm{AlPO}_{4}-\mathrm{Al}_{2} \mathrm{O}_{3}$ catalysts (5-15 wt.\% $\mathrm{Al}_{2} \mathrm{O}_{3}$ ). React. Kinet. Catal. Lett. 1996, 57, 61-70.

83. Sabu, K.R.; Rao, K.V.C.; Nair, C.G.R. Alkylation of benzene, toluene and xylene isomers with $\mathrm{C}_{2}, \mathrm{C}_{3}$ and $\mathrm{C}_{4}$ aliphatic alcohols on $\mathrm{TiO}_{2}-\mathrm{SiO}_{2}-\mathrm{Al}_{2} \mathrm{O}_{3}$ and $\mathrm{MoO}_{3}-\mathrm{SiO}_{2}-\mathrm{Al}_{2} \mathrm{O}_{3}$. Indian J. Chem. B 1994, 33B, 1053-1061.

84. Kaspi, J.; Montgomery, D.D.; Olah, G.A. Heterogeneous catalysis by solid superacids. 5. Methylation of benzene and methylbenzenes with methyl alcohol over a perfluorinated resin sulfonic acid (Nafion-H) catalyst. J. Org. Chem. 1978, 43, 3147-3150.

85. Kaeding, W.W.; Chu, C.; Young, L.B.; Weinstein, B.; Butter, S.A. Selective alkylation of toluene with methanol to produce para-Xylene. J. Catal. 1981, 67, 159-174.

86. Corma, A. Inorganic solid acids and their use in acid-catalyzed hydrocarbon reactions. Chem. Rev. 1995, 95, 559-614.

87. Kim, J.-H.; Kunieda, T.; Niwa, M. Generation of shape-selectivity of $p$-xylene formation in the synthesized ZSM-5 zeolites. J. Catal. 1998, 173, 433-439.

88. Vinek, H.; Derewinski, M.; Mirth, G.; Lercher, J.A. Alkylation of toluene with methanol over alkali exchanged ZSM-5. Appl. Catal. 1991, 68, 277-284. 
89. Vinek, H.; Lercher, J.A. Production and reactions of xylenes over H-ZSM5. J. Mol. Catal. 1991, 64, 23-39.

90. Čejka, J.; Wichterlová, B. Acid-catalyzed synthesis of mono- and dialkyl benzenes over zeolites: Active sites, zeolite topology, and reaction mechanisms. Catal. Rev. 2002, 44, 375-421.

91. Mirth, G.; Lercher, J.A. On the Role of Product Isomerization for Shape Selective Toluene Methylation over HZSM5. J. Catal. 1994, 147, 199-206.

92. Philippou, A.; Anderson, M.W. Solid-State NMR Investigation of the Alkylation of Toluene with Methanol over Basic Zeolite X. J. Am. Chem. Soc. 1994, 116, 5774-5783.

93. Itoh, H.; Miyamoto, A.; Murakami, Y. Mechanism of the side-chain alkylation of toluene with methanol. J. Catal. 1980, 64, 284-294.

94. Wieland, W.S.; Davis, R.J.; Garces, J.M. Solid base catalysts for side-chain alkylation of toluene with methanol. Catal. Today 1996, 28, 443-450.

95. Tanabe, K.; Takahashi, O.; Hattori, H. Anomalous effect of nitrogen on side-chain alkylation of toluene with methanol over solid bases. React. Kinet. Catal. Lett. 1977, 7, 347-352.

96. McCaulay, D.A.; Lien, A.P. Relative Basicity of the Methylbenzenes. J. Am. Chem. Soc. 1951, 73, 2013-2017.

97. Patnasamy, P.; Bhat, R.N.; Pokhriyal, S.K.; Hegde, S.G.; Kumar, R. Reactions of aromatic hydrocarbons over zeolite $\beta$. J. Catal. 1989, 119, 65-70.

98. Smirniotis, P.G.; Ruckenstein, E. Alkylation of Benzene or Toluene with $\mathrm{MeOH}$ or $\mathrm{C}_{2} \mathrm{H}_{4}$ over ZSM-5 or $\beta$ Zeolite: Effect of the Zeolite Pore Openings and of the Hydrocarbons Involved on the Mechanism of Alkylation. Ind. Eng. Chem. Res. 1995, 34, 1517-1528.

99. Bjørgen, M.; Olsbye, U.; Kolboe, S. Coke precursor formation and zeolite deactivation: Mechanistic insights from hexamethylbenzene conversion. J. Catal. 2003, 215, 30-44.

100. Sassi, A.; Wildman, M.A.; Ahn, H.J.; Prasad, P.; Nicholas, J.B.; Haw, J.F. Methylbenzene Chemistry on Zeolite HBeta: Multiple Insights into Methanol-to-Olefin Catalysis. J. Phys. Chem. B 2002, 106, 2294-2303.

101. Kamiguchi, S.; Takahashi, I.; Nagashima, S.; Nakamura, A.; Chihara, T. Catalytic N-Alkylation of Amines with Primary Alcohols over Halide Clusters. J. Clust. Sci. 2007, 18, 935-945.

102. Bhattacharyya, A.K.; Nandi, D.K. Synthesis of N.,N.-Dimethylaniline from Aniline and Methanol. Ind. Eng. Chem., Prod. Res. Dev. 1976, 15, 201-206.

103. Galík, V.; Kafka, Z.; Landa, S.; Śafář, M. Über stickstoffhaltige verbindungen in erdöl und erdölfraktionen IV. Darstellung einiger 1-alkylpiperidine. Collect. Czech. Chem. Commun. 1968, 33, 609-613.

104. Matsuhashi, H.; Arata, K. Synthesis of N.-Methylaniline and N.,N.-Dimethylaniline with Methanol over Alumina Catalyst. Bull. Chem. Soc. Jpn. 1991, 64, 2605-2606.

105. Ko, A.; Yang, C.; Zhu, W.; Lin, H. Selective $N$-alkylation of aniline with methanol over

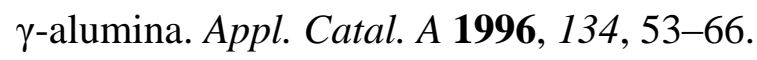

106. Valot, F.; Fache, F.; Jacquot, R.; Spagnol, M.; Lemaire, M. Gas-phase selective $N$-alkylation of amines with alcohols over $\gamma$-alumina. Tetrahedron Lett. 1999, 40, 3689-3692.

107. Parera, J.M.; González, A.; Barral, M.A. Acidic Catalysts for Methylation of Aromatic Amines. Activity, Selectivity, and Stability of Alumina and Silica-Alumina, Synthetic or Natural, in the Preparation of Dimethylaniline. Ind. Eng. Chem., Prod. Res. Dev. 1968, 7, 259-262. 
108. Su, B.L.; Barthomeuf, D. Alkylation of aniline with methanol: Change in selectivity with acido-basicity of faujasite catalysts. Appl. Catal. A 1995, 124, 73-80.

109. Rao, P.R.H.P.; Massiani, P.; Barthomeuf, D. Alkylation of aniline with methanol of Beta and EMT zeolites exchanged with alkaline cations. Stud. Surf. Sci. Catal. 1994, 84, 1449-1455.

110. Nagaraju, N.; Kuriakose, G. Activity of amorphous V-AlPO 4 and Co-AlPO 4 in the selective synthesis of $N$.-monoalkylated aniline via alkylation of aniline with methanol or dimethyl carbonate. New J. Chem. 2003, 27, 765-768.

111. Prasad, S.; Rao, B.S. Mechanism of aniline alkylation with methanol over $\mathrm{AlPO}_{4-5}$. J. Mol. Catal. 1990, 62, L17-L22.

112. Frank, B.; Habel, D.; Schomäcker, R. $N$-alkylation of aniline with ethanol over an industrial niobic acid catalyst-Influence of water formation on kinetics and selectivity. Catal. Lett. 2005, 100, 181-187.

113. Li, K.-T.; Peng, Y.-C. Methylation of $n$-butylamine over solid-acid catalysts. Appl. Catal. A 1994, 109, 225-233.

114. Tyutyunnikov, B.N.; Basov, A.S.; Petryakova, N.K. Synthesis of dimethylalkylamines. Khim. Prom.-st. (Moscow) 1969, 45, 667-669.

115. Bitsi, G.; Schleiffer, E.; Antoni, F.; Jenner, G. $N$-alkylation d'amines en catalyse homogène. Synthèse de mono- et de diamines cycliques. J. Organomet. Chem. 1989, 373, 343-352.

116. Hackenberger, A.; Kolbinger, H.J.; Baer, K. 2-Substituted 6-methylanilines. DE Patent 3309 354, 1984.

117. Takahata, K.; Taniguchi, K. o-Alkylated aromatic amine. U.S. Patent 4 351 958, 1982.

118. Chen, P.Y.; Chen, M.C.; Chu, H.Y.; Chang, N.S.; Chuang, T.K. The Selective Alkylation of Aniline with Methanol over ZSM-5 Zeolite. Stud. Surf. Sci. Catal. 1986, 28, 739-746.

119. Nagashima, S.; Kamiguchi, S.; Ohguchi, S.; Chihara, T. Gas-Phase Alkylation of Pyridine and Phenol with Alcohols Over Halide Clusters of Group 5-7 Transition Metals as Solid Acid Catalysts. J. Clust. Sci. 2011, 22, 647-660.

120. Gudz, V.N.; Trifonova, S.A.; Shpagina, A.N. Catalytic alkylation of pyridine and its homologs. II. Alkylation of 2-picoline by methanol in the presence of hydrogen chloride. Khim. Geterotsikl. Soedin. 1972, 1092-1093.

121. Kashiwagi, H.; Fujiki, Y.; Enomoto, S. Catalytic reactions of pyridines. VI. heterogeneous vapor-phase ring alkylation of pyridines with alcohols over $\mathrm{H}^{+}-, \mathrm{Li}^{+}-$, and alkaline earth cation-exchanged zeolites. Chem. Pharm. Bull. 1982, 30, 2575-2578.

122. Myerly, R.C.; Weinberg, K.G. The catalytic methylation of pyridine and its derivatives in the vapor phase. J. Org. Chem. 1966, 31, 2008-2009.

123. Kameswari, U. Methylation of pyridine over zeolites. FT-IR studies for selectivity and acidity correlations. React. Kinet. Catal. Lett. 1995, 55, 291-304.

124. Kaspi, J.; Olah, G.A. Heterogeneous catalysis by solid superacids. 4. Methylation of phenols with methyl alcohol and the rearrangement of anisole and methylanisoles over a perfluorinated resinsulfonic acid (Nafion-H) catalyst. J. Org. Chem. 1978, 43, 3142-3147.

125. Sato, S.; Koizumi, K.; Nozaki, F. Ortho-Selective Methylation of Phenol Catalyzed by $\mathrm{CeO}_{2}-\mathrm{MgO}$ Prepared by Citrate Process. J. Catal. 1998, 178, 264-274. 
126. Yamawaki, J.; Ando, T. Potassium fluoride on inorganic solid supports. A search for further efficient reagents promoting hydrogen-bond-assisted alkylations. Chem. Lett. 1979, $755-758$.

127. Santacesaria, E.; Grasso, D.; Gelosa, D.; Carrá, S. Catalytic alkylation of phenol with methanol: Factors influencing activities and selectivities: I. Effect of different acid sites evaluated by studying the behaviour of the catalysts: $\gamma$-alumina, nafion- $\mathrm{H}$, silica-alumina and phosphoric acid. Appl. Catal. 1990, 64, 83-99.

128. Kharlampovich, G.D.; Vinogradova, V.N.; Churkin, Y.V.; Kruglikov, A.A.; Gritsenko, B.D.; Petrova, L.A.; Strukova, L.V. Technology for production of synthetic phenols and its improvement. Khim. Prom.-st. (Moscow) 1990, 649-651.

129. Wang, W.; De Cola, P.L.; Glaeser, R.; Ivanova, I.I.; Weitkamp, J.; Hunger, M. Methylation of Phenol by Methanol on Acidic Zeolite H-Y Investigated by in situ CF MAS NMR Spectroscopy. Catal. Lett. 2004, 94, 119-123.

130. Santacesaria, E.; Serio, M.D.; Ciambelli, P.; Gelosa, D.; Carrá, S. Catalytic alkylation of phenol with methanol: Factors influencing activities and selectivities: II. Effect of intracrystalline diffusion and shape selectivity on H-ZSM5 zeolite. Appl. Catal. 1990, 64, 101-107.

131. Campelo, J.M.; Garcia, A.; Luna, D.; Marinas, J.M.; Moreno, M.S. Phenol alkylation and anisole rearrangement on aluminum orthophosphate, titanium dioxide and aluminum orthophosphate-titanium dioxide catalysts. Bull. Soc. Chim. Fr. 1988, 283-292.

132. Romero, M.D.; Ovejero, G.; Rodríguez, A.; Gómez, J.M.; Águeda, I. O Methylation of Phenol in Liquid Phase over Basic Zeolites. Ind. Eng. Chem. Res. 2004, 43, 8194-8199.

133. Sad, M.E.; Padró, C.L.; Apesteguía, C.R. Synthesis of cresols by alkylation of phenol with methanol on solid acids. Catal. Today 2008, 133-135, 720-728.

134. Sad, M.E.; Padró, C.L.; Apesteguía, C.R. Selective synthesis of $p$-cresol by methylation of phenol. Appl. Catal. A 2008, 342, 40-48.

135. Bautista, F.M.; Campelo, J.M.; Garcia, A.; Luna, D.; Marinas, J.M.; Romero, A.A.; Urbano, M.R. Conversion of anisole in the presence of methanol over $\mathrm{AlPO}_{4}-\mathrm{Al}_{2} \mathrm{O}_{3}$ catalysts modified with fluoride and sulfate anions. React. Kinet. Catal. Lett. 1995, 54, 99-106.

136. Nagashima, S.; Kudo, K.; Yamazaki, H.; Kamiguchi, S.; Chihara, T. Gas-phase S-alkylation of benzenethiol with aliphatic alcohols, ethers, esters, alkyl halides and olefins over halide cluster catalysts of Groups 5 and 6 transition metals. Appl. Catal. A 2013, 450, 50-56.

137. Areshidze, K.I.; Gadzhiev, M.K. Catalytic alkylation of thiophenol by methyl alcohol. Soobshch. Akad. Nauk. Gruz. SSR 1977, 87, 609-612.

138. Onoe, A.; Tai, S. Preparation of alkyl phenyl sulfides from thiophenol and ethers or alcohols. JP Patent 2002-371056. Sumitomo Seika Chemicals Co., Ltd., Tokyo, Japan, 2002.

139. Selva, M.; Trotta, F.; Tundo, P. Esters and orthoesters as alkylating agents at high temperature. Applications to continuous-flow processes. J. Chem. Soc. Perkin Trans. 2 1992, 519-522.

140. Areshidze, K.I.; Gadzhiev, M.K.; Nebieridze, N.M. Catalytic synthesis of $n$-alkyl aryl sulfides. Neftekhimiya 1976, 16, 898-901.

141. Vijaikumar, S.; Pitchumani, K. Simple, solvent free syntheses of unsymmetrical sulfides from thiols and alkyl halides using hydrotalcite clays. J. Mol. Catal. A 2004, 217, 117-120. 
142. Venuto, P.B.; Hamilton, L.A.; Landis, P.S.; Wise, J.J. Organic reactions catalyzed by crystalline aluminosilicates: I. Alkylation reactions. J. Catal. 1966, 5, 81-98.

143. Tundo, P.; Trotta, F.; Moraglio, G.; Ligorati, F. Continuous-flow processes under gas-liquid phase-transfer catalysis (GL-PTC) conditions: The reaction of dialkyl carbonates with phenols, alcohols, and mercaptans. Ind. Eng. Chem. Res. 1988, 27, 1565-1571.

144. Kawamura, M.; Hatta, M.; Koune, N.; Kitagishi, N. Alkyl phenyl sulfides. U.S. Patent 4124 646, 1978.

145. Kataev, E.G.; Gabdrakhmanov, F.G.; Tutubalina, V.P. Synthesis of thio ethers in the presence of KU-2 cation-exchange reins. Zh. Org. Khim. 1971, 7, 122-125.

146. Bartkus, E.A.; Hotelling, E.B.; Neuworth, M.B. Ring Alkylation of Aromatic Thiols. J. Org. Chem. 1960, 25, 232-233.

147. Laufer, R.J. Catalytic process for preparing o-alkylthiophenols. U.S. Patent 3076 848, 1963.

148. Kamiguchi, S.; Takahashi, I.; Kurokawa, H.; Miura, H.; Chihara, T. Vapor-phase synthesis of 1,2-dihydro-2,2,4-trimethylquinolines from anilines and acetone over group 5-7 metal halide clusters as catalysts. Appl. Catal. A 2006, 309, 70-75.

149. Manske, R.H.F.; Kulka, M. The Skraup Synthesis of Quinolines. Org. React. 1953, 7, 59-98.

150. Lugovik, B.A.; Yudin, L.G.; Kost, A.N. Technology of the reaction of acetone with aniline. Zh. Prikl. Khim. (Sankt.-Peterburg.) 1965, 38, 216-220.

151. Layer, R.W. Synthesis of 1,3,5-trialkylbenzenes from anils of methyl alkyl ketones. J. Org. Chem. 1981, 46, 4552-4555.

152. Shimizu, S.; Nagaoka, T. High-quality 2,2,4-trimethyl-1,2-dihydroquinolines. JP Patent 56014 516, 1981.

153. Kojima, T.; Okino, E.; Hatanaka, K.; Ishimoto, R. 2,2,4-Trimethyl-1,3-dihydroquinoline. JP Patent 55040 661, 1980.

154. Sadykhov, S.G.; Guseinov, N.S.; Abdalov, D.D. Reaction of aniline and diphenylamine with alkylcyclenes. Neftekhimiya. 1986, 46, 117-123.

155. Wilde, B.E. Quinoline derivatives. GB Patent 764 957, 1957.

156. Kojima, T.; Ymamaka, E.; Nagasaki, H. 2,2,4-Trimethyl-1,2-dihydroquinoline. JP Patent 57011968 , 1982.

157. Spaczynska, B.; Kolodko, M.; Lachman, I.; Jedrzejewski, W.; Straszewski, J.; Byrka, T.; Kowalski, Z.; Maciolek, R. Antioxidant. Prosynchem. PL Patent 107 925, 1980.

158. Takimoto, K. 2,2,4-Trimethyl-1,2-dihydroquinolines. JP Patent 52116 478, 1977.

159. Mcateer, C.H.; Davis, R.D., Sr.; Calvin, J.R. Preparing quinoline derivatives adapted to fluidized bed systems. U.S. Patent 5700 942, 1997.

160. Nagashima, S.; Kamiguchi S.; Ohguchi, S.; Chihara, T. Direct synthesis of 3-methylbenzofuran from phenol and acetone over halide cluster catalysts taking advantage of acidic and metallic properties. Chem. Eng. J. 2010, 161, 384-387.

161. Mustafa, A. Benzofurans. In The Chemistry of Heterocyclic Compounds; Weissverger, A., Taylor, E.C., Eds.; Wiley: New York, NY, USA, 1974; Volume 29.

162. Ligorati, F.; Nova, V.E.; Aglietti, G. Isomer-free bisphenol A. DE Patent 2359 500, 1974.

163. Inaba, S.; Yamamori, T.; Morimoto, Y. Bisphenol A. JP Patent 61078 741, 1986. 
164. Hunter, S.E.; Savage P.E. Kinetics and mechanism of isopropenylphenol synthesis in high-temperature water. J. Org. Chem. 2004, 69, 4724-4731.

165. Umansky, B.S.; Hall, W.K. A spectrophotometric study of the acidity of some solid acids. J. Catal. 1990, 124, 97-108.

166. Okuhara, T.; Nishimura, T.; Watanabe, H.; Misono, M. Insoluble heteropoly compounds as highly active catalysts for liquid-phase reactions. J. Mol. Catal. 1992, 74, 247-256.

167. Hansch, C.; Saltonstall, W.; Settle, J. Catalytic Synthesis of Heterocycles. III. Benzofuran. J. Am. Chem. Soc. 1949, 71, 943-944.

168. Hori, K.; Kitagawa, H.; Miyoshi, A.; Ohta, T.; Furukawa, I. Transition metal-catalyzed cyclization of 2-allylphenol to 2,3-dihydro-2-methylbenzofuran without $\beta$-elimination. Chem. Lett. 1998, 1083-1084.

169. Stadlbauer, W.; Laschober, R.; Kappe, T. Palladium-catalyzed ring closure reactions to benzofuranes: A new and effective approach to azacoumestrol derivatives. Lieb. Ann. Chem. 1990, 1990, 531-539.

170. Kamiguchi, S.; Nishida, S.; Takahashi, I.; Kurokawa, H.; Miura, H.; Chihara, T. Aldol condensation of acyclic ketones with benzaldehyde and subsequent cyclodehydration to form indenes over halide cluster catalysts. J. Mol. Catal. A 2006, 255, 117-122.

171. Nielsen, A.T.; Houlihan, W.J. The Aldol Condensation. Org. React. 1968, 16, 1-438.

172. Stiles, M.; Wolf, D.; Hudson, G.V. Catalyst selectivity in the reactions of unsymmetrical ketones; reaction of butanone with benzaldehyde and p-nitrobenzaldehyde. J. Am. Chem. Soc. 1959, 81, 628-632.

173. Gettler, J.D.; Hammett, L.P. Rates and temperature coefficients of the hydroxyl ion catalyzed aldol condensation of benzaldehyde with methyl ethyl ketone and acetone. J. Am. Chem. Soc. 1943, 65, 1824-1829.

174. Powell, S.G.; Nielsen, A.T. Condensation of butanal with 4-heptanone and 3-hexanone and attempted condensation of 2-ethyl-2-hexenal with 4-heptanone. J. Am. Chem. Soc. 1948, 70, 3627-3630.

175. Nagashima, S.; Kamiguchi, S.; Kudo, K.; Sasaki, T.; Chihara, T. Intramolecular condensation of 1,2- $\mathrm{C}_{6} \mathrm{H}_{4}\left(\mathrm{CH}_{2} \mathrm{RH}\right)_{2}(\mathrm{R}=\mathrm{O}, \mathrm{S}$, and $\mathrm{NH})$ to yield heterocyclic compounds over halide-cluster catalysts. Chem. Lett. 2011, 40, 78-80.

176. Nagashima, S.; Sasaki, T.; Yamazaki, H.; Kamiguchi, S.; Chihara, T. Vapor-Phase Intramolecular Eliminative Cyclization of $\alpha, \omega$-Disubstituted Alkanes to Yield Heterocyclic Compounds over Halide Cluster Catalysts. In Proceedings of the 7th International Symposium on Acid-Base Catalysis, Tokyo, Japan, 12-15 May 2013; PA-051.

177. Kamiguchi, S.; Kondo, K.; Kodomari, M.; Chihara, T. Catalytic ring-attachment isomerization and dealkylation of diethylbenzenes over halide clusters of group 5 and group 6 transition metals. J. Catal. 2004, 223, 54-63.

178. Guisnet, M.; Gnep, N.S.; Morin, S. Mechanisms of xylene isomerization over acidic solid catalysts. Microporous Mesoporous Mater. 2000, 35-36, 47-59.

179. Tsai, T.-C.; Liu, S.-B.; Wang, I. Disproportionation and transalkylation of alkylbenzenes over zeolite catalysts. Appl. Catal. A 1999, 181, 355-398. 
180. Kaeding, W.W.; Barile, G.C.; Wu, M.M. Mobil Zeolite Catalysts for Monomers. Catal. Rev. Sci. Eng. 1984, 26, 597-612.

181. Halgeri, A.B.; Das, J. Recent advances in selectivation of zeolites for para-disubstituted aromatics. Catal. Today 2002, 73, 65-73.

182. Kareem, M.A.A.; Chand, S.; Mishra, I.M. Disproportionation of Toluene to Produce Benzene and p-Xylene-A Review. J. Sci. Ind. Res. 2001, 60, 319-327.

183. Bolton, A.P.; Lanewala, M.A.; Pickert, P.E. Isomerization of the diethylbenzenes using zeolite catalysts. J. Org. Chem. 1968, 33, 1513-1517.

184. Engelhardt, J. Transformation of Some Light Mono-Benzenes and Dialkylbenzenes on H-ZSM-5. J. Catal. 1994, 145, 574-577.

185. Beck, J.S.; Haag, W.O. Isomerization and Transalkylation of Alkylaromatics. In Handbook of Heterogeneous Catalysis; Ertl, G., Knözinger, H., Weitkamp, J., Eds.; Wiley-VCH: Weinheim, Germany, 1997; Volume 5, pp. 2136-2139.

186. Brini, M.; Mislin, R.; Sommer, J.M. Redistribution of ethylbenzene in the presence of aluminum chloride. Bull. Soc. Chim. Fr. 1965, 3654-3658.

187. Nambu, N.; Yamamoto, K.; Hamanaka, S.; Ogawa, M. A Study on the Complex Layer of Alkylbenzene- $\mathrm{AlCl}_{3}-\mathrm{HCl}$ System during Transalkylation-Diethylbenzene- $\mathrm{AlCl}_{3}-\mathrm{HCl}$ SystemNippon Kagaku Kaishi 1979, 1979, 925-930.

188. Bakoss, H.J.; Roberts, R.M.G.; Sadri, A.R. Studies in trifluoromethanesulfonic acid. 3. Kinetics and mechanism of transalkylation reactions. J. Org. Chem. 1982, 47, 4053-4055.

189. Dumitriu, E.; Guimon, C.; Hulea, V.; Lutic, D.; Fechete, I. Transalkylation of toluene with trimethylbenzenes catalyzed by various AFI catalysts. Appl. Catal. A 2002, 237, 211-221.

190. Kamiguchi, S.; Nakamura, A.; Suzuki, A.; Kodomari, M.; Nomura, M.; Iwasawa, Y.; Chihara, T. Catalytic dehydrogenation of aliphatic amines to nitriles, imines, or vinylamines and dealkylation of tertiary aliphatic amines over halide cluster catalysts of group 5 and 6 transition metals. J. Catal. 2005, 230, 204-213.

191. Fujibayashi, S.; Nakayama, K.; Hamamoto, M.; Sakaguchi, S.; Nishiyama, Y.; Ishii, Y. An efficient aerobic oxidation of various organic compounds catalyzed by mixed addenda heteropolyoxometalates containing molybdenum and vanadium. J. Mol. Catal. A 1996, 110, 105-117.

192. Okano, K.; Saito, Y.; Ogino, Y. The Dehydrogenation of Amines by Molten Metal Catalysts. Bull. Chem. Soc. Jpn. 1972, 45, 69-73.

193. Kanazirev, V.; Price, G.L. Activity of Ga, In and $\mathrm{Cu}$ modified MFI zeolites for amine reactions. Stud. Surf. Sci. Catal. 1994, 84, 1935-1942.

194. Sedláček, J.; Koubek, J. The reactivity of amines in deamination reaction on alumina. Collect. Czech. Chem. Commun. 1983, 48, 755-765.

195. Xu, B.-Q.; Yamaguchi, T.; Tanabe, K. Acid-base bifunctional catalysis in the decomposition of alkylamines. Appl. Catal. 1991, 75, 75-86.

196. Brey, W.S.; Cobbledick, D.S. Catalytic Reactions of Butylamines over Alumina. Ind. Eng. Chem. 1959, 51, 1031-1034.

197. Catry, J.P.; Jungers, J.C. Kinetics of heterogeneous catalysis. Action of aliphatic amines on alumina. Bull. Soc. Chim. Fr. 1964, 2317-2324. 
198. Ebeid, M.F.; Pašek, J. Reaction of amines on acid catalysts. III. Formal kinetics of deamination and disproportionation of diethylamine on alumina. Collect. Czech. Chem. Commun. 1970, 35, 2166-2173.

199. Kanazirev, V.I.; Price, G.L.; Dooley, K.M. On the Interaction of 1-Propanamine with Cation-Containing MFI Zeolite. J. Catal. 1994, 148, 164-180.

200. Ali, A.-G.A.; Ali, L.I. Dehydrogenation, Deamination and Disproportionation of Diethylamine over Heteropoly Compounds. Collect. Czech. Chem. Commun. 1995, 60, 2047-2056.

201. Izumi, Y.; Matsuo, K.; Urabe, K. Efficient homogeneous acid catalysis of heteropoly acid and its characterization through ether cleavage reactions. J. Mol. Catal. 1983, 18, 299-314.

202. Okuhara, T.; Mizuno, N.; Misono, M. Catalytic Chemistry of Heteropoly Compounds. Adv. Catal. 1996, 41, 113-252.

203. Mizuno, N.; Misono, M. Heterogeneous Catalysis. Chem. Rev. 1998, 98, 199-218.

204. Furuta, M.; Sakata, K.; Misono, M.; Yoneda, Y. Structure and acidity of 12-molybdophosphoric acid and its salts in solid state as characterized by infrared spectroscopy. Chem. Lett. 1979, 31-34.

205. Barcza, L.; Pope, M.T. Heteroconjugation of inorganic anions in nonaqueous solvents. III. Complexes of polymolybdates and -tungstates with chloral hydrate. J. Phys. Chem. 1975, 79, 92-93.

206. Sokoll, R.; Hobert, H. Infrared study of the adsorption of octadecylamine at the $\mathrm{MgO} / \mathrm{CCl}_{4}$ interface. A comparison with investigations of the adsorption of octadecylamine on $\mathrm{SiO}_{2}$ and $\mathrm{Al}_{2} \mathrm{O}_{3}$. J. Chem. Soc., Faraday Trans. 1 1986, 82, 1527-1535.

207. Marx, U.; Sokoll, R.; Hobert, H. Thermal desorption and infrared studies of primary aliphatic amines adsorbed on haematite $\left(\alpha-\mathrm{Fe}_{2} \mathrm{O}_{3}\right)$. J. Chem. Soc., Faraday Trans. 1 1986, 82, 2505-2514.

208. Nagashima, S.; Kamiguchi, S.; Ohguchi, S.; Chihara, T. Vapor-phase Beckmann rearrangement of cyclohexanone oxime over halide cluster catalysts. Catal. Today 2011, 164, 135-138.

209. Dahlhoff, G.; Niederer, J.P.M.; Holderich, W.F. $\varepsilon$-Caprolactam: New by-product free synthesis routes. Catal. Rev. 2001, 43, 381-441.

210. England, D.C. Caprolactam. U.S. Patent 2634 269, 1953.

211. Dawydoff, W. Die katalytische umlagerung von cyclischen oximen in heterogener Phase. Chem. Technol. Leipzig 1955, 7, 647-655.

212. Ushikubo, T.; Wada, K. Vapor-Phase Beckmann Rearrangement over Silica-Supported Tantalum Oxide Catalysts. J. Catal. 1994, 148, 138-148.

213. Aucejo, A.; Burguet, M.C.; Corma, A.; Fornes, V. Beckman rearrangement of cyclohexanone-oxime on HNaY zeolites: Kinetic and spectroscopic studies. Appl. Catal. 1986, 22, 187-200.

214. Dai, L.-X.; Koyama, K.; Miyamoto, M.; Tatsumi, T. Highly selective vapor phase Beckmann rearrangement over H-USY zeolites. Appl. Catal. A 1999, 189, 237-242.

215. Dai, L.-X.; Hayasaka, R.; Iwaki, Y.; Koyano, K.A.; Tatsumi, T. Vapour phase Beckmann rearrangement of cyclohexanone oxime catalysed by $\mathrm{H} \beta$ zeolite. Chem. Commun. 1996, 1071-1072.

216. Dai, L.-X.; Koyama, K.; Tatsumi, T. Catalytic application of mesoporous molecular sieves to vapor-phase Beckmann rearrangement of cyclohexanone oxime. Catal. Lett. 1998, 53, 211-214.

217. Izumi, Y.; Ichihashi, H.; Shimazu, Y.; Kitamura, M.; Sato, H. Development and Industrialization of the Vapor-Phase Beckmann Rearrangement Process. Bull. Chem. Soc. Jpn. 2007, 80, 1280-1287. 
218. Röseler, J.; Heitmann, G.; Hölderich, W.F. Vapour-phase Beckmann rearrangement using B-MFI zeolites. Appl. Catal. A 1996, 144, 319-333.

219. Tsuji, H.; Setoyama, T. Gas-phase Catalytic Beckmann Rearrangement over Crystalline $\mathrm{BPO}_{4}$ of Dehydration Ability. Chem. Lett. 2005, 34, 1232-1233.

220. Landis, P.S.; Venuto, P.B. Organic reactions catalyzed by crystalline aluminosilicates: IV. Beckmann rearrangement of ketoximes to amides. J. Catal. 1966, 6, 245-252.

221. Takahashi, T.; Nasution, M.N.A.; Kai, T. Effects of acid strength and micro pore size on $\varepsilon$-caprolactam selectivity and catalyst deactivation in vapor phase Beckmann rearrangement over acid solid catalysts. Appl. Catal. A 2001, 210, 339-344.

222. Nagashima, S.; Yamazaki, H.; Kudo, K.; Kamiguchi, S.; Chihara, T. S.-Acylation of aliphatic and aromatic thiols with carboxylic acids and their esters over solid acid catalysts in the gas phase at temperatures above $200{ }^{\circ} \mathrm{C}$. Appl. Catal. A 2013, 464-465, 332-338.

223. Wuts, P.G.M.; Greene, T.W. Greene's Protective Groups in Organic Synthesis, 4th ed.; Wiley: Hoboken, NJ, USA. 2006; pp. 223-227, 419-413.

224. Firouzabadi, H.; Iranpoor, N.; Farahi, S. Solid trichlorotitanium (IV) trifluoromethanesulfonate $\mathrm{TiCl}_{3}$ (OTf) catalyzed efficient acylation of $-\mathrm{OH}$ and $-\mathrm{SH}$ : Direct esterification of alcohols with carboxylic acids and transesterification of alcohols with esters under neat conditions. J. Mol. Catal. A 2008, 289, 61-68.

225. Kumar, P.; Pandey, R.K.; Bodas, M.S.; Dagade, S.P.; Dongare, M.K.; Ramaswamy, A.V. Acylation of alcohols, thiols and amines with carboxylic acids catalyzed by yttria-zirconia-based Lewis acid. J. Mol. Catal. A 2002, 181, 207-213.

226. Hawkins, D.T.; Worrell, W.L. Hydrogen reduction of $\mathrm{MoO}_{3}$ at temperatures between $300^{\circ}$ and 450 . Metallurg. Trans. 1970, 1, 271-273.

227. Mashkina, A.V.; Grunvald, V.R.; Nasteka, V.I.; Borodin, B.P.; Yakovleva, V.N.; Khairulina, L.N. Decomposition of alkanethiols to dialkyl sulfides and hydrogen sulfide. React. Kinet. Catal. Lett. 1990, 41, 357-362.

228. Mashkina, A.V.; Borodin, B.P.; Yakovleva, V.N. Catalytic reaction of methanol with alkanethiols. React. Kinet. Catal. Lett. 1996, 59, 309-314.

229. Kamiguchi, S.; Takaku, S.; Kodomari, M.; Chihara, T. Variable catalytic behavior of Nb, Mo, $\mathrm{Ta}, \mathrm{W}$, and Re halide clusters: Isomerization of alkynes to conjugated dienes under nitrogen and hydrogenation to alkenes under hydrogen. J. Mol. Catal. A 2006, 260, 43-48.

230. Ramhold, K.; Zimmermann, G. Zur Bindungsisomerisierung von Acetylen- und Allen-Kohlenwasserstoffen. I. Kinetische Untersuchungen über die Isomerisierung von Butin-(1), Butin-(2) sowie Butadien-(1,2) an sauren Molsiebkatalysatoren in der Gasphase. J. Prakt. Chem. 1974, 316, 839-850.

231. Calihan, L.E.; Kay, E.L.; Roberts, D.T., Jr.; Wakefield, L.B. Synthesis of 1,2-butadiene. Vapor phase isomerization of 2-butyne over base-modified catalysts. Ind. Eng. Chem. Prod. Res. Dev. 1975, 14, 287-290.

232. Mortreux, A.; Blanchard, M. Gas phase isomerization of acetylenic hydrocarbons on acidic catalysts. Bull. Soc. Chim. Fr. 1970, 11, 4035-4040.

233. Levina, R.Y.; Viktorova, E.A.; Akishin, P.A. Contact reactions of 1-heptyne and 1-hexyne on chromium oxide on aluminum oxide. Vestn. Mosk. Univ. 1951, 6, 71-76. 
234. Smadja, W. Carbanionic isomerization of linear hydrocarbons-acetylenes-allenes-conjugated dienes. Ann. Chim. (Paris) 1965, 10, 105-144.

235. Sokol'skii, D.V.; Ualikhanova, A. Silver, gold, and rhenium supported on magnesium oxide catalysts in the hydrogenation of acetylenic compounds. Zh. Prikl. Khim. 1984, 57, 461-464.

236. Kamiguchi, S.; Takahashi, I.; Kondo, K.; Nagashima, S.; Kurokawa, H.; Miura, H.; Chihara, T. Catalytic Hydration of Alkynes over Brønsted Acid Sites Developed on Halide Clusters. J. Clust. Sci. 2007, 18, 845-853.

237. Pearson, R.G. Hard and Soft Acids and Bases. J. Am. Chem. Soc. 1963, 85, 3533-3539.

238. Izumi, Y. Hydration/hydrolysis by solid acids. Catal. Today 1997, 33, 371-409.

239. Beller, M.; Seayad, J.; Tillack, A.; Jiao, H. Catalytic Markovnikov and anti-Markovnikov Functionalization of Alkenes and Alkynes: Recent Developments and Trends. Angew. Chem. Int. Ed. 2004, 43, 3368-3398.

240. Gorin, Y.A.; Aref'eva, T.G.; Gurfein, N.S.; Dorokhov, A.P.; Ioffe, I.I. Kinetics of the vapor-phase hydration of acetylene. I. Activity and selectivity of a cadmium calcium phosphate catalyst and calculation of kinetic constants for the initial period of its use. Kinet. Katal. 1968, 9, 1285-1290.

241. Gut, G.; Aufdereggen, K. Reaktionskinetische Untersuchungen der Hydratisierung von Acetylen zu Acetaldehyd an Molekularsieben, die mit katalytisch wirksamen Metall-Ionen beladen sind. Helv. Chim. Acta 1974, 57, 441-452.

242. Finiels, A.; Geneste, P.; Marichez, F.; Moreau, P. Hydration reaction of alkynes catalyzed by zeolites. Catal. Lett. 1989, 2, 181-184.

243. Matsuo, K.; Urabe, K.; Izumi, Y. Electrophilic addition reactions to phenylacetylene catalyzed by heteropoly acid. Chem. Lett. 1981, 1315-1316.

244. Olivi, N.; Thomas, E.; Peyrat, J.-F.; Alami, M.; Brion, J.-D. Highly Efficient $p$-Toluenesulfonic Acid-Catalyzed Alcohol Addition or Hydration of Unsymmetrical Arylalkynes. Synlett. 2004, $12,2175-2179$.

245. Tsuchimoto, T.; Joya, T.; Shirakawa, E.; Kawakami, Y. Brønsted Acid-Catalyzed Hydration of Alkynes: A Convenient Route to Diverse Carbonyl Compounds. Synlett. 2000, 2000, 1777-1778.

246. Tanaka, K.; Tamaru, K. Acid-base Concept and Catalytic Activity of Oxides. Bull. Chem. Soc. Jpn. 1964, 37, 1862-1865.

247. Kamiguchi, S.; Watanabe, M.; Kondo, K.; Kodomari, M.; Chihara, T. Catalytic dehydrohalogenation of alkyl halides by $\mathrm{Nb}, \mathrm{Mo}, \mathrm{Ta}$, and $\mathrm{W}$ halide clusters with an octahedral metal framework and by a Re chloride cluster with a triangular metal framework. J. Mol. Catal. A 2003, 203, 153-163.

248. Tavoularis, G.; Keane, M.A. Gas phase catalytic dehydrochlorination and hydrodechlorination of aliphatic and aromatic systems. J. Mol. Catal. A 1999, 142, 187-199.

249. Tavoularis, G.; Keane, M.A. Direct formation of cyclohexene via the gas phase catalytic dehydrohalogenation of cyclohexyl halides. Appl. Catal. A 1999, 182, 309-316.

250. Venuto, P.B.; Givens, E.N.; Hamilton, L.A.; Landis, P.S. Organic reactions catalyzed by crystalline aluminosilicates: V. Dehydrohalogenation and related reactions. J. Catal. 1966, 6, 253-262.

251. Mochida, I.; Take, J.; Saito, Y.; Yoneda, Y. Linear free-energy relationships in heterogeneous catalysis. VI. Catalytic elimination reaction of hydrogen chloride from chloroethanes on solid acids and bases. J. Org. Chem. 1967, 32, 3894-3898. 
252. Mochida, I.; Anju, Y.; Yamamoto, H.; Kato, A.; Seiyama, T. The Catalytic Dehydrohalogenation of Haloethanes on Solid Acids and Bases. Bull. Chem. Soc. Jpn. 1971, 44, 3305-3310.

253. Noller, H.; Kladnig, W. Elimination Reactions over Polar Catalysts: Mechanistic Considerations. Catal. Rev. Sci. Eng. 1976, 13, 149-207.

254. Davenport, W.H.; Kollonitsch, V.; Kline, C.H. Advances in rhenium catalysts. Ind. Eng. Chem. 1968, 60, 10-19.

255. Wiersma, A.; van de Sandt, E.J.A.X.; den Hollander, M.A.; van Bekkum, H.; Makkee, M.; Moulijn, J.A. Comparison of the Performance of Activated Carbon-Supported Noble Metal Catalysts in the Hydrogenolysis of $\mathrm{CCl}_{2} \mathrm{~F}_{2}$. J. Catal. 1998, 177, 29-39.

256. Hakkaku, K.; Sakakibara, Y. Polymerization catalyst using metal cluster halide and polymerization of $\alpha$-olefin. JP Patent 2002256 014, 2002.

257. Kamiguchi, S.; Takeda, K.; Kajio, R.; Okumura, K.; Nagashima, S.; Chihara, T. Application of Solid-State Molybdenum Sulfide Clusters with an Octahedral Metal Framework to Catalysis: Ring-Opening of Tetrahydrofuran to Butyraldehyde. J. Clust. Sci. 2013, 24, 559-574.

258. Kamiguchi, S.; Ikeda, S.; Nagashima, S.; Kurokawa, H.; Miura, H.; Chihara, T. Catalytic Condensation of Primary Amines, Dehydrogenation of Secondary Amines, and Dealkylation of Tertiary Amines Over Solid-State Rhenium Sulfide Clusters with an Octahedral Metal Framework. J. Clust. Sci. 2009, 20, 683-693.

259. Kamiguchi, S.; Nagashima, S.; Chihara, T. Catalytic Hydrogenation and Dehydrogenation over Solid-state Rhenium Sulfide Clusters with an Octahedral Metal Framework. Chem. Lett. 2007, $36,1340-1341$.

260. Nagashima, S.; Furukawa, S.; Kamiguchi, S.; Kajio, R.; Nagashima, H.; Yamaguchi, A.; Shirai, M.; Kurokawa, H.; Chihara, T. Catalytic Activity of Molecular Rhenium Sulfide Clusters $\left[\operatorname{Re}_{6} \mathrm{~S}_{8}(\mathrm{OH})_{6-n}\left(\mathrm{H}_{2} \mathrm{O}\right)_{n}\right]^{(4-n)^{-}}(n=0,2,4,6)$ with Retention of the Octahedral Metal Frameworks: Dehydrogenation and Dehydration of 1,4-Butanediol. J. Clust. Sci. 2014, doi:10.1007/s10876-014-0700-x.

(C) 2014 by the authors; licensee MDPI, Basel, Switzerland. This article is an open access article distributed under the terms and conditions of the Creative Commons Attribution license (http://creativecommons.org/licenses/by/3.0/). 